University of Redlands

\title{
Analyzing Historical Crime Data for the City of Redlands in California
}

\author{
A Major Individual Project submitted in partial satisfaction of the requirements \\ for the degree of Master of Science in Geographic Information Systems \\ by \\ Sarah Drallos-Kopecky \\ Dr. Fang Ren, Ph.D., Committee Chair \\ Dr. Douglas Flewelling, Ph.D.
}

August 2010 
Analyzing Historical Crime Data for the City of Redlands in California

Copyright (C) 2010

by

Sarah Elizabeth Drallos-Kopecky 
The report of Sarah Drallos-Kopecky is approved.

Douglas Flewelling, Ph.D.

Fang Ren, Ph.D., Committee Chair

August 2010 



\section{Acknowledgements}

There are many people who I would like to thank in the MS GIS program. I would like to thank Fang Ren, my advisor, for all the support and encouragement she gave me along with everything she taught me in order to complete this project successfully. I would also like to thank Doug Flewelling for the advice and help he provided me for this project. I would also like to thank the rest of the faculty and staff for everything that they have taught me and done for me throughout the year. In addition, I would like to thank Debbie Riley for all her smiles and encouragement throughout the process of this project.

I would like to thank Phil Mielke and the Redlands Police Department for providing this great project that opened my eyes to crime in Redlands and the opportunity to help in their fight against crime. Finally, I would like to thank my friends and family for their support throughout the year. 



\begin{abstract}
The Historical Crime Analysis of Redlands, CA over the Past 20 Years

by

Sarah Drallos-Kopecky
\end{abstract}

The City of Redlands crime rate has increased over the past 20 years, which has led to a need for a better understanding of why this is happening. In order to look at this problem in an effective and interactive manner, the City and law enforcement agencies would like to incorporate animated maps that show the crime densities over the past 20 years. To create these density maps, crime data will be analyzed using a model built in Model Builder, to accurately assess the crime densities. Once the maps are created in ArcMap, the maps can be exported and the animation toolbar will be incorporated to animate the results visually. This will show a story of crime over the past 20 years allowing law enforcement and the City to understand the crime patterns. To further understand crime patterns the project utilized linear regression tools. After running the regression tools significant variables were identified. These variables influence crime types. Ultimately, it is perceived that being able to see the crime densities over the past 20 years and knowing the variables that influence crime will help solve future problems. 



\section{Table of Contents}

Chapter 1 - Introduction $\quad 17$

1.1 Client 18

1.2 Problem Statement 18

1.3 Proposed Solution 18

1.3.1 Goals and Objectives 18

$\begin{array}{lll}1.3 .2 & \text { Scope } & 19\end{array}$

$\begin{array}{lll}1.3 .3 & \text { Methods } & 19\end{array}$

$\begin{array}{lll}1.4 & \text { Audience } & 20\end{array}$

1.5 Overview of the Rest of This Report 20

Chapter 2 - Background and Literature Review 21

$2.1 \quad$ Place in Crime Research $\quad 21$

2.2 Crime Pattern Analysis $\quad 21$

2.3 Crime Demographics 23

2.4 Summary 25

Chapter 3 - $\quad$ Systems Analysis and Design $\quad 27$

$\begin{array}{lll}3.1 & \text { Problem Statement } & 27\end{array}$

3.2 Requirements Analysis $\quad 27$

3.3 System Design 28

$3.4 \quad$ Project Plan 29

3.4.1 Requirements 29

3.4.2 Data Collection 30

3.4.3 Geodatabase Development 30

3.4.4 Model Development 30

$\begin{array}{lll}3.4 .5 & \text { Statistical Analysis } & 30\end{array}$

3.4.6 Project delivery 31

3.5 Summary 31

Chapter 4 - Database Design 33

4.1 Conceptual Data Model 33

4.2 Logical Data Model 33

4.3 Data Sources 36

4.4 Data Scrubbing and Loading 36

4.5 Summary 36

Chapter 5 - Implementation $\quad 37$

5.1 Kernel Density Analysis Maps 37

5.1.1 Crime Density Model 37

5.1.2 Crime Density Classification $\quad 41$

5.1.3 Animation 44

5.2 Regression Analysis $\quad 48$

5.2.1 Ordinary Least Squares 48

5.2.2 Geographically Weighted Regression 51

5.3 Summary $\quad 52$ 
Chapter 6 - $\quad$ Results and Analysis $\quad 53$

6.1 Kernel Density Model Results 53

6.2 Animation Results 55

6.3 Regression Analysis Results 57

6.3.1 Residential Burglary $\quad 57$

6.3.2 Disturbances $\quad 62$

$\begin{array}{lll}6.3 .3 & \text { Assaults } & 68\end{array}$

6.3.4 Alcohol/Drug-related crimes $\quad 73$

6.3.5 Auto Thefts 79

6.4 Summary $\quad 85$

Chapter 7 - Conclusions and Future Work 87

$\begin{array}{lll}7.1 & \text { Conclusion } & 87\end{array}$

7.2 Future Work 87

7.2.1 Additional Crime Types 87

$\begin{array}{lll}7.2 .2 & \text { Temporal Analysis } & 87\end{array}$

7.2.3 Web Application 88

7.2.4 Geographic Factors for Regression Analysis 88

$\begin{array}{ll}\text { Works Cited } & 89\end{array}$

Appendix A. Important but Extraneous Information $\quad 91$ 


\section{Table of Figures}

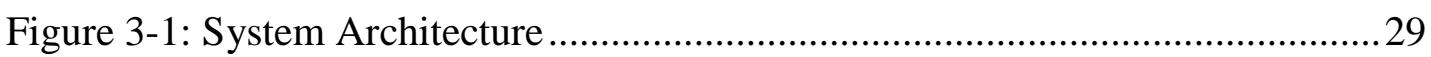

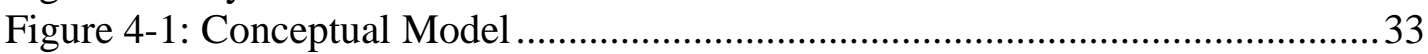

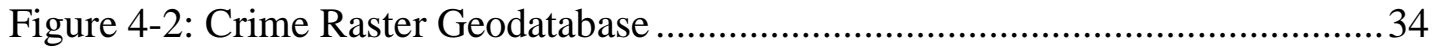

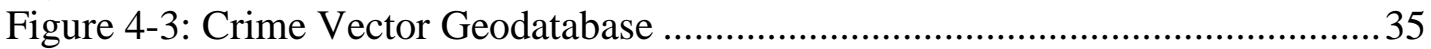

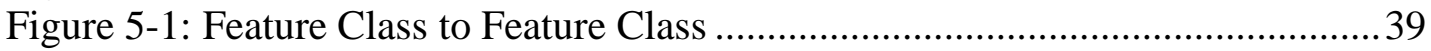

Figure 5-2: Kernel Density Form........................................................................ 40

Figure 5-3: Crime Kernel Density Model ..............................................................4 41

Figure 5-4: Range and Symbolization process ........................................................4 43

Figure 5-5: Kernel Density Map ........................................................................ 44

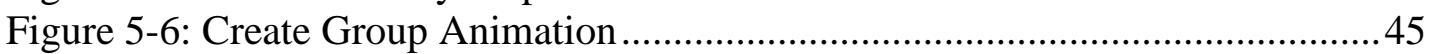

Figure 5-7: Group Animation Interface ................................................................. 45

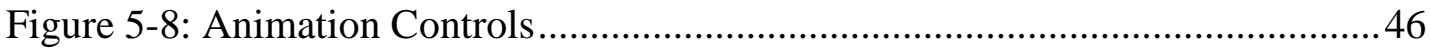

Figure 5-9: Annotation Process ............................................................................. 47

Figure 5-10: Animated Kernel Density Maps..........................................................4 48

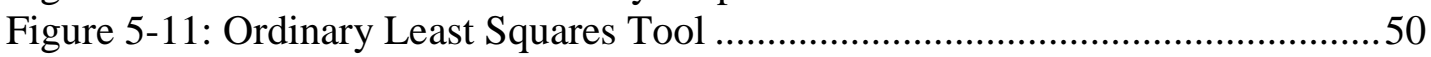

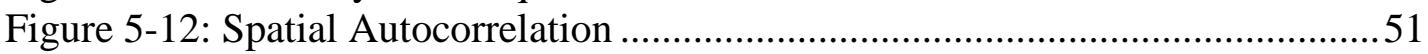

Figure 5-13: Geographically Weighted Regression Tool ........................................52

Figure 6-1: Density Maps of five Crime Types in 1989 and 2009 ............................54

Figure 6-2: Animation Results for all five crimes from 2007-2009 ...........................56

Figure 6-3: Crime Count for Residential Burglaries..................................................57

Figure 6-4: OLS Spatial Autocorrelation Results for Residential Burglaries.............59

Figure 6-5: GWR Spatial Autocorrelation for Residential Burglaries.........................61

Figure 6-6: Coefficient map for Percent Higher Education ............................................. 62

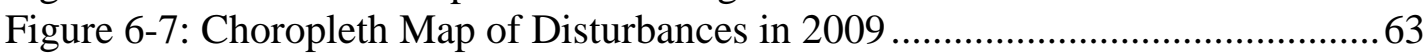

Figure 6-8: OLS Spatial Autocorrelation Results for Disturbances .............................65

Figure 6-9: GWR Spatial Autocorrelation for Disturbances .......................................67

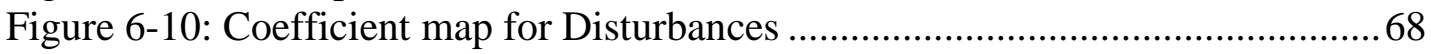

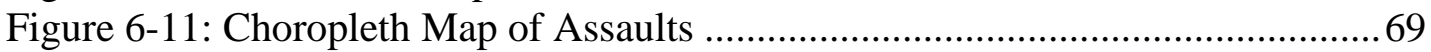

Figure 6-12: OLS Spatial Autocorrelation Results for Assaults................................. 71

Figure 6-13: GWR Autocorrelation results for Assault .............................................72

Figure 6-14: Coefficient Map for Assaults ...........................................................73

Figure 6-15: Alcohol/Drug Crime Count..............................................................74

Figure 6-16: OLS Spatial Autocorrelation Results....................................................76

Figure 6-17: GWR Autocorrelation results for Alcohol and drug-related crimes .....78

Figure 6-18: Coefficient Map for Alcohol/Drug-Related Crimes ………………....... 79

Figure 6-19: Choropleth Map of Auto Thefts in 2009............................................... 80

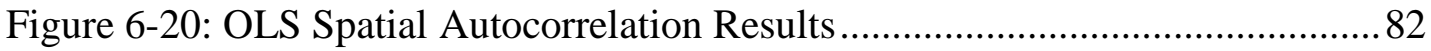

Figure 6-21: GWR Spatial Autocorrelation Results for Auto Thefts .......................... 84

Figure 6-22: Coefficient Map for Auto Thefts ........................................................... 85 



\section{List of Tables}

Table 1. Requirements ................................................................................. 28

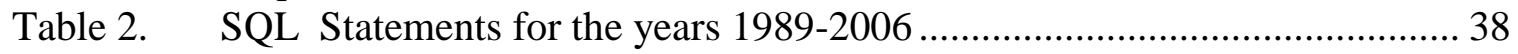

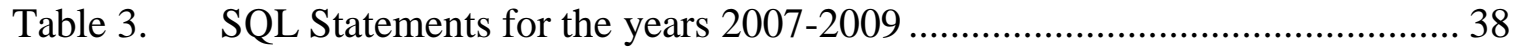

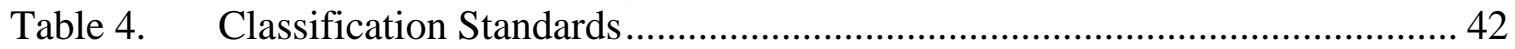

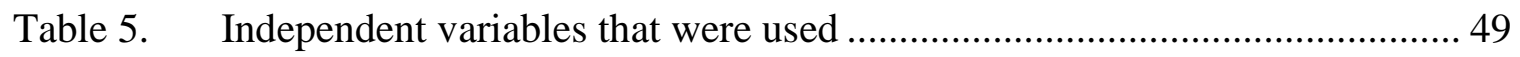

Table 6. Crime Kernel Density Results ........................................................... 55

Table 7. Model 1: Linear Regression Results on Residential Burglaries in 2000 ...... 58

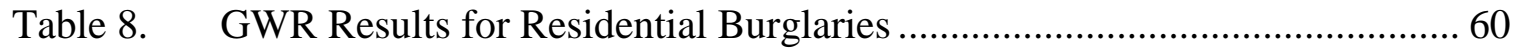

Table 9. Model 2: Linear Regression Results on Disturbances in 2000 ..................... 64

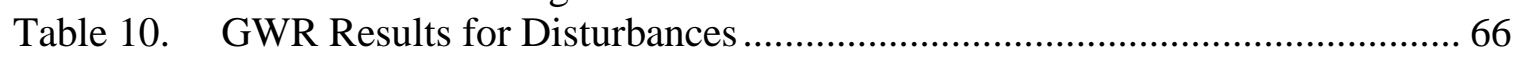

Table 11. Model 3: Linear Regression Results on Assaults in 2000 .......................... 70

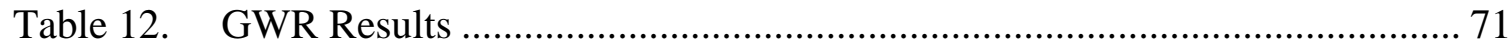

Table 13. Model 4 : Linear Regression Results on Alcohol/drug crimes in 2000 ....... 75

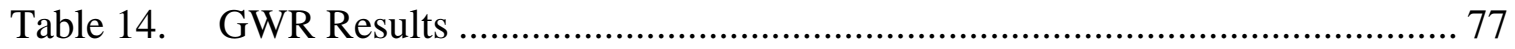

Table 15. Model 5: Linear Regression Results on Residential Burglaries in 2000 ...... 81

Table 16. GWR results for Auto Thefts ................................................................... 83 



\title{
List of Acronyms and Definitions
}

\author{
AICc Akaike information criterion \\ AVI Movie file \\ DBF Database files \\ ESRI Environmental Systems Research Institute \\ GIS Geographical Information System \\ GWR Geographically weighted regression \\ OLS Ordinary Least Squares
}





\section{Chapter 1 - Introduction}

Today, police departments are making more use of computer technology, and law enforcement has found that the incorporation of computer assisted crime analysis is beneficial to their overall ability to protect the public from criminal activity. The recent increase in crime research and the incorporation of GIS has aided law enforcement to have a better understanding of criminal activity across space and place, which has been found to be very important for crime control and prevention. Digital technology has encouraged proactive law enforcement techniques as opposed to the traditional reactive approach (Olligschlaeger, 1997). With this in mind, the City of Redlands, California, was in need of a more comprehensive approach of crime analysis in order to take full advantage of advanced digital technology.

Redlands is located in the southwest part of the state in San Bernardino County. The City of Redlands has grown in population significantly (by about 50\%) over the past 20 years, from 43,619 people in 1980 to a current figure of 63,591 people (Redlands Police Department, 2009). Redlands is moderately sized and centered around agriculture, manufacturing, retail, and service industries (Katz, Scheafer, \& Uchida, 2002). With the increase in population, there has also been an increase in the crime rate, growing from 34.4 per 1,000 residents in 2002 , to 45.6 per 1,000 residents at the present time (Redlands Police Department, 2009). Given this increase, there is a strong need to increase law enforcement agencies' analytical capabilities so that they can identify crime and risk factors in the community and take the necessary preventative measures. Therefore, the goal of this project was to use past data to help understand why crime has increased and in turn, use that information proactively.

In order to accurately identify crime risk relative to locations, the incorporation of crime mapping over time may allow for a better understanding of what type of crimes are happening where and shed some light on why. This concept is not new, given that it is said that the first spatial correlation analysis of crime data in the United Sates was implemented during the 1920s and 1930s by sociologists in Chicago (Boba, 2005). However, crime data mapping during that era was seen more as a theoretical concept as opposed to a dynamic tool. Because the concept was perceived as a strictly theoretical approach, analysts during that time articulated that certain areas were more prone to crime than other areas (Boba, 2005). It was not until the 1980s that researchers shifted from the aggregate analysis of crime and social factors, to the analysis of discrete criminal events and their locations together (Boba, 2005). Recently, law enforcement has utilized crime mapping, which has become more common in policing and crime analysis. With advancements in computer software and technology, "crime analysts have had improvement in preventing crime within cities" (Boba, 2005 p.47). Interactive crime mapping has gained much popularity due to its comprehensible visualization and instant results, giving the audience a better grasp of crime statistics. For example, interactive crime mapping facilitates the ability for law enforcement and the public to access statistics in a user-friendly way that can show trends and correlations in the crime data, allowing the viewer to see where crime occurs more predominantly and where crime is less pervasive (Ceccato, Haining, \& Signoretta, 2002). 
In particular, due to the "geographic nature of the crime" (Boba, 2005, p.3), geographic information systems (GIS) have proven in the past and present that they effectively analyze and visualize distributions and trends of crime in space and place. Overall, this project aimed to aid the Redlands Police Department to analyze the crime pattern in space and time by using GIS technology. In doing so, the Redlands Police Department can have a better grasp on why certain crimes are recurring in reference to locations and what preventative actions can be introduced to solve these problems.

\subsection{Client}

The client for this project was Philip Mielke, the GIS Administrator for the City of Redlands. Mr. Mielke provided the data and the information on how to use the programs needed to create the animated crime density maps. He has previous experience in creating animated crime maps and was a good source of information throughout the life of this project.

\subsection{Problem Statement}

Crimes are not evenly distributed in space and time; instead, they recur in certain areas and time (Eck, 2005). Those places where crimes concentrate are called "hot spots". It is important to identify crime hot spots in order to implement crime preventive strategies effectively. The City of Redlands has created a series of crime density maps for the past eight years and the maps show that crime has increases in the city. To further understand the crime-growth pattern and examine why crimes concentrate in certain areas, the client needs to expand crime maps over a longer span of years. As such, the client needed a tool and an analytical method to help analyze their historical crime data over the past 20 years.

\subsection{Proposed Solution}

The primary goal of the project was to help the police department explore the spatial and temporal patterns of crime in the City of Redlands over the past 20 years. To achieve this goal, the proposed solution was to develop a user-friendly model to generate a crime density surface, and animate the results based on the temporal parameters specified by the client. This will allow for the City of Redlands and Redlands Police Department to better understand crime patterns over a period of time, which will eventually help make informed decisions on preventative tactics in an effort to decrease the amount of crime in Redlands.

\subsubsection{Goals and Objectives}

The ultimate goal of this project was to assist the police department, as well as the citizens to analyze how the crime patterns have changed in the City of Redlands. Given this primary goal, there were two objectives that the project aimed to accomplish. First, an interactive animated mapping tool of crime across the past 20 years was to be developed. In doing so, the spatial and temporal patterns of the crime of interest can be 
revealed. Second, the project was intended to examine the correlation between the crime of interest and the demographic and socioeconomic characteristics of the neighborhoods in which these crimes occur. This would help the police department perform better preventive crime control in the future.

\subsubsection{Scope}

One of the objectives was to examine the correlation between the crimes of interest and then look at the demographic status of different neighborhoods. Due to the time frame allowed for this project, which was 11 months, the project focused primarily on crime densities of the crimes of interest, the correlation between these crimes and the population densities, household income, and the house value of the different neighborhoods. Therefore, crime data were provided by the client to be compared to census population data over the past 20 years. Using the data provided by the client, the project deliverables included the following products: a kernel density model built in model builder, two databases (one that has all of the vector data files and the other database that contains the raster surfaces). Animated maps that show five different crime types using ArcGIS animation tool bar to animate these are exported into AVI video files that can be watched on a desktop computer. Finally, significant variables will be found using linear regression analysis.

\subsubsection{Methods}

To ensure that this project could be completed successfully, several meetings with the client were conducted to keep the lines of communication open and to make sure that the final result was what the client wanted and needed. The main methods used to complete this project were kernel density estimation, animation, and linear regression tools. There are different approaches to analyze the crime patterns such as, mapping crime densities and mapping crime hotspots. According to the client's request, kernel density estimation was applied in this study to show the variations of crime distribution in space. This method allowed for a smooth surface of crime densities for the entire area, since every grid cell of Redlands would have a crime density measured (Paulsen \& Robinson, 2009). Using kernel density estimation ultimately provided more visualization for true high concentrated areas of crime (Paulsen \& Robinson, 2009). In order to create the kernel densities for the past 20 years a model was created. This allowed for the crime type of interest to be extracted from the crime database. Shapefiles were created that were then used by the kernel density tool to create raster surface of the crime type of interest. Once the models were run, it was necessary to create two personal geodatabases that allowed for all of the vector data to be exported to it and another personal geodatabase that allowed the raster surface data to be exported into it.

Once the crime density maps were generated, animation was chosen to visualize them. After careful consideration, the animation was completed using the animation toolbar in ArcGIS so that the 20 years worth of crime data could be visualized in a unique and understandable way. In order to make the transition from year to year it was decided that one year of crime densities would be shown at a time. Therefore, five different crime 
types have their own set of animated maps showing the crime between 1989 and 2009. The third main concern of the client was the relationships between the crimes and the demographic data for the area, the demographic data might be able to explain why certain crimes are happening in certain areas. To address this issue, linear regression tools were applied.

\subsection{Audience}

The audiences for this project are people that have some experience with GIS and tailored more toward experts. The City of Redlands police department will also be using this project if the city's GIS department feels it is needed.

\subsection{Overview of the Rest of This Report}

The rest of report is organized as follows: Chapter 2, which is the literature review, discusses the research and other projects that were used to develop this project. Chapter 3 discusses the system analysis and design. Chapter 4 describes the geodatabase that supports the models built for this project. Chapter 5 explains the implementation of the models and the regression analysis. Chapter 6 discusses the results and the analysis of the project. Chapter 7 discusses the overall success of the project, what went well, what went wrong, the challenges that were faced, and possible future work. 


\section{Chapter 2 - Background and Literature Review}

As crime rates continue to rise, law enforcement agencies are always searching for new and different ways to quantify and analyze crime data. Various mapping technologies have proven to be valuable tools for exploring spatial distribution of crime in a visual and user-friendly manner. Most recently, there has been a rapid increase in computerized mapping technologies used by many police forces (Brundson, Corcoran, \& Higgs, 2007). This has improved police forces' ability to pinpoint and foresee the locations of crime within their areas of focus. This chapter discusses the meaning of place when it comes to crime analysis. It also focuses on different crime patterns, and finally it describes two different types of linear regression used in crime analysis.

\subsection{Place in Crime Research}

The first step in analyzing crime statistics was to establish an understanding of what crime research is and what it sets out to accomplish. French social ecologists Guerry and Quetelet, focused on the concentration of crime in distinct types of communities. For example, they were interested in understanding and explaining differences in community crime levels that were associated with social conditions the population had at the time (Anselin, Cohen, Cook, Gorr, \& Tita, 2000, p. 216). The School of Chicago contributed to the theoretical development of criminology the idea that, "one cannot understand social life without understanding the arrangements for particular social actors in particular social times and places...Social facts are located facts" (Anselin, Cohen, Cook, Gorr, \& Tita, 2000, p. 217). For example, Shaw and McKay's social disorganization theory suggests that, "crime research focuses on the characteristics of neighborhoods instead of the characteristics of the offenders" (p.217). This statement suggests the spatial perspective of crime analysis has to do with the orientation and geography of where crimes are committed. Another approach to this idea that provides some fundamental support was found in Ceccato, Haining, and Signoretta's article (2002). The authors discuss Wikstom's model, which suggests crime patterns coincide with changes in land use patterns (Ceccato, Haining, \& Signoretta, 2002). According to the authors, the land use change provides an important underpinning to any explanation of how crime patterns might change (Ceccato, Haining, \& Signoretta, 2002). Understanding placebased theories regarding crime research is important to the complete and comprehensive understanding of the analysis portion of the project.

\subsection{Crime Pattern Analysis}

After establishing a basis for crime research, the next step is to understand crime analysis. Boba (2005) provides a concise definition for crime analysis as the "qualitative and quantitative study of crime and law enforcement information in combination with sociodemographic and spatial factors to apprehend criminals, prevent crime, reduce disorder, and evaluate organizational procedures" (p. 9). This definition clearly implies that crimes are committed within spatial context. That Boba (2005) lists spatial factors along with 
the use of law enforcement and socio-demographic information stresses the importance of spatial context if an accurate analysis is to be performed.

Technology, in combination with sound theoretical work, has led to the development and implementation of analytical systems. These analytical systems use the technology to detect crime "hotspots". Anselin et al (2000) define a crime hotspot as a "location or small area within an identifiable boundary, with concentration of criminal incidents" ( $p$. 222). Location quotients are one of several methods used to display crime hotspots. Location quotients are described as the Getis and Ord Gi and Moran Local I techniques, which were developed to create kernel surface estimation algorithms and the Local Indicators of Spatial Association (Ratcliffe, 2004). Local Indicators of Spatial Association (LISA) statistics can be explained as, "a measure of the extent to which the arrangement of values around a specific location deviates from spatial randomness" (Anselin, Cohen, Cook, Gorr, \& Tita, 2000, pp. 233-234). In order for the location quotients to work properly, they require the generation of many random points to help create the density surfaces that can easily be calculated and mapped (Ratcliffe, 2004). These methods are constantly used because they are applied to block groups, police divisional boundaries, or census tracts.

All of the above techniques are used for identifying spatial clusters but have not addressed the temporal aspect of crime hotspots. Ratcliffe and McCullagh (1998)have created the aoristic analysis, which uses temporal weighting when the time of the crime is unknown. The analysis requires a start and end time for when the crime occurred (Ratcliffe, 2004). The aoristic model allows the use of a probability matrix that consisted of crime event for each hour of the day. The aoristic model has given law enforcement the ability to determine the best times for patrols in areas of high crime. The aforementioned methods apply to the area data that have crime as the attributes. As far as the crime point data is concerned, different methods have also been developed including measures of central tendency, measures of dispersion, and regression analysis ( The International Association of Crime Analysts, 2004). More specifically, Grubesic and Mack (2008) discuss appropriate various statistical methods that are designed to uncover spatio-temporal relationships (Grubesic and Mack, 2008).

Two specific statistics that they recommend to use are the Knox test and the Jaquez$k$-nearest neighbor test $(k-\mathrm{NN})$. The results of the study show that these two tests cannot replace the purely spatial or temporal methods of hotspot analysis, but could be complimentary. Another approach is to use bandwidth estimation based on $k$-nearest neighbor distances between points, it is an improvement compared to other methods because it is based on the spatial relationship among the points (Williamson, McLafferty, Goldsmith, Mollenkopf, \& McGuire, 1999). This study finds the optimal $k$. For instance if $k$ was 10 , the bandwidth is estimated as the average distance from each point to its 10 nearest neighbors. Furthermore, if a higher $k$ value is used it will give a larger bandwidth and search a larger area; a smaller $\mathrm{k}$ value will give a smaller bandwidth and search a smaller area. Finally, as $k$ increases, the process searches larger areas for more nearest neighbors. This adds larger distances to the calculations.

Another approach that has been used is to create a density map in lieu of a hotspot analysis. Paulsen and Robinson claim that kernel density maps hold many advantages over the "hotspot" techniques because of the continuous view of densities that are created 
(Paulsen \& Robinson, 2004). Another advantage is that the continuous surface gives information about the whole area, which provides a picture of the density of crime for each location instead of which incidents are most directly related. Another method that has been used is quadrant count, where a square grid is overlaid on the points, and the number of points in each grid cell is counted and compared to the "expected" number that is given by spatial randomness by a chi-squared test of goodness-of-fit (Anselin et al., 2000, p. 227).

In addition to the above methods, there are also programs that can be developed to perform statistical analysis, such as CrimeStat. CrimeStat inputs the incident point locations and the outputs statistics that can be shown in a GIS (Levine, 2005). The program can also allow secondary data to be compared to the crime statistics and can calculate different spatial statistics that range from "summary spatial description, hotspot analysis, interpolation, space-time analysis, and journey-to-crime modeling" (Levine, 2005 , p. 41). Some other programs that have been used are S+SpatialStats add-on for the S-Plus statistical system and the SpaceStat Package (Anselin et al, 2000). Another form of software that has been used is obtained between the ArcGIS and the XGobi and XploRe software packages; the links between the two are based on the point data and allows for the brushing of a variogram cloud plot (Anselin et al. 2000, p. 235). An older program that has been used was the STAC (Spatial and Temporal Analysis of Crime) package. The STAC was developed in Chicago and was designed to detect 'Hot Clusters,' or specific locations with high crime statistics. The next section explains in depth demographic data and crime count using regression analysis techniques.

\subsection{Crime Demographics}

To understand why certain crimes are occurring, it is important to examine the demographic variables that influence crime in cities. Shaw and McKay bring up three structural factors that lead to the disruption of community social organization, which include "economic status, ethnic heterogeneity, and residential mobility" (Sampson \& Groves, 1989, p. 778). Up to date, the social disorganization theory has not been fully tested, but most researchers have examined the effects of the characteristics of median income, racial composition, and residential mobility on crime rates (Sampson \& Groves. 1989, p.775). Sampson and Groves addressed the fundamental limitations of past research by using the unique design of the British Crime Survey (BCS), which enabled them to measure both social disorganization and crime rates for more than 200 local communities. Their approach applied Shaw and McKay's community level theory of crime and delinquency (Sampson \& Groves, 1989, p. 777). They tested social organization by measuring local friendship networks, control of street-corner teenage peer groups, and prevalence of organizational participation. The model was tested on 238 localities in Great Britain that was constructed from a national survey of 10,905 residents after that the model was replicated on an independent national sample of 11,030 of residents in 300 British localities in 1984. Overall, the models supported Shaw and McKay's theory that social disorganization is caused by "criminal victimization and criminal offending" (Sampson \& Groves, 1989, p.774) 
To further understand the relationship between crime and demographic factors. In the past, there were few studies that examined the determinants of population change at the neighborhood level, but this line of research has important implications for the relationship between crime, socioeconomic disadvantage, and population change (Morenoff \& Sampson, 1997, p. 35). Sampson and Morenoff refer to Wilson's Theory (1989) that a variety of demographics may operate simultaneously and they extracted a testable hypothesis out of his theory stating the existence of a, "connection between the increasing concentration of socioeconomic disadvantage and the depletion of urban neighborhood populations" (Sampson \& Morenoff, 1997, p. 35). Sampson and Morenoff conducted an empirical analysis on both tract-level census data and geo-coded homicides data for the city. They used a dependant variable of change in a tract's population over each decade, and they looked at separate analyses for change in the black and white populations of a given tract (Sampson \& Morenoff, 1997, p. 38). Two approaches were used to measure the change they were the raw change scores and residual change scores. Raw change scores are found more in sociological literature and the residual is found more in criminological research (Sampson \& Morenoff, 1997, p.38). The article explains that population residual scores have an advantage over raw change scores because they are statistically independent of initial levels of population. In addition, they explain that the residual change reflects the population change of a neighborhood beyond the citywide pattern of population change (Sampson \& Morenoff, 1997).

In terms of methods for investigating the relationships between crime and sociodemographic factors, a variety of regression techniques have been applied, including the linear regression models, autoregression models, and other regression models specifically designed for geographic data. Ordinary least squares regression is a linear regression and is a procedure where the predictions of the dependent variables are obtained through a linear combination of the independent variables. This model used a constant weight in the estimation no matter how far away the observation might be (Charlton \& Fotheringham, 2009). To address the temporal autocorrelations of the data, autoregression models have been used. One of these models is the vector autoregression (VAR) model, which is a time series model that estimates and tests leading indicators, where the variable(s) of interest are explained by its own past value and past values of all other variables that are in the system (Anselin et al., 2000). Another model that is based off the VAR model is the Bayesian vector autoregression (BVAR), which has been successful in time series analysis and forecasting models for regional data (Anselin et al., 2000). Regression analysis assumes that the observations that are made should be independent of one another this is not always the case with spatial data, because Tobler's law states, "Everything is related to everything else, but near things are more related than distant things." This means that not only might the variables that are used for the model show spatial dependence but also the models' residuals might also show spatial dependence. This spatial dependence is something that needs to be avoided when running regression analysis. One of the regression processes that has taken into account the nearness and similarity described by Tobler's law is geographically weighted regression (GWR). For example, if there is a need to estimate parameters for a model at a given location, then observations nearer to that location are given a greater weight in the estimation than observations that are further away (Charlton \& Fotheringham, 2009). 
Geographically weighted regression (GWR) and ordinary least squares (OLS) are two ways of analyzing dependent and independent variables that have been incorporated into the ArcGIS software package. Regression is a method of modeling the relationship between dependent variables and a set of one or more independent variables (Charlton \& Fotheringham, 2009). The results of the regression model is a residual which is a predicted or fitted value; the residual should be both independent and drawn identically from the normal distribution with a mean of zero, which is accomplished by using the procedures known as OLS (Charlton \& Fotheringham, 2009, p. 2). With GWR there is the ability to use parameters to estimate anywhere in the study area given a dependent variable and a set of one or more independent variables that are measured by location. According to Tobler's law, since regression is based on location, the independent variables that are observed nearer to the location of the dependent variable should have a greater weight in the estimation than other variables that are farther away (Charlton \& Fotheringham, 2009, p. 5). The regression ultimately will produce output points that are predictions for the dependent variables (fitted values), residuals, and standardized residuals, which help determine if certain demographic variables influence specific crimes in populated cities (Charlton \& Fotheringham, 2009).

\subsection{Summary}

Based on consideration among the choices, it seemed that using kernel density estimation for the model was the appropriate means of establishing crime densities. To meet the project goals, a series of animated crime density maps can represent how crime changes in the city of Redlands.

There have been many researchers and organizations that have used various statistical methods to understand why certain crimes are happening consistently in specific areas. Investigating the socio-demographic factors of these crime-prone areas may shed light on the relationships between place and crime. Both linear regression and geographically weighted regression models were used in this project to examine why the crime clustered in certain neighborhoods in the city. In doing so, it should help the City of Redlands fight against crime. 



\section{Chapter 3 - Systems Analysis and Design}

This chapter focuses on the client's objective of creating animated crime density maps and running regression analysis tools, to understand where crimes are and why they are occurring. The problem addressed by this project is examined first. Next, the requirements that are needed for this project are considered. In addition, the design of the system implementation is discussed. Finally, the project plan is reviewed.

\subsection{Problem Statement}

Crime has increased in the City of Redlands and the city had a need to examine crime distribution and understand factors that influence the occurrence of crimes. Armed with historical crime data for the past twenty years, the Redlands Police Department wished to explore the changes in crime distribution over time and to understand the sociodemographic characteristics of the crime-prone neighborhoods in the city.

\subsection{Requirements Analysis}

The project involved a requirements analysis, where functional and nonfunctional requirements were identified. The client requested a method by which to display a large amount of data over a period of 20 years in a unique way, but also wanted to investigate the reasons behind the distribution of crime in Redlands. To display the crime data over 20 years, there were five necessary functional requirements for implementation within a model. The first functional requirement was to query crime data for a particular crime type over 20 years, the second requirement was to query the time period for the estimation, and the third requirement was to create kernel densities for each crime type. This model produced raster kernel densities for the specified crime types. Two additional functional requirements were necessary in order to understand why certain crimes are happening. The fourth functional requirement involved the ordinary least squares (OLS) and geographically weighted regression (GWR) statistical tools. Utilizing these statistical analysis methods revealed the relationship between the characteristics of neighborhoods and crime. In addition, a file geodatabase was implemented for convenient storage due to the large amount of data Table 1 summarizes the project's functional and non-functional requirements. 
Table 1. Requirements

\begin{tabular}{|l|l|}
\hline Nonfunctional & \multicolumn{1}{|c|}{ Functional } \\
\hline \hline Efficiency, updateable & Query crime types \\
\hline Efficiency, updateable & Query time period \\
\hline Efficiency & Kernel Density Estimation \\
\hline Analyze & Statistical regression tools \\
\hline Updateable & File geodatabase \\
\hline
\end{tabular}

\subsection{System Design}

The client's requirements shaped the system design that consisted of nine components. The initial component was a file geodatabase maintained by the City of Redlands. This geodatabase fueled two separate procedures, one resulted in a series of animated maps and the other was used for statistical regression analysis. The first task was utilizing a crime kernel density model that extracted the crimes of interest for the generation of density surfaces. Once the density surfaces were created, they were saved into the crime kernel density geodatabase. The second task was manually extracting the crime incidents into a newly created file geodatabase for crime vector data. Census-joined data from the new file geodatabase was used for the statistical regression model. The system architecture can be found in Figure 3-1. 


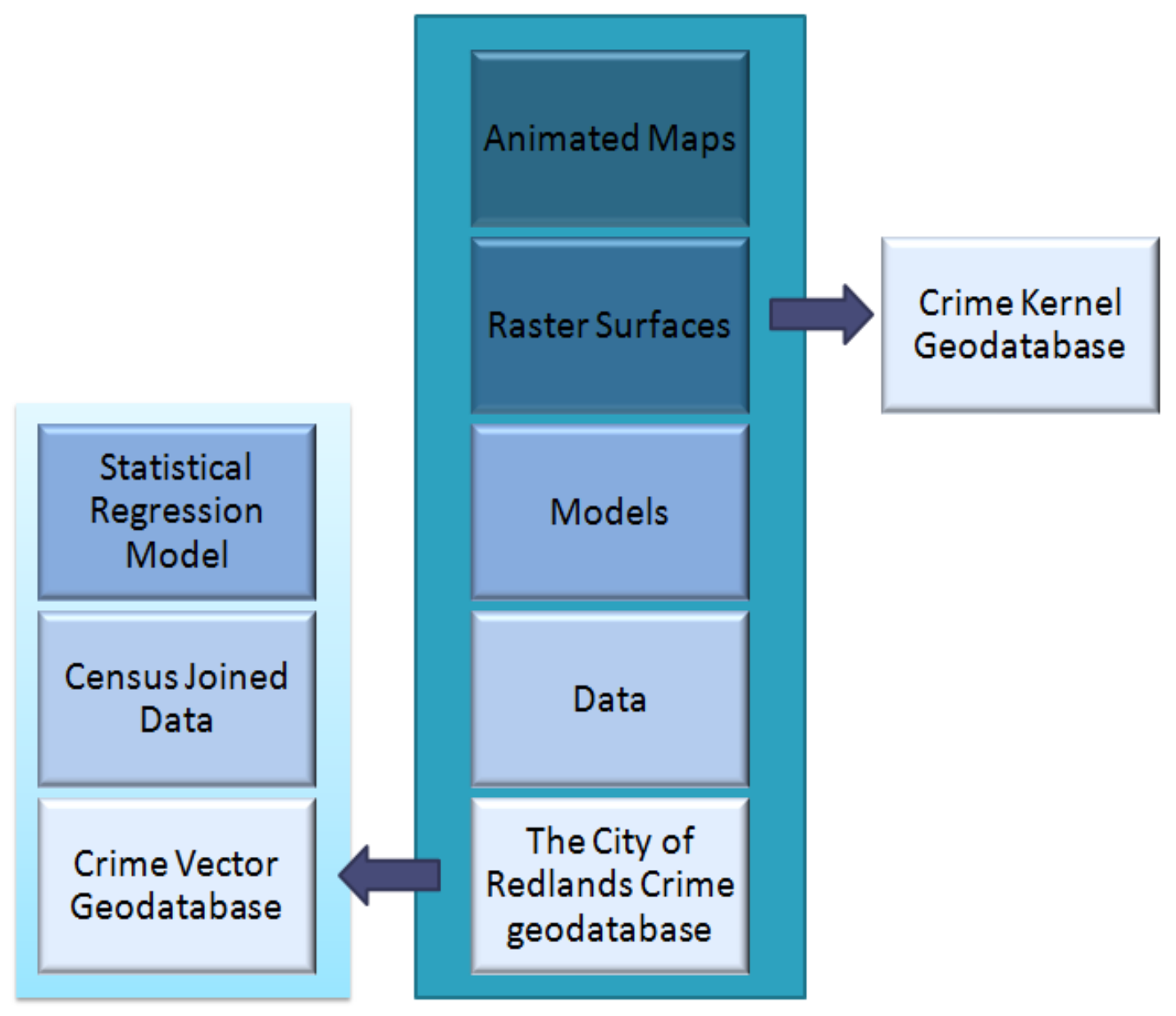

Figure 3-1: System Architecture

\subsection{Project Plan}

The original plan for the project was to create animated crime density maps for the past 20 years for the City of Redlands GIS Department. The primary tasks for this project included a requirements analysis, a data needs assessment, a database design, model builder implementation, project documentation, and project delivery.

These steps were generally completed in order using the waterfall model where each successive step begins upon the successful completion of the previous step.

\subsubsection{Requirements}

The requirements were evaluated based on the needs of the client. There were four unique categories of requirements: functional, technical, operational, and transitional requirements. In order to meet these requirements, there were several discussions with the client to determine the necessary steps for the successful completion of the project. During these meetings, the client was able to discuss the data capabilities as well as 
software and hardware needs. The technical requirements included having ArcGIS software with an ArcInfo license, which enabled the client to run the model, produce the animated maps, and perform the statistical analysis. The client also helped to define the operational and transitional requirements. These requirements included the specification of what needed to come out of the model and how the Redlands GIS Department would transfer the models and use them at their place of business. The client was able to give insight and feedback on the construction of the model and the process of creating the animated maps.

\subsubsection{Data Collection}

The client provided some of the data that was needed for the project. This data included a geodatabase that contained street data, boundary data, and parcel data. The rest of the data provided by the client was the crime incidents shapefile. ESRI provided censusjoined data from in the Business Analyst datasets. Mandatory data that was needed for the project included the five chosen crime types, the year they occurred, the location, and a street map of Redlands, CA. The data was separated into five different feature data sets depicting 20 years of each crime type. The joined census data was also put into different feature data sets. Though additional crimes and demographic data could have added value to the analysis, the scope and limited timeframe of the project did not allow for this inclusion.

\subsubsection{Geodatabase Development}

Once the requirements and the data needs were determined, it was possible to develop the geodatabase. It was determined that a file geodatabase would be used since it is the most common data storage format that is used by the client. Due to the large volume of the historical crime data, two geodatabases were designed for input data and output layers, respectively, which will make it easier when the client needs to update the models in the future.

\subsubsection{Model Development}

Once the data was prepared, the next step was to develop models to create the crime density maps. It was determined that Model Builder would be the best tool to use when creating the kernel densities in ArcGIS. Using the output from the models, the animation toolbar was then applied to create animated maps of the five crime types.

\subsubsection{Statistical Analysis}

The crime density maps allowed the client to explore the changing crime concentrations over time. However, to answer why certain areas are prone to crime, a regression analysis was necessary. In this project, both ordinary least squares and geographically weighted regression were used with the tools implemented in the ArcToolbox. 


\subsubsection{Project delivery}

The project was concluded with the delivery of a DVD containing the animated maps and the results of the regression models. The DVD contained the final report, the file geodatabases, metadata, and the model built in Model Builder along with the animated maps and the regression analysis.

\subsection{Summary}

In order to ensure the success of the project, it was necessary to perform and understand the requirement analysis. The process included sorting the crime data, creating a model to produce kernel densities of the five chosen crimes, and examining demographic data for variables that influenced the occurrence of crime. The use of Model Builder and ArcMap were critical factors in creating the crime densities maps; using the statistical regression analysis tools helped determine what demographics influenced certain crimes to occur. Success of the project hinged on a functioning map animation that displayed the data throughout the 20 years. Also, by using the statistical regression analysis tool it was possible to produce a better understanding of why certain crimes are occurring in the City of Redlands. 



\section{Chapter 4 - Database Design}

This chapter explains the conceptual model, which describes what needed to be stored in the database. The logical model was also discussed which is in the form of an ESRI File Geodatabase. Once the models were determined, the next step was to develop the project database that would allow the input data to be stored. Finally, the loading of the database and the cleaning of the data is outlined.

\subsection{Conceptual Data Model}

The conceptual data model was based on the crime data, since the goal of the project was to show where crimes have been occurring. It was important to make sure that crime data is the focus of the conceptual model. The other datasets in this model showing how the crime was analyzed and displayed. Figure 4-1 shows the process that was needed to illustrate the five different crime types displayed on the map in hotspot form; also, it shows that the maps will display the population data.

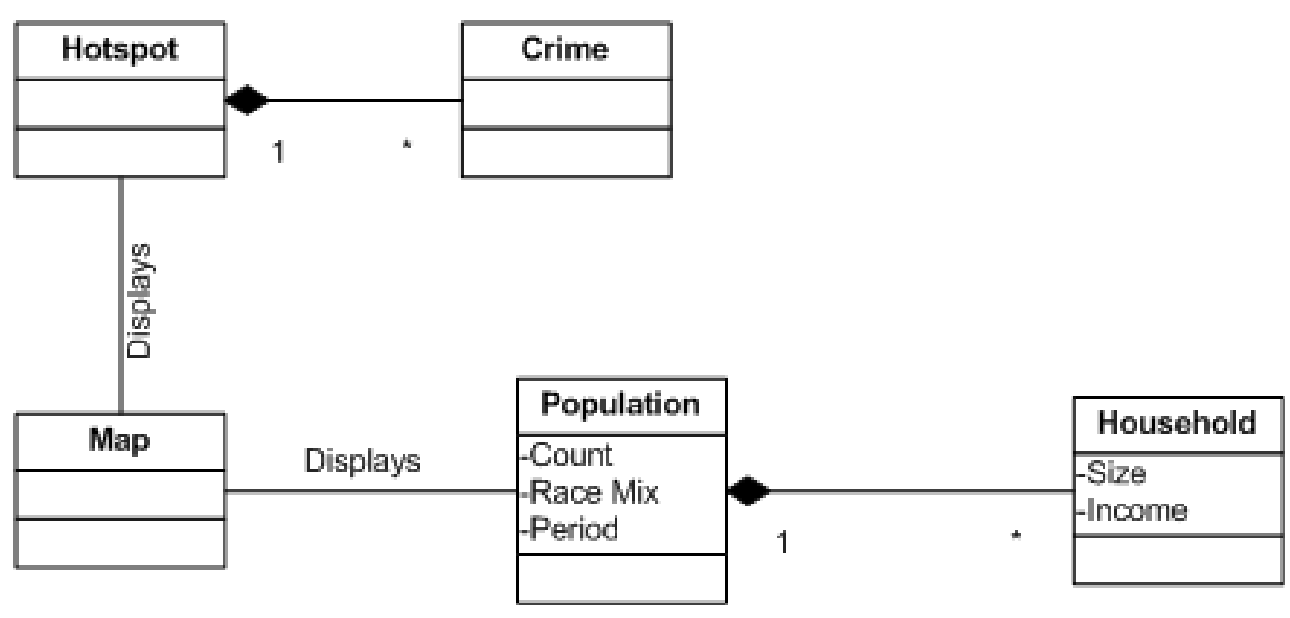

Figure 4-1: Conceptual Model

\subsection{Logical Data Model}

After reviewing the outcome of the project, it was decided that a file geodatabase would be the optimal way to store and organize the data. Because of its ability to store large amounts of data and because it has the ability to add more data can be added if needed in the future. This database was structured so that the client could easily access the data. There were two different file geodatabases used: one that stores the vector datasets and the other raster datasets. In the vector geodatabase, each crime type has a feature dataset that consists of the crime type and the 20 associated years. Therefore, there are five 
feature datasets with 20 shapefiles stored in them. There are also datasets that store the joined crime and census data for the regression and hot spot analysis. The raster geodatabase is made up of all the rasters that were created from the five different crime type models. There are 100 rasters stored in this geodatabase.

In Figure 4-2 illustrates the raster geodatabase structure. Due to its content of 100 rasters, it was not possible to display all of the rasters in one image.

Also, Figure 4-3 shows the crime vector geodatabase with the different feature classes that were included in this geodatabase they included the different crime typed and the spatial joined census and crime types.

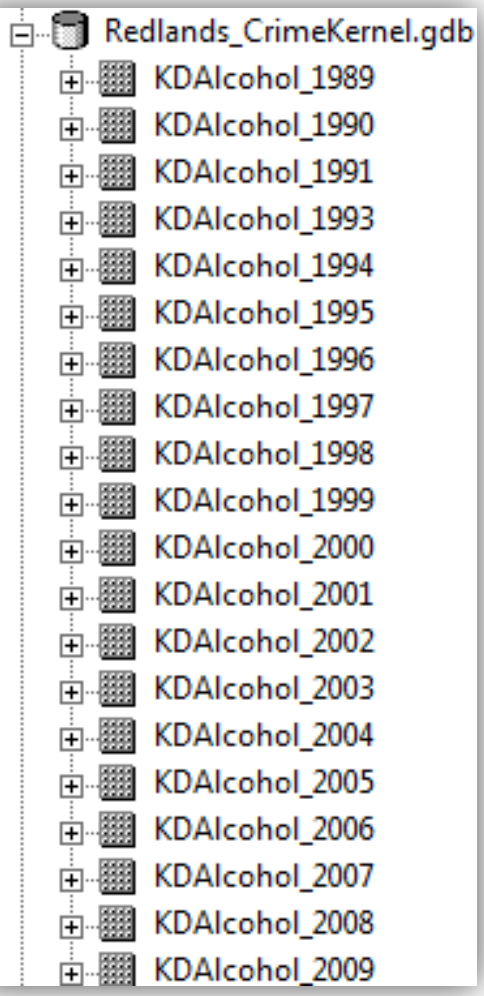

Figure 4-2: Crime Raster Geodatabase 


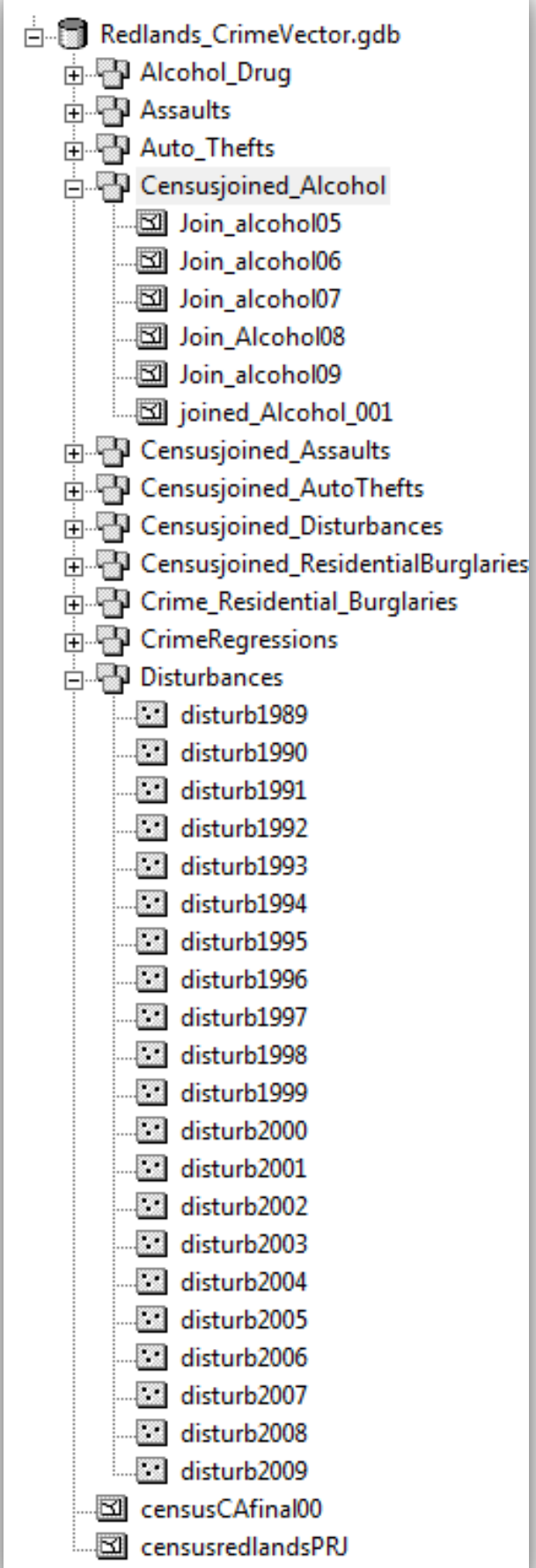

Figure 4-3: Crime Vector Geodatabase 


\subsection{Data Sources}

Philip Mielke, the GIS Administrator at the City of Redlands, provided the data for this project. The data was originally projected in NAD 1983 State Plane California Zone V FIPS 0405 Feet. For the project, five different crime types were used that have the same projection as stated above. To condense the data it was important to extract the five different crime types using SQL statements, the crime types that were extracted, included assaults, auto theft, alcohol/drug-related crimes, disturbances, and residential burglaries. The other data source used was the Business analysis datasets that store the ESRI census data for 2000. The ESRI census data was originally projected in WGS 1984 and then was reprojected into NAD 1983 State Plane California Zone V FIPS 0405 Feet.

\subsection{Data Scrubbing and Loading}

The projection for this file geodatabase was NAD 1983 State Plane Zone V. This was chosen because Redlands is in the Southern portion of California. The shapefiles that were not projected were reprojected and then loaded into the database. Time constraints limited the project scope to five different crime types, it was therefore necessary for those five crimes to be sorted out of the data with SQL statement that extracted the specific crime type of interest. Also in order for the data to be seen in density form, the data were converted into raster surfaces that could then be classified into five different value fields. This helped depict where the crime was the densest. Since the crime densities are focused on the center of Redlands a clipped roads layer was used in order to focus on the areas of interest. Once all the above data processing was done, it was possible for all the data to be uploaded into the two geodatabases.

\subsection{Summary}

The conceptual data model explains how the different crime types that were used were part of creating the density maps. In addition, the conceptual model helped explain the analysis of the crime types and the demographic data. After constructing the conceptual model, it was determined that the logical model needed to consist of an ESRI file geodatabase. After this was determined, the necessary datasets were created and loaded into the geodatabase. Because the client had provided the datasets, the only processing that was needed was to make sure that the data was exported into the geodatabase. 


\section{Chapter 5 - Implementation}

The primary objective of the project was to understand where and why the crime in the City of Redlands has been concentrated from the historic crime data. To address this issue, two approaches were implemented: the first method was to create animated maps, and the second was to run regression analysis. Specifically, ArcGIS software and Model Builder were applied to create densities for the different crime types of interest. The first step was to develop the crime kernel density model. Once the model was developed, the crime density maps were then animated using the animation tool bar in ArcMap. As for the regression analysis, both ordinary least squares and the geographically weighted regression were conducted. Both regression and autocorrelation tools in ArcGIS were used to run the analysis.

\subsection{Kernel Density Analysis Maps}

There are many different crime types in Redlands but five were examined for this project. These included: disturbances, residential burglaries, alcohol/drug-related crimes, auto thefts, and assaults. Kernel density maps were made for all crime types of interest. These were created for a better understanding of where the crimes of interest are occurred the most. This allowed for a comparison of how crime has changed from year to year. The following subsection describes the model process.

\subsubsection{Crime Density Model}

To make the kernel densities for the different crime types, a model was produced. The first step in creating the model was to use an input feature class of all of the crimes that occurred in the year of interest. Next, SQL statements were used to extract the crime types. Since the original crime database had two different schemas before and after 2006, two sets of SQL statements were used, as summarized in Tables 1 and 2. 
Table 2. SQL Statements for the years 1989-2006

\begin{tabular}{|c|c|}
\hline Crime Type & SQL Statement \\
\hline Disturbances & $\begin{array}{l}\text { ("CLS" >= 909 AND "CLS" <=914) OR } \\
\text { "CLS" = } 226\end{array}$ \\
\hline Auto Thefts & $\begin{array}{l}((" C L S ">=710.00) \text { and }(" C L S "<=740.99) \\
\text { and }(" C T S "<=1))\end{array}$ \\
\hline Alcohol/Drug-related crimes & $\begin{array}{l}\text { "CLS" = } 230 \text { OR "CLS" = } 232 \text { OR "CLS" = } \\
934\end{array}$ \\
\hline Residential Burglaries & $\begin{array}{l}((((" C L S ">=511.00) \text { and }(" C L S "<=513.99)) \\
\text { or }((" C L S ">=521.00) \text { and }(" C L S "<= \\
523.99)) \text { or }((" C L S ">=531.00) \text { and }(" C L S " \\
<=533.99))) \text { and }(" C T S "<=1))\end{array}$ \\
\hline Assaults & $\begin{array}{l}((" \mathrm{CLS} ">=410.00) \text { and }(" \mathrm{CLS} "<=441) \text { and } \\
(\text { "CTS" }<=1))\end{array}$ \\
\hline
\end{tabular}

Table 3. SQL Statements for the years 2007-2009

\begin{tabular}{|l|l|}
\hline Crime Type & SQL Statement \\
\hline Disturbances & $\begin{array}{l}\text { ([CVLEGEND01] = "Disturbance") OR } \\
\text { ([CVLEGEND02] = "Disturbance") }\end{array}$ \\
\hline Auto Thefts & $\begin{array}{l}\text { ([OFFCODE01] = "TH05") OR } \\
\text { ([OFFCODE02] = "TH05") }\end{array}$ \\
\hline Alcohol/Drug-related crimes & $\begin{array}{l}\text { ([OFFCODE01] = "VCAL") OR } \\
\text { ([OFFCODE02] = "VCAL") }\end{array}$ \\
\hline Residential Burglaries & $\begin{array}{l}\text { ([CVLEGEND01] = "Burglary - } \\
\text { Residential") OR ([CVLEGEND02] = } \\
\text { "Burglary - Residential") }\end{array}$ \\
\hline Assaults & $\begin{array}{l}\text { [CVLEGEND01] = 'Assault - DV' OR } \\
\text { [CVLEGEND01] = 'Assault - Felony' OR } \\
\text { [CVLEGEND01] = 'Assault - Misdemeanor' }\end{array}$ \\
\hline
\end{tabular}

Next, an expression is needed and the SQL statement is used to pick out the crime type of interest. The SQL statement is used as a model parameter. The next step is to use the feature class to feature class tool in order to create a shapefile that will store all of the crimes of interest. In order to create this shapefile, the fields specified in Figure 5-1 were populated. 


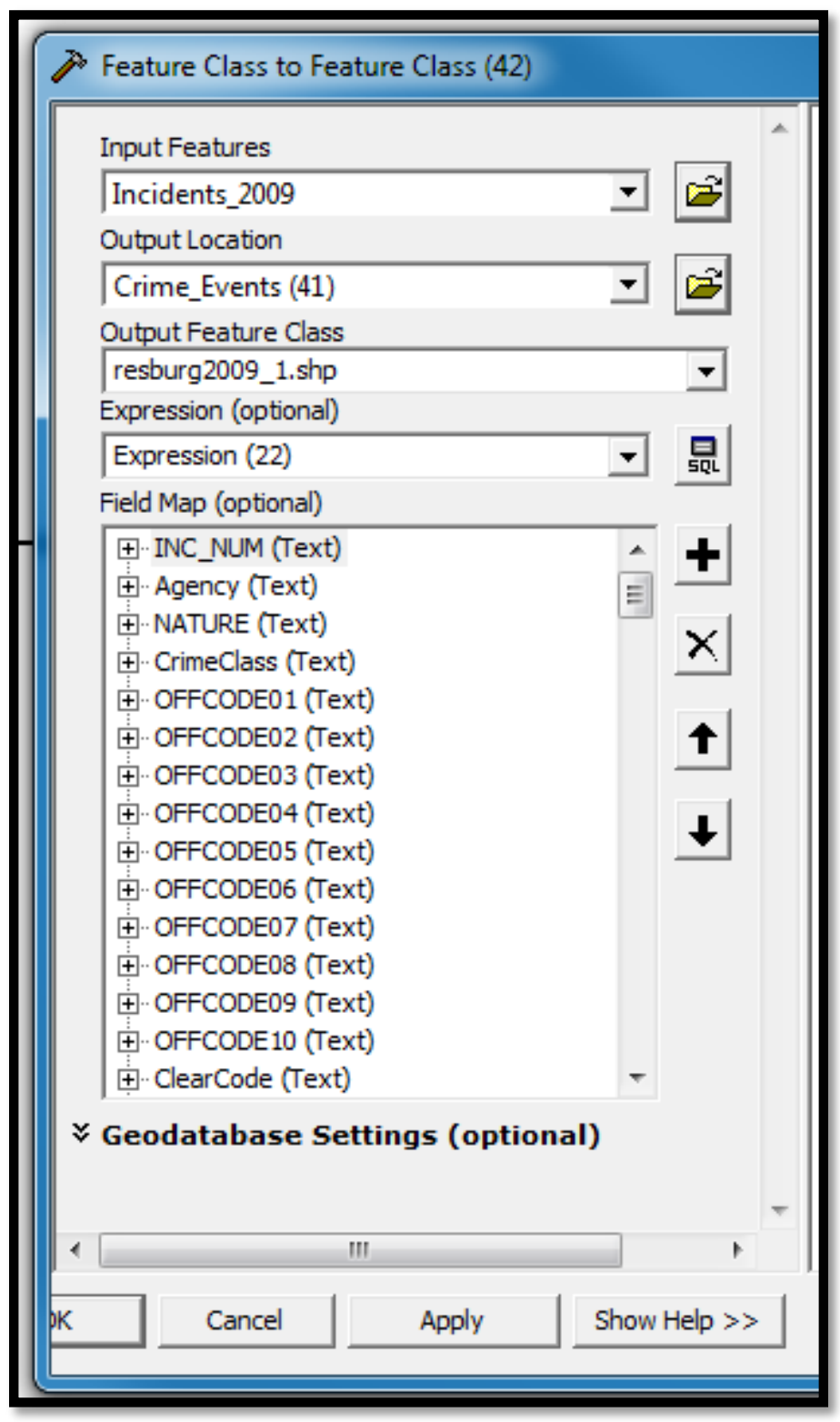

Figure 5-1: Feature Class to Feature Class

Once this shapefile was created, it was outputted into the output feature class of crime events. Another feature class to feature class tool was then used to extract the time period of interest. It was crucial for the expression field to be filled in with a date expression. For example, the client would have the option of how many months of that crime that they would need in order to create the density surfaces. For the sake of the project, the entire year was used. For example if the year 2009 was needed, the expression for this would be ("ocurDt1" > '2009-01-03 00:00:00' AND "ocurDt1" < '2009-12-30 00:00:00'). The date expression is also considered a parameter for this model. When the shapefile was created, it was outputted into the feature class of crime events. Finally, the kernel density tool from ArcMap toolbox Spatial Analyst toolset was 
used. This tool was used to create the raster surfaces to show the density of the crime of interest. It was necessary to fill out the fields in the form (Figure 5-2).

The first field that was filled was the Input point or polyline feature, the crime type, the field named population field, and the output raster field. Finally, the output cell size was set to 30 meters, the search radius field was set to 1000 feet, and the area unit field was set to square miles.

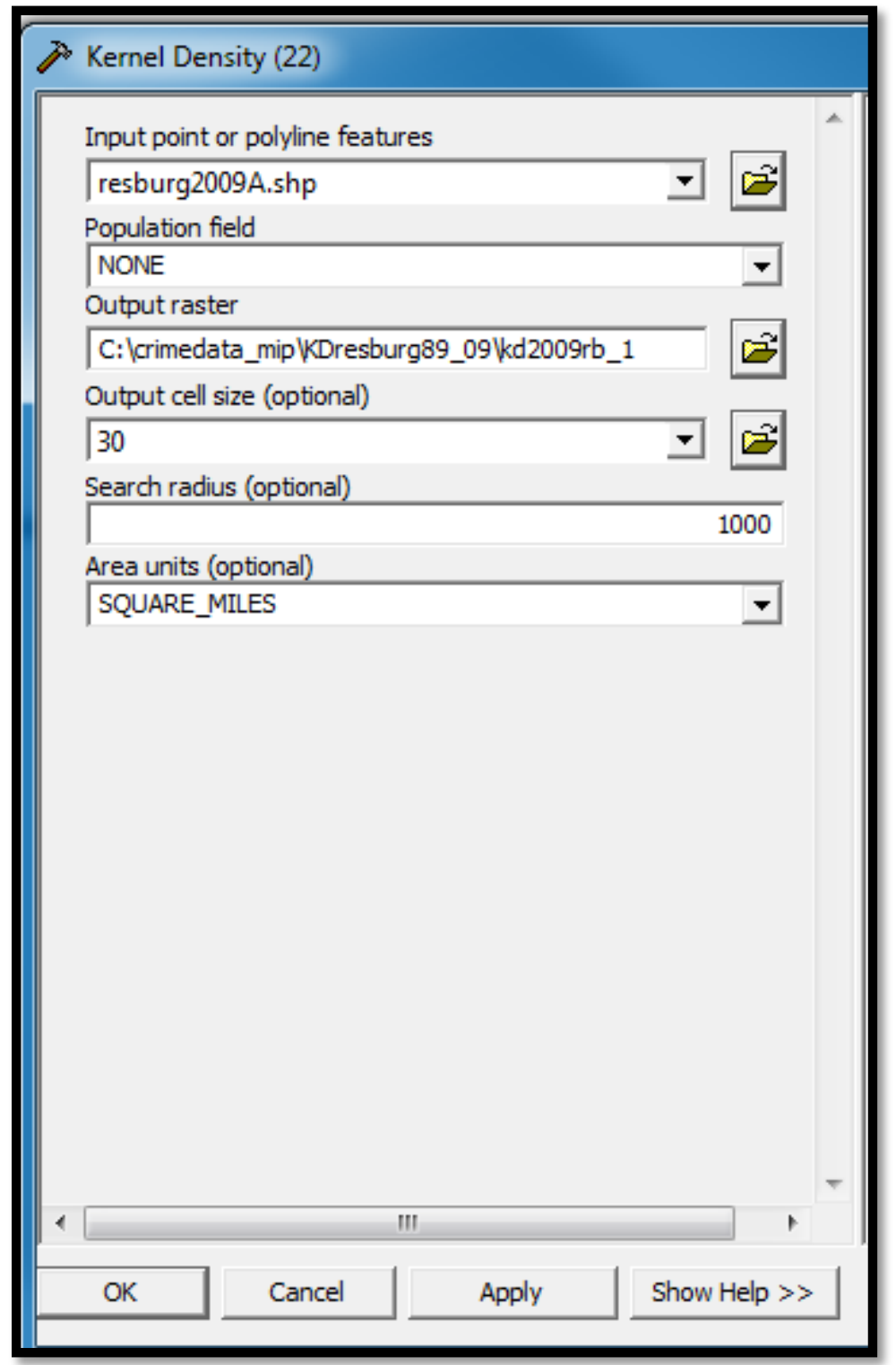

Figure 5-2: Kernel Density Form

All 20 models were filled out identically. Once the raster surfaces were created, they were inputted into the Crime Kernel geodatabase. The final model can be found in Figure 5-3. 


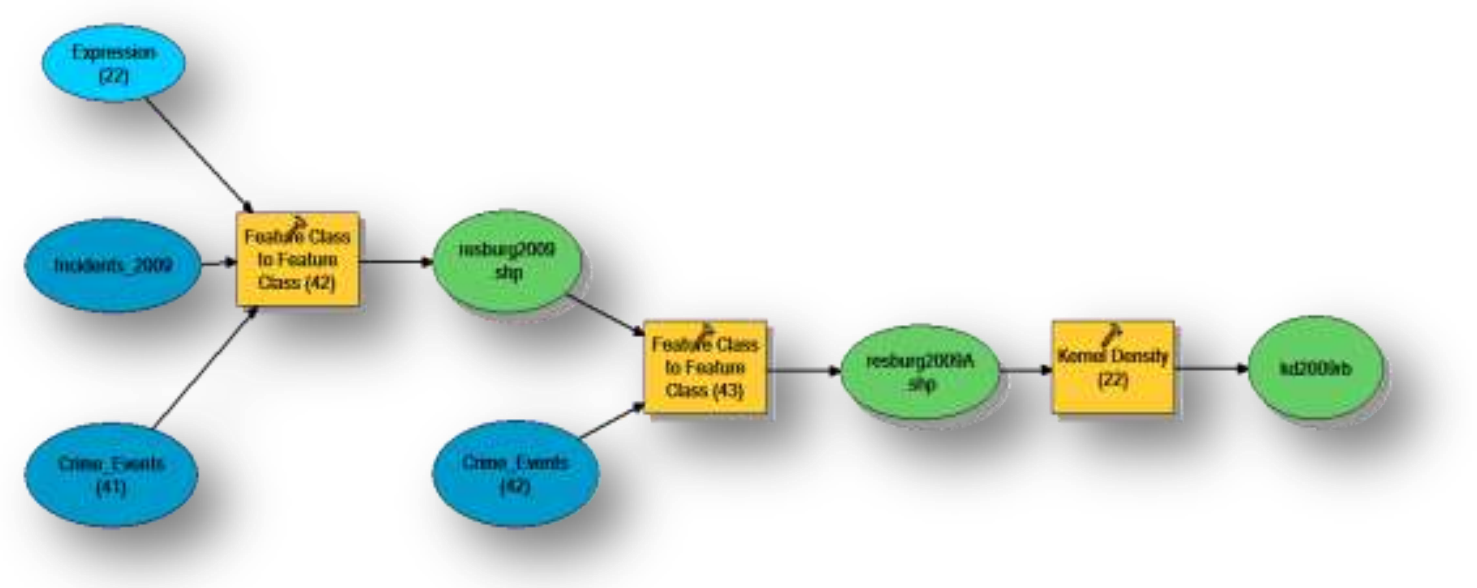

Figure 5-3: Crime Kernel Density Model

This model was repeated 100 times so that all 5 crime types and 20 years, worth of crimes were created. As mentioned earlier, the only change from model to model were certain parameters, these included the crime type and the year. To change the parameter of crime type, the correct SQL statement would need to be used. In addition, the user would need to know what time period needed to create the densities. This would require the correct date expression. The next step was to create maps out of the raster surfaces so that the crime densities could be visualized.

\subsubsection{Crime Density Classification}

The crime density surfaces for the 20 years of five different crime types were produced using the model, and then loaded into ArcMap. Once the data was loaded in, it had to be classified. At this point, the same classification scheme was required to make a comparison between multiple crime density surfaces of each type of crime. First, the largest range of crime density values was found and the natural break classification was made, as summarized in Table 4. These classification standards were applied to the rest of density surfaces. In doing so, the distribution of the crime of interest can be compared over time. 
Table 4. Classification Standards

\begin{tabular}{|c|c|}
\hline Crime Type /Year & Range \\
\hline Assaults in /2007 & $\begin{array}{c}\square \quad 0-31 \\
\square \quad 32-108 \\
\square 109-259 \\
\\
260-554 \\
\square 55-988\end{array}$ \\
\hline Disturbances /1996 & $\begin{array}{cc}\square \quad 0-180 \\
\square \quad 181-644 \\
645-1,443 \\
\square 1444-3117 \\
\quad 3118-6570\end{array}$ \\
\hline Residential Burglaries /1994 & $\begin{array}{c}\square \quad 0-17 \\
\square \quad 18-61 \\
62-136 \\
137-393 \\
\quad 394-865 \\
\end{array}$ \\
\hline Auto Thefts /1996 & $\begin{array}{c}\square \quad 0-27 \\
\square \quad 28-113 \\
114-270 \\
271-685 \\
686-1377 \\
\end{array}$ \\
\hline Alcohol/Drug Crimes / 2005 & $\begin{array}{cc}\square \quad 0-58 \\
\square \quad 59-302 \\
\square \quad 303-818 \\
\quad 819-1567 \\
\square 1568-2482\end{array}$ \\
\hline
\end{tabular}

Once each raster was classified, the next step was to symbolize the ranges. The ranges were labeled as very low, low, medium, high, and very high. The colors associated with these labels were red for the very high values, dark purple for the high values, a lighter purple for the medium values, and then white for the low and the very low values.

After the density maps were symbolized, the next step was to add in the street layer that included freeways, major roads, and neighborhood streets. The freeways were symbolized with a red line, while the major roads were symbolized with a bold black line. The neighborhood streets were symbolized with a solid gray line.

Figure 5-4 shows an example of how the range and symbolization were done. 


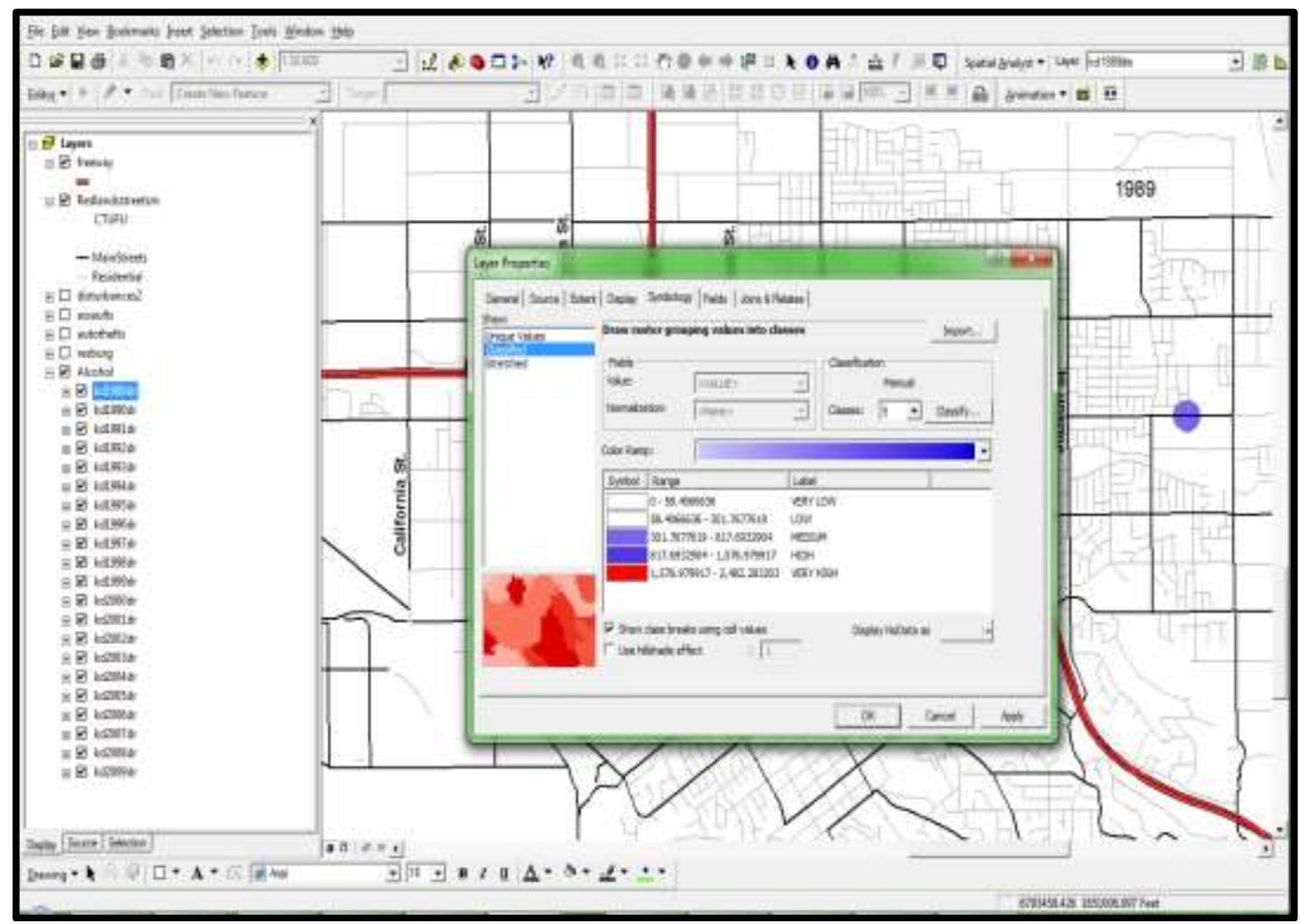

Figure 5-4: Range and Symbolization Process

Once each crime type had 20 maps labeled and symbolized, the next step was to present them in a way that would compare each density from year to year. Because this was a large amount of data over a long span of time, animation proved to be the best way to present the data. This was done using the animation toolbar in ArcMap. Figure 5-5 is 
an example of what one of the final crime kernel density map looks like.

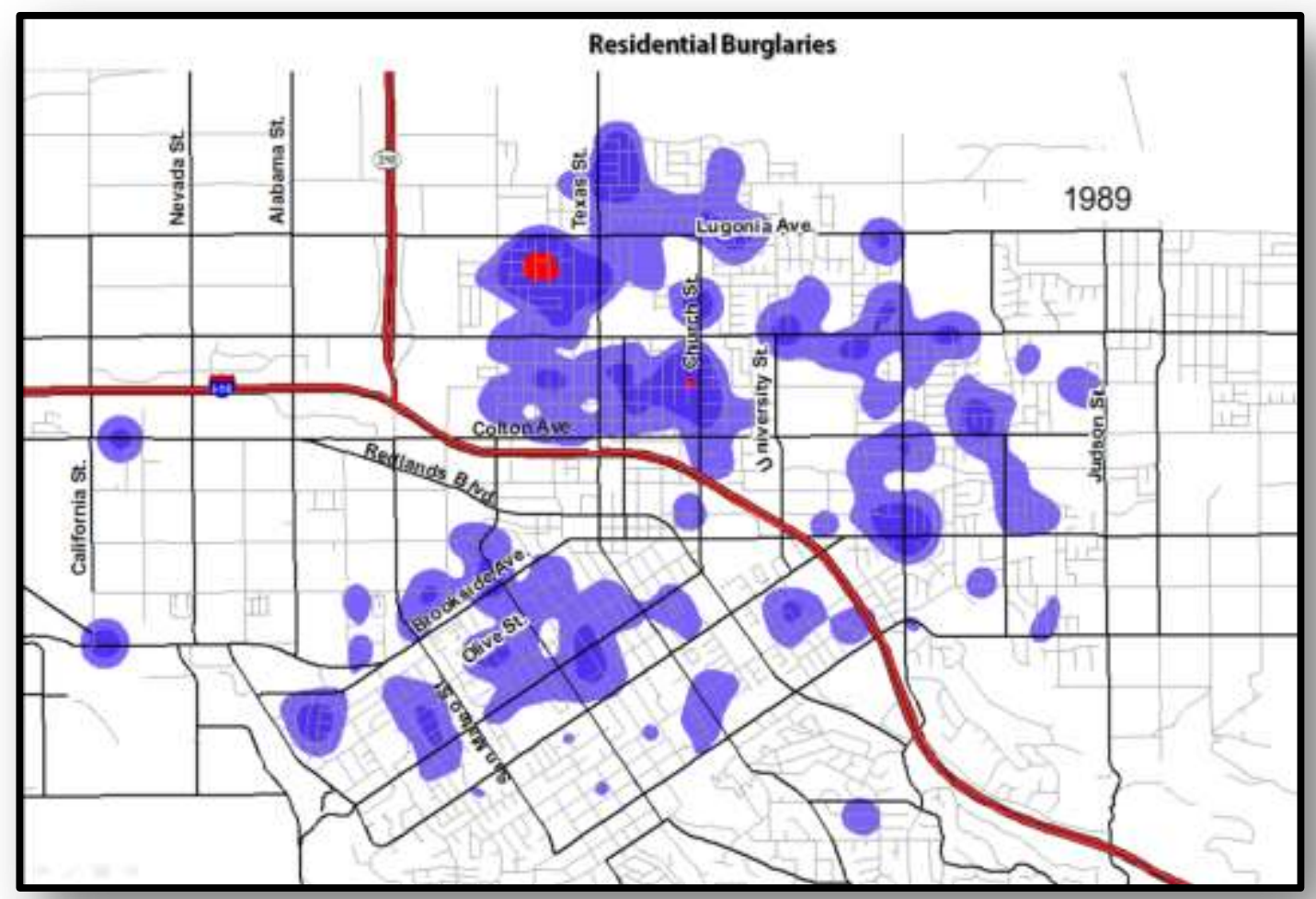

Figure 5-5: Kernel Density Map

The next subsection explains in more detail the process of animating the five sets of crime kernel density maps.

\subsubsection{Animation}

To create the animation, the animation toolbar was enabled in ArcMap. All 20 density surfaces of a particular type of crime had to be selected and grouped into a single group (Figure 5-6). For example, to animate assaults, all 20 of the raster surfaces would be grouped and the group name would be "grouped assaults." 


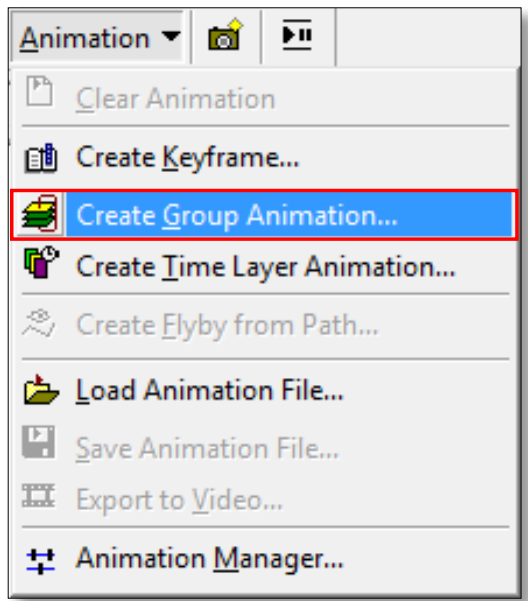

Figure 5-6: Create Group Animation

Once the crime of interest is grouped, the group animation can be created (Figure 57). Within this form, a group layer needs to be specified; for example, the group of assaults is selected in the figure. Also within this form, it was important to specify the transition fading which controls the fading between each display as it animates. This was set to the middle of the fading bar.

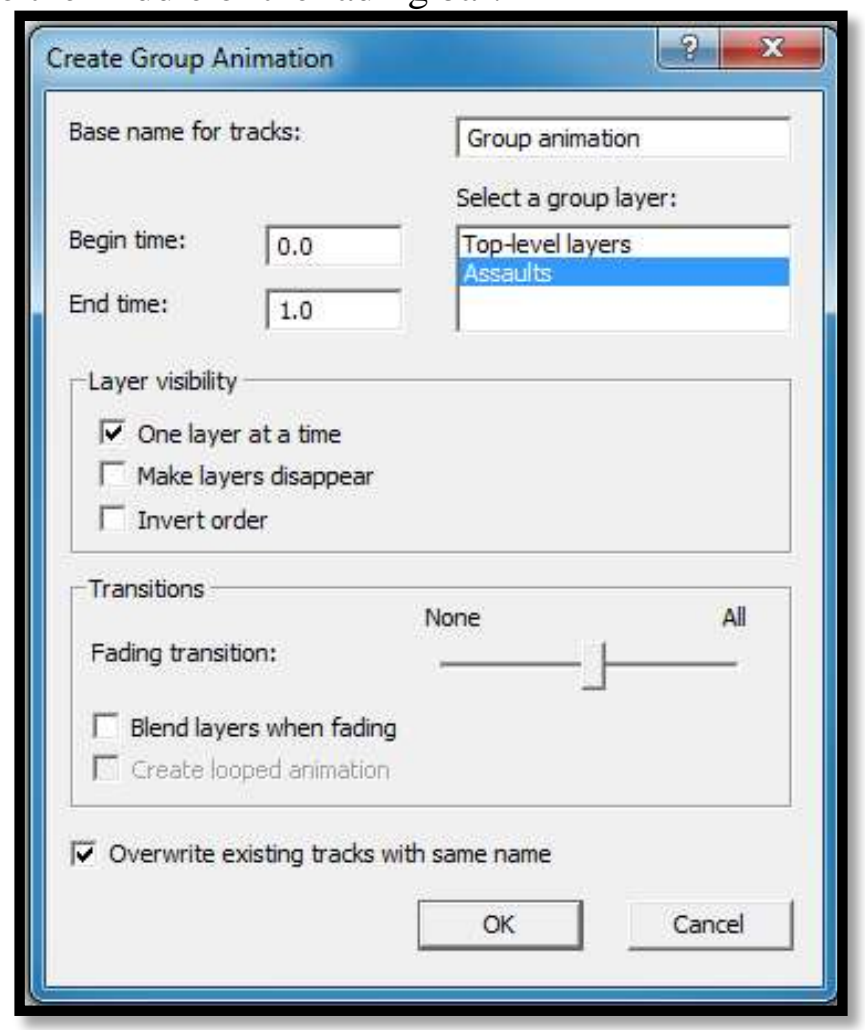

Figure 5-7: Group Animation Interface 
Once all of the necessary fields were filled in, the next step was to set the timing for the animation. In order to do this, the animation controls tool was selected and the duration box was set to 60 seconds. The next step was to play the animation to make sure the mapped densities were transitioning correctly. Figure 5-8 illustrates the form for controlling the speed of the animations.

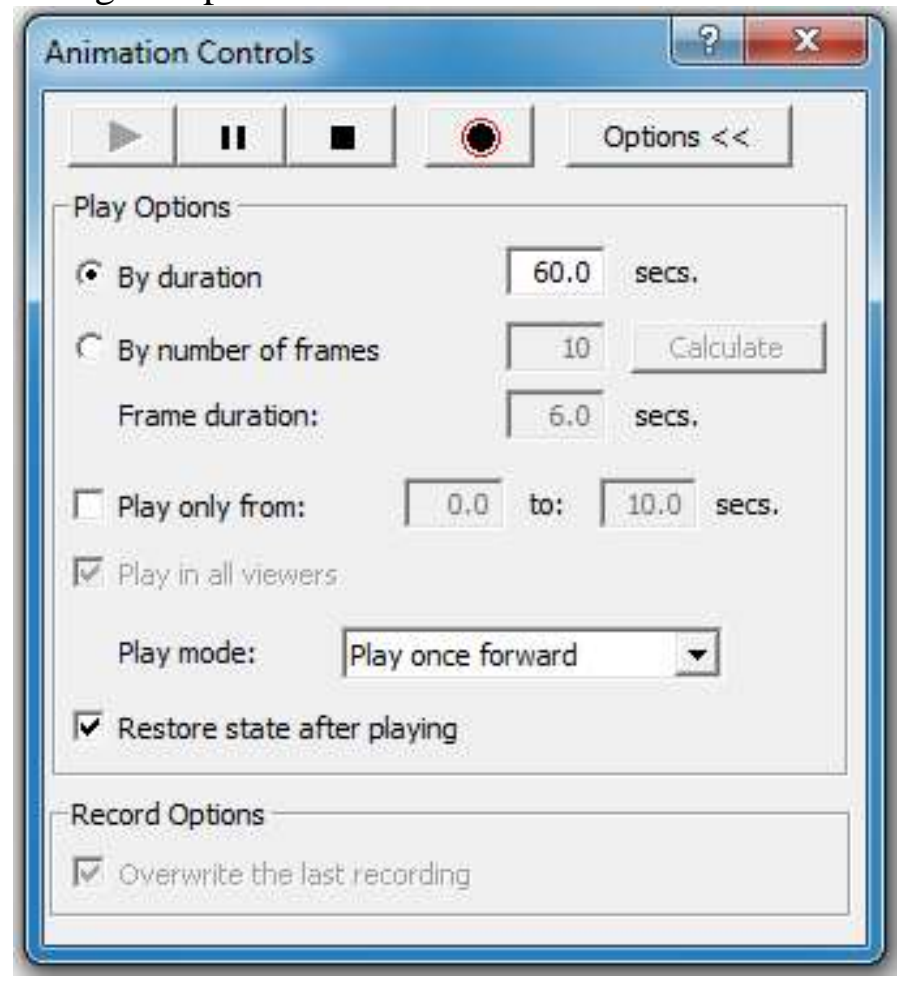

Figure 5-8: Animation Controls

Once the animations were running correctly, it was important to display what year the densities represented while cycling through the animation. The year was displayed using annotation. In order to create annotation for each year, the draw tool was selected and a new annotation group was selected. From there, an annotation group name was typed in and the associated layer was selected. For example, if there were crime densities for 1996, the annotation group name would be the crime type and the year 1996. The associated layer would then be the raster surface for that crime type in 1996. After this was done, the rectangle tool was used to draw a rectangle on the map. This rectangle was filled with white and had no outline. The year was then typed in the rectangular box. Figure 5-9 depicts the process of how the annotation was created for each density. 


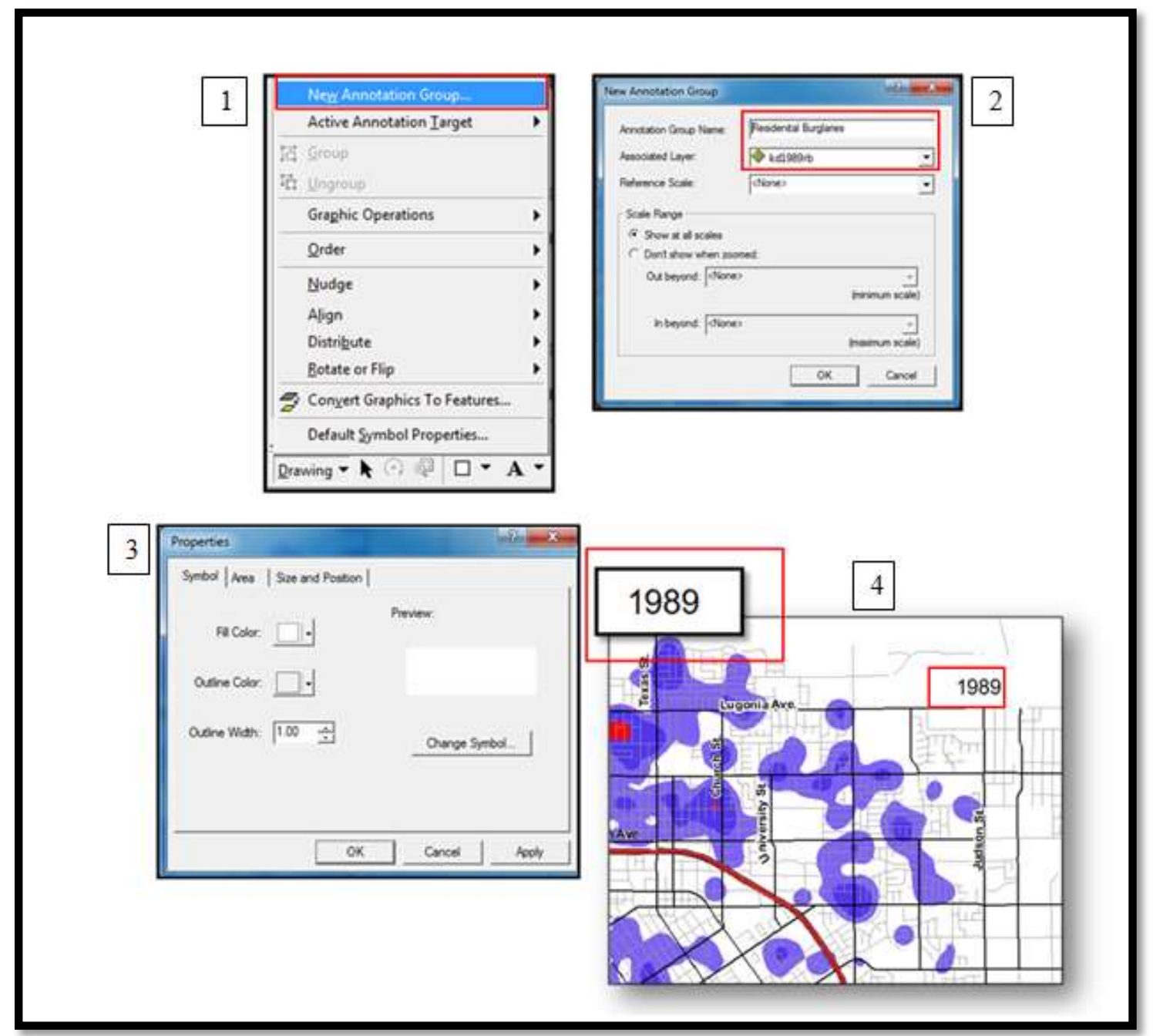

Figure 5-9: Annotation Process

After all of the annotations were created for the 20 year period the next step was to export the animations to a video file (AVI). Once a name was given to the video, the kernel density maps were then animated and recorded in an AVI format so it could be viewed when needed. The AVI files can be played with Windows Media Player. While the video is playing, there is the option to slow down or stop the video when needed. Figure 5-10 shows how some of the animated maps would appear. 


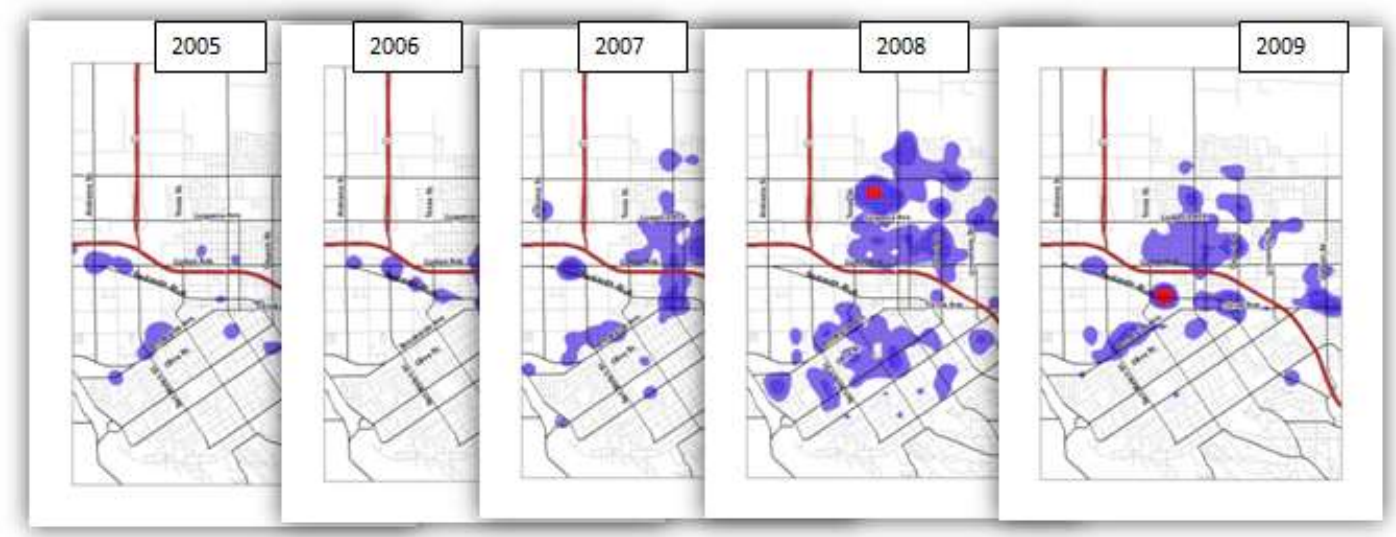

Figure 5-10: Animated Kernel Density Maps

The density maps displayed in the above figure are the residential burglary densities for the years between 2005 and 2009. For the final product, 20 maps showed how the crime densities changed over time. The next step was to understand why the selected crimes occur in Redlands. This was done using regression analysis and will be explained in more detail in the next section.

\subsection{Regression Analysis}

Regression analysis was used to model relationships between the factors and the crime patterns. Two regression models were used: ordinary least squares (OLS) and geographically weighted regression (GWR). A dependent variable of the Log raw crime count was used and a series of independent variables were used to determine what factors could be causing the different crime types used in this project.

\subsubsection{Ordinary Least Squares}

The OLS tool was used to determine which independent variables had an impact on certain crimes. In order to perform the regressions, the data needed to be prepared. This involved clipping the 2000 block groups Census data for the whole United States down to Redlands. Once the Census data of the city was prepared, the crime data of year 2000 were joined to census block groups in Redlands. Once the data was joined with the spatial join tool, it created a count field that provided the number of crime incidents that occurred in each block group. New fields were also created for the independent variables. Based on the literature, six categories of variables were included in the analysis (Table 5). 
Table 5. Independent variables that were used

\begin{tabular}{|c|c|}
\hline Houses & Description: year 2000 \\
\hline Total Household Units & Total number of household units \\
\hline \multicolumn{2}{|l|}{ Physical Situation: } \\
\hline Population Density & Population per unit area \\
\hline Total Population & Total population \\
\hline Total Households & Total number of Households \\
\hline Total Family Population & Population in Families \\
\hline \multicolumn{2}{|l|}{ Social Status: } \\
\hline Percent Youth & $\begin{array}{l}\text { Percent of people that are the age } \\
15 \text { to } 19\end{array}$ \\
\hline Percent Youth Males & $\begin{array}{l}\text { Percent of Males that are the age } 15 \\
\text { to } 24\end{array}$ \\
\hline Percent Youth 18 to 25 & $\begin{array}{l}\text { Percent of people that are the age } \\
18 \text { to } 25\end{array}$ \\
\hline Percent Foreign Born & $\begin{array}{l}\text { Percent of Persons that were } \\
\text { foreign born }\end{array}$ \\
\hline Percent Hispanic & Percent of Persons that are Hispanic \\
\hline Percent Black & Percent of Persons that are Black \\
\hline Percent Separated & $\begin{array}{l}\text { Percent of Persons that are } \\
\text { separated }\end{array}$ \\
\hline Percent Divorced & Percent of Persons that are divorced \\
\hline Percent that walk to Work & $\begin{array}{l}\text { Percent of Persons that walk to } \\
\text { work }\end{array}$ \\
\hline Percent with vehicles & $\begin{array}{l}\text { Percent of Persons with } 1 \text { or more } \\
\text { vehicles }\end{array}$ \\
\hline \multicolumn{2}{|l|}{ Economic Status: } \\
\hline Unemployment Rate & Unemployment Rate \\
\hline Median House Value & $\begin{array}{l}\text { Median Value of Occupied Housing } \\
\text { Units }\end{array}$ \\
\hline $\begin{array}{l}\text { Percent Household Income } \\
10,000 \text { to } 20,000\end{array}$ & $\begin{array}{l}\text { Percent of Households that have an } \\
\text { income of } \$ 10,000 \text { to } 20,000\end{array}$ \\
\hline \multicolumn{2}{|l|}{ Family Structure: } \\
\hline $\begin{array}{l}\text { Percent of Non Family } \\
\text { households two or more persons }\end{array}$ & $\begin{array}{l}\text { Percent of Non Family households: } \\
2+\text { Persons }\end{array}$ \\
\hline $\begin{array}{l}\text { Percent of Family households } \\
\text { two or more persons }\end{array}$ & $\begin{array}{l}\text { Percent of Family households:2+ } \\
\text { Persons }\end{array}$ \\
\hline \multicolumn{2}{|l|}{ Education: } \\
\hline Percent Higher Education & $\begin{array}{l}\text { Percent of the population with a } \\
\text { degree }\end{array}$ \\
\hline
\end{tabular}


The regression analysis tool run first was the OLS tool. The above variables were run through the OLS tool with a multicolinearity check. Figure 5-11 shows the form that was used to specify the model structure and the coefficient and diagnostic tables.

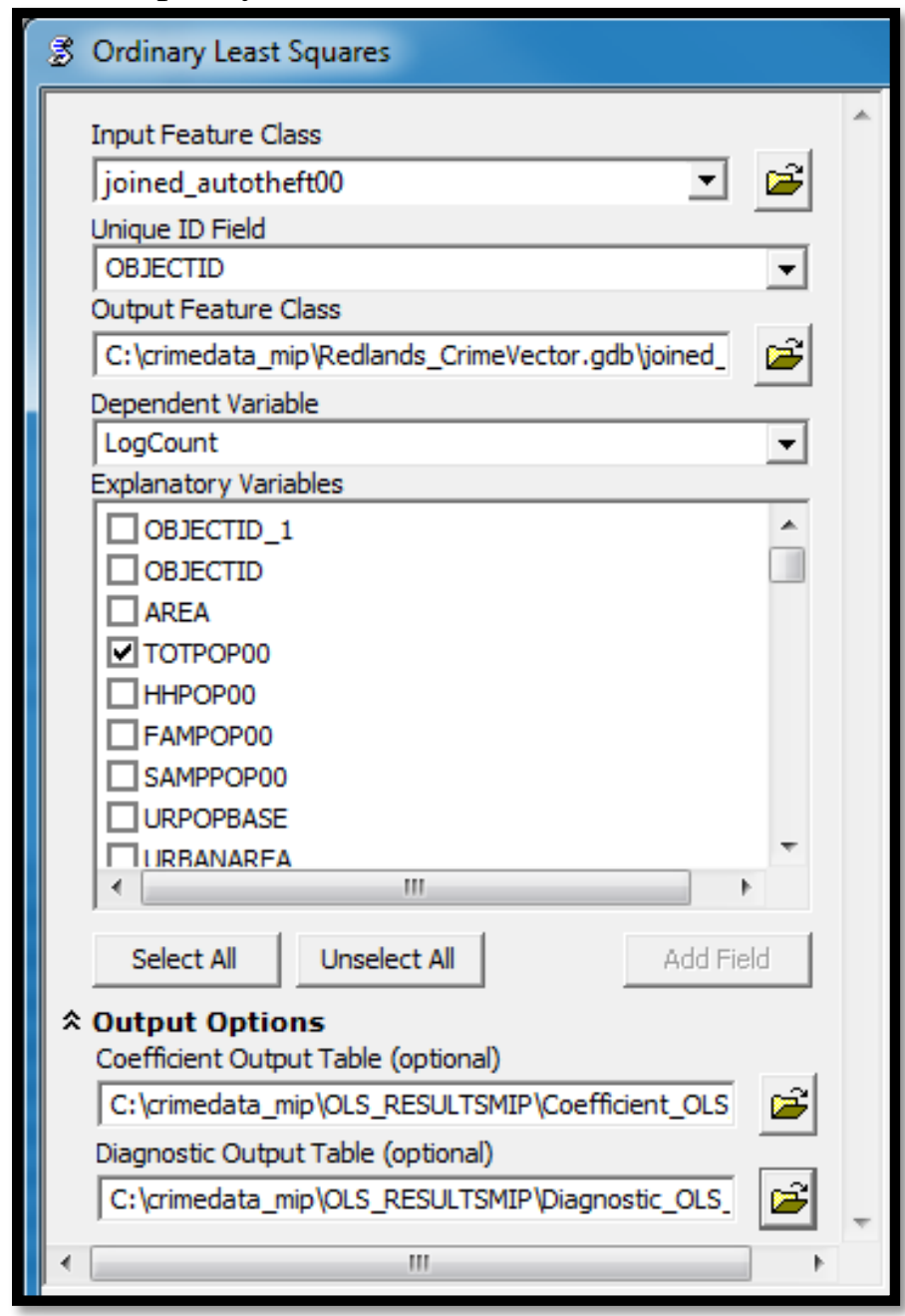

Figure 5-11: Ordinary Least Squares Tool

Within this form, the required inputs are the input features class, the unique ID field, the output feature class, the dependent variable, and the explanatory variables. Finally, the coefficient and the diagnostic DBF tables need to be saved in a folder. The test results in the output file show the significance of estimated coefficients. Only the significant independent variables were included in the final model. In addition, it was important to examine the model fitness using measures like R-square, F test, and normality of residuals. A high value in R-square and significant $\mathrm{F}$ test result indicate good model fitness. The insignificance result of a normality test would suggest the normality assumption of OLS is not violated. Another measure, Akaike Information Criterion (AICc), is also included in the output file, which is used to compare models with the same set of variables. The model with a lower AICc is better. Another 
component of regression analysis are residuals. The residuals were mapped and autocorrelation was checked using the global Moran's I statistic (Figure 5-12).

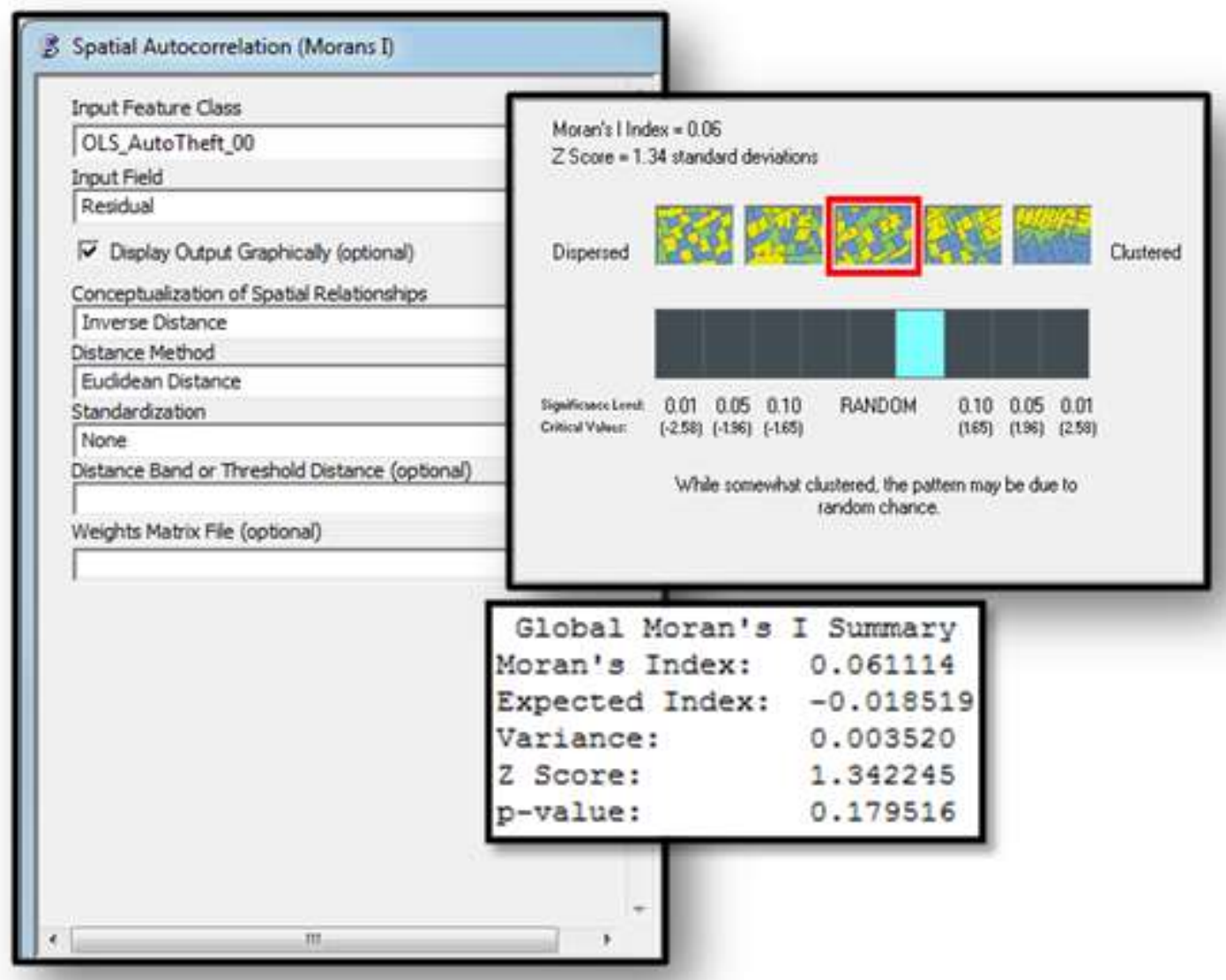

Figure 5-12: Spatial Autocorrelation

A random pattern of residuals is desired. It is always possible to improve the reliability of the predictions from the OLS model by using geographically weighted regression, which is explained in more detail in the next subsection.

\subsubsection{Geographically Weighted Regression}

In order to improve the model, the geographically weighted regression (GWR) tool was used. To run the GWR tool, the variables shown to be significant in the OLS results were used as the explanatory variables. The form for this tool can be found in Figure 5-13. 


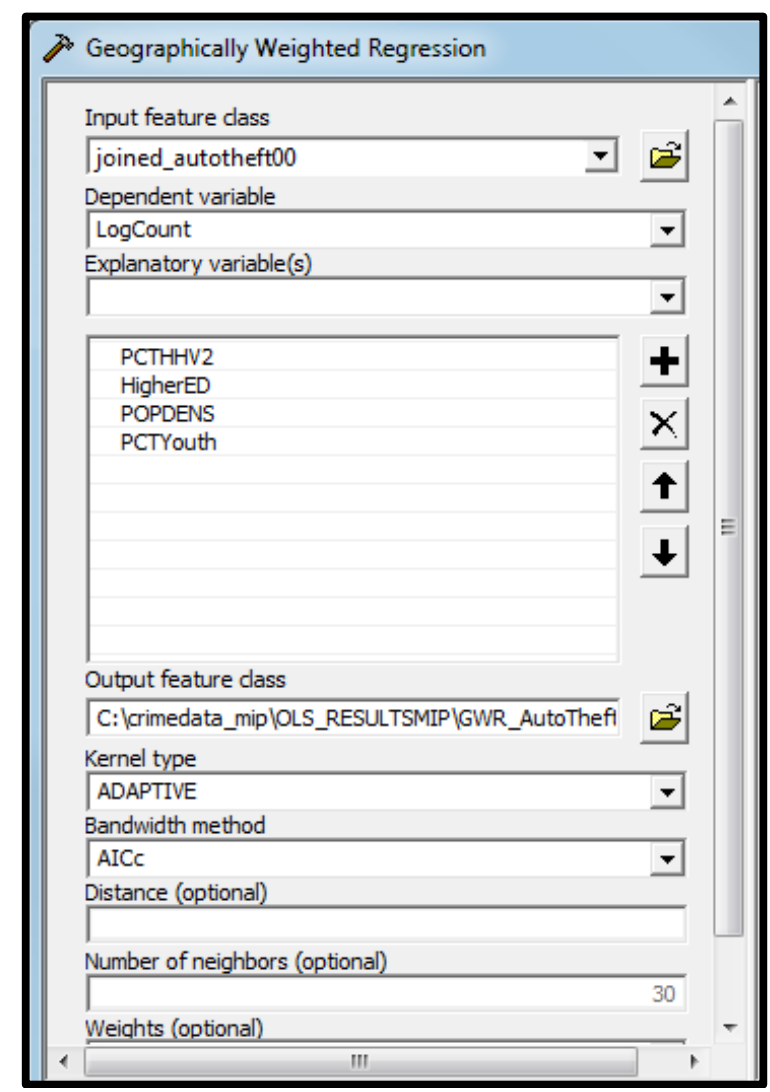

Figure 5-13: Geographically Weighted Regression Tool

The fields that needed to be filled in for the regression analysis were the input field, and the explanatory variable fields along with the output feature class field. The kernel type that was chosen was the spatial kernel of adaptive and the bandwidth method that was used was the AICc.

Once that model was run, the diagnostic results were put into a DBF table that could be viewed in ArcMap. If the GWR model can produce a higher R2 and lower AICc than the OLS model, GWR is a better model. In addition, the global Moran's I was used once again to make sure that the residuals of the GWR were not clustered.

\subsection{Summary}

Using Model builder and the regression tools in ArcMap helped the user understand the distribution of crime. The crime database, Model Builder, ArcMap, and the animation toolbar were needed to create animated crime density maps. In addition, the ordinary least squares tool and geographically weighted regression tools were used to find out what explanatory variables influence crime. Also, the spatial autocorrelation tool was used to determine the model residuals are randomly distributed. 


\section{Chapter 6 - Results and Analysis}

This chapter begins with a discussion of the results from the crime kernel density model, which allowed the client to see locations where crimes are the densest. The rest of this chapter discusses the regression analysis results that help explain why the crimes of interest are concentrating in specific neighborhoods.

\subsection{Kernel Density Model Results}

The model generated 100 different raster surface results, which show where the five different crime types of interest occurred over the past 20 years. The density appearances are mainly circular since kernel density estimation was used. The color scheme ranges from white to purple to red, with red signifying the areas of highest density. An example of the five different crime kernel density models can be found in Figure 6-1. 

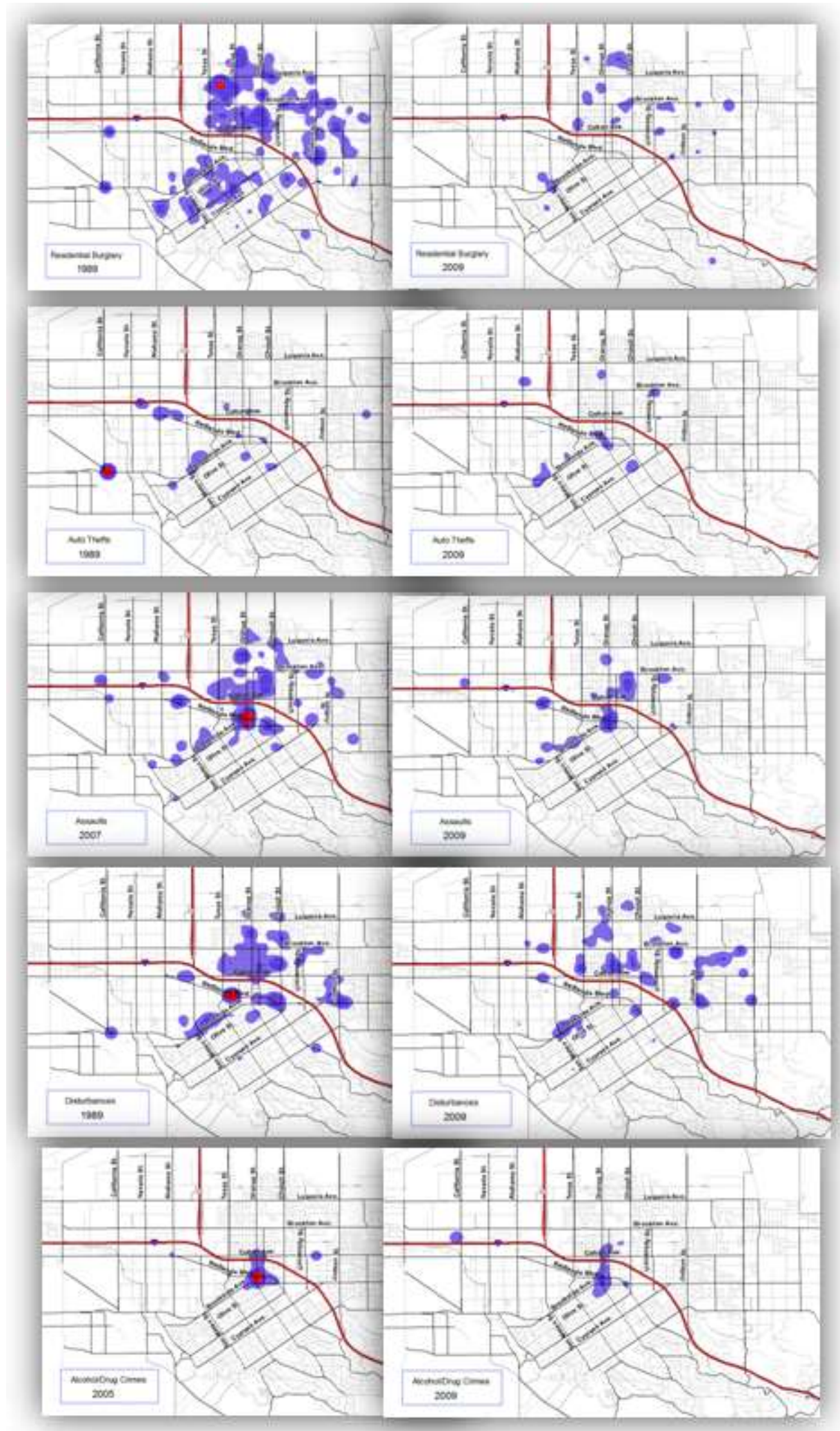

Figure 6-1: Density Maps of five Crime Types in 1989 and 2009 
Once all kernel density maps were generated, it was possible to analyze what years had high crime densities, as shown in red (Table 6).

\section{Table 6. Crime Kernel Density Results}

\begin{tabular}{|l|l|}
\hline Crime Type & Years \\
\hline $\begin{array}{l}\text { Residential } \\
\text { Burglaries }\end{array}$ & $\begin{array}{l}1989,1991,1993,1994 \\
1995,1996,1998,2000\end{array}$ \\
\hline $\begin{array}{l}\text { Alcohol/Drug } \\
\text { Crimes }\end{array}$ & $1991,2005,2007$ \\
\hline Assaults & 2007,2008 \\
\hline Auto Thefts & $\begin{array}{l}1989,1990,1991,1994 \\
1995,1996,2001,2005\end{array}$ \\
\hline Disturbances & $1989-2008$ \\
\hline
\end{tabular}

A review of the results revealed that residential burglaries, auto thefts, and disturbances all showed high densities during 1989. In 1991, residential burglaries, alcohol/drug-related crimes, auto thefts, and disturbances had the highest density results. In 1992, disturbances were the only crime that had the highest density. In 1993, residential burglaries and disturbances had the highest densities. In 1994, 1995, and 1996, residential burglaries, auto thefts, and disturbances had the highest densities. In 1997, residential burglaries had the highest densities. In 1998, residential burglaries and disturbances had the highest densities. In 1999, disturbances had the highest densities. In 2000, residential burglaries and disturbances had the highest densities. Auto thefts and disturbances had the highest densities in 2001. The highest densities in 2002, 2003, 2004, and 2006 were found in disturbances. In 2005, auto thefts and disturbances had the highest densities. In 2007, alcohol/drug-related crimes, assaults, and disturbances had the highest densities. Finally, in 2008, assaults and disturbances had the highest densities. The year 2009 did not show high densities for any of the crime types. The following subsections analyze the animation results.

\subsection{Animation Results}

Images in Figure 6-2 depict how the animation maps look. The maps were exported into video files; each video file contained 20 maps that transitioned from year to year to illustrate how crime has changed over the years. 


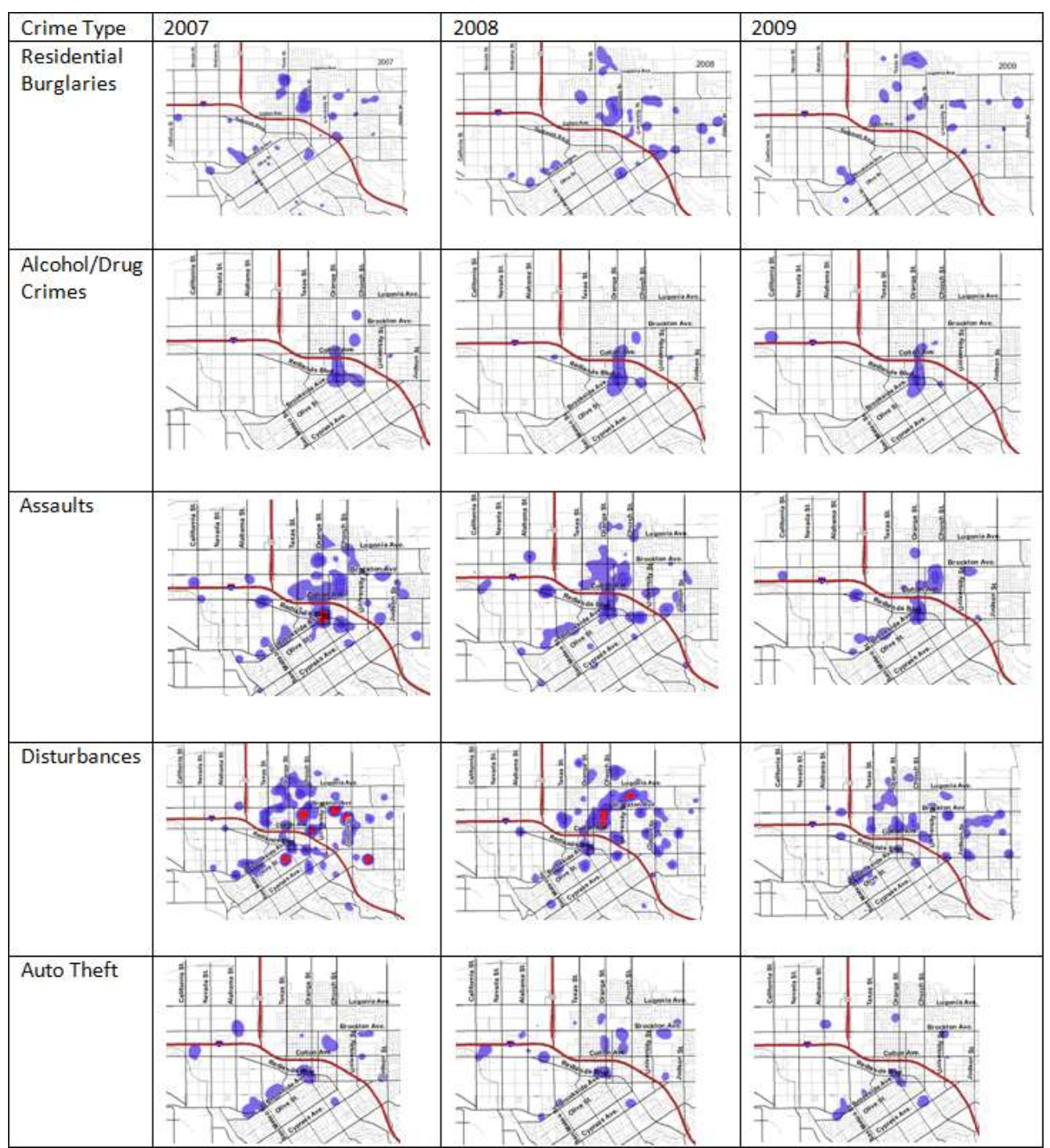

Figure 6-2: Animation Results for all five crimes from 2007-2009

Each crime type shows a different pattern in Redlands. The assaults map shows many crimes around the downtown area by Redlands Boulevard. In addition, there are large amount of assaults above Colton Avenue all the way to Brockton Avenue. The residential burglaries map shows that the densities are dispersed around the central part of the city ranging from Brookside Avenue north to Lugonia and to the east of Judson Street. The disturbances map appears to follow the same pattern as the residential burglaries map, where the densities are mostly dispersed through the center of the city and east of Judson Street. An inspection of the auto theft map reveals the crimes are also very dispersed starting near Alabama Street and moving east toward Cypress Avenue. Finally, the alcohol/drug-related crimes are clustered on the map by Redlands Boulevard and Colton Avenue. Overall, the densities maps helped summarize and explain the different patterns of crime in Redlands. 


\subsection{Regression Analysis Results}

As discussed in Chapter 5, both linear regression and geographically weighted regression models were built to examine what variables influence the crime types. Special attention was paid to checking autocorrelation of residuals. In this regard, the global Moran's I was used in ArcGIS. Although the historical data contains crime over the last 20 years, only crime data from 2000 were used for the following analysis because the complete socio-economic data were only available for 2000. If a longitudinal analysis is needed, different regression models with varied socio-economic data should be used to address temporal autocorrelations, such as the autoregressive model (described in Chapter 2). Both the regression results and Moran's I are summarized by the crime type below in the following sections. Only the significant variables were included in the final models.

\subsubsection{Residential Burglary}

Figure 6-3 provides a choropleth map of residential burglaries in 2009 in order to help understand the descriptive information about crime distribution.

\section{Residential Burglary Number of Crimes per Block group}

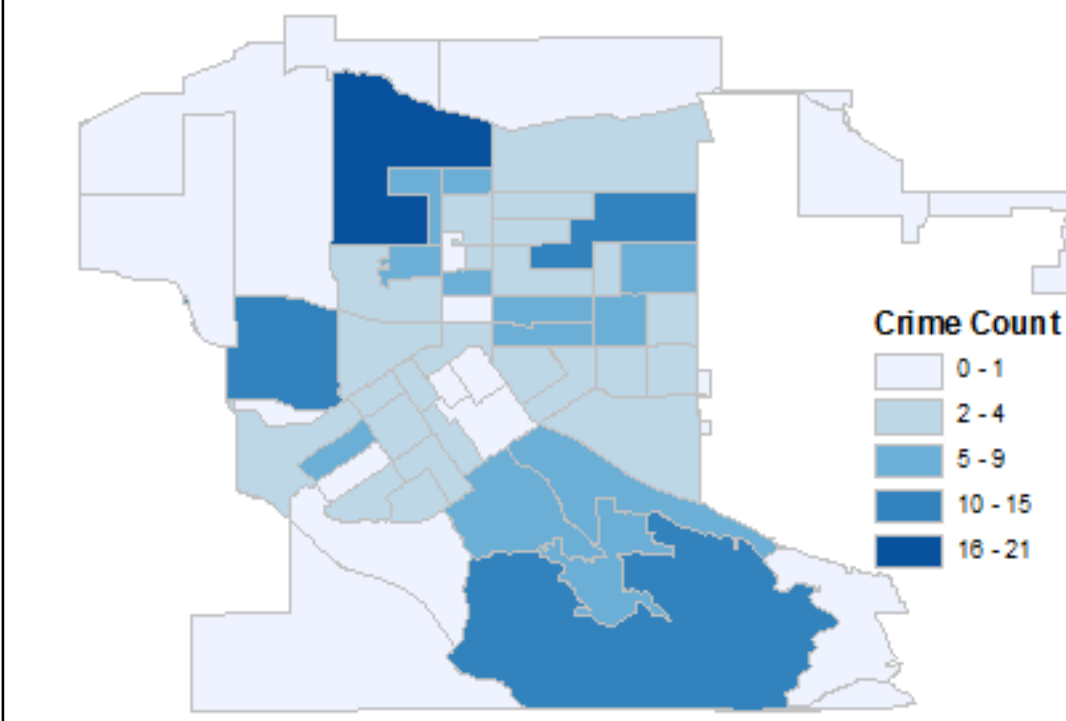

Figure 6-3: Crime Count for Residential Burglaries 
The map in Figure 6-3 reveals that most residential burglaries occur in the northwest and southwest parts of the city. This may be due to the number and value of the houses within those areas.

According to the regression, there are four significant variables: total household units, median house value, population density, and percent higher education. Originally, household units were expected to relate positively to the residential burglaries because more houses meant more expected burglaries. Median house value was also expected to relate positively to the residential burglaries because it is expected that a more valuable home will have expensive items. The influence of population density was expected to have a negative impact on the residential burglaries as a property is better guarded with surrounding people. Finally, percent higher education was expected to relate negatively to residential burglaries, because individuals with higher education possibly have the means to take more precautions when securing their homes.

Table 7 summarizes the significant variables that were found after running the ordinary least squares tool and the model fitness.

Table 7. Model 1: Linear Regression Results on Residential Burglaries in 2000

\begin{tabular}{|lllll|}
\hline Independent Variables & Coefficient & $\begin{array}{l}\text { Standard } \\
\text { Error }\end{array}$ & Relationship & $\begin{array}{l}\text { Significant } \\
\text { Level }\end{array}$ \\
\hline Total Household units & 0.001 & 1.089 & + & 0.000 \\
Median House Value & $<0.001$ & 0.000 & + & 0.069 \\
Population Density & -26.593 & 9.921 & - & 0.002 \\
Percent Higher Education & -5.622 & 1.663 & - & 0.000 \\
& & & & \\
$\mathrm{R}^{2}=.460$ & & & & \\
AICc=123.176 & & & \\
Adjusted R $\mathrm{R}^{2}=.352$ & & & \\
$\mathrm{~F}=4.265$ & & & \\
Significant level $=0.05$ & & & & \\
\hline
\end{tabular}

As shown in Table 7, the coefficient of household units is positive, which meets the hypothesis. Controlling for other factors, that when one household unit increase in the neighborhood this could result in a $0.1 \%(\exp (0.001))$ increase in the crime. The coefficient of median house value is positive, which meets the hypothesis. The coefficients of population density and percent higher education are negative, which also meets the hypothesis. Controlling for other factors, a one percent higher education increase in the neighborhood results in a $0.3 \%(\exp (-5.622))$ decrease in crime.

Besides the coefficients, goodness of fit measures were also examined. The Rsquared was 0.460 and the adjusted R-squared was 0.352 . The R-squared measures the proportion of the variation in the dependent variables. A value that is closer to 1 indicates the model has a better prediction of what is causing certain crimes. The adjusted R-squared adjusts for the number of variables in the model so it is the preferred measure. The adjusted R-squared had a value of 0.35 , which indicated that the model accounts for about $35 \%$ of the variation in the dependent variable. This statistic implies that some variables have been omitted from the model because it is failing to account for 
$65 \%$ of the variation in the dependent variable. Another goodness of fit measure is the Akaike Information Criterion (AICc) which measures the relative distance between the model that has been fitted and the unknown true model. Models that have low AICc values are preferred to models that have higher values; the AICc in this case is 123.176.

The residual pattern was also examined. The results of global Moran's I shows that the residuals are random, which means that there is no autocorrelation present (Figure 6-4).

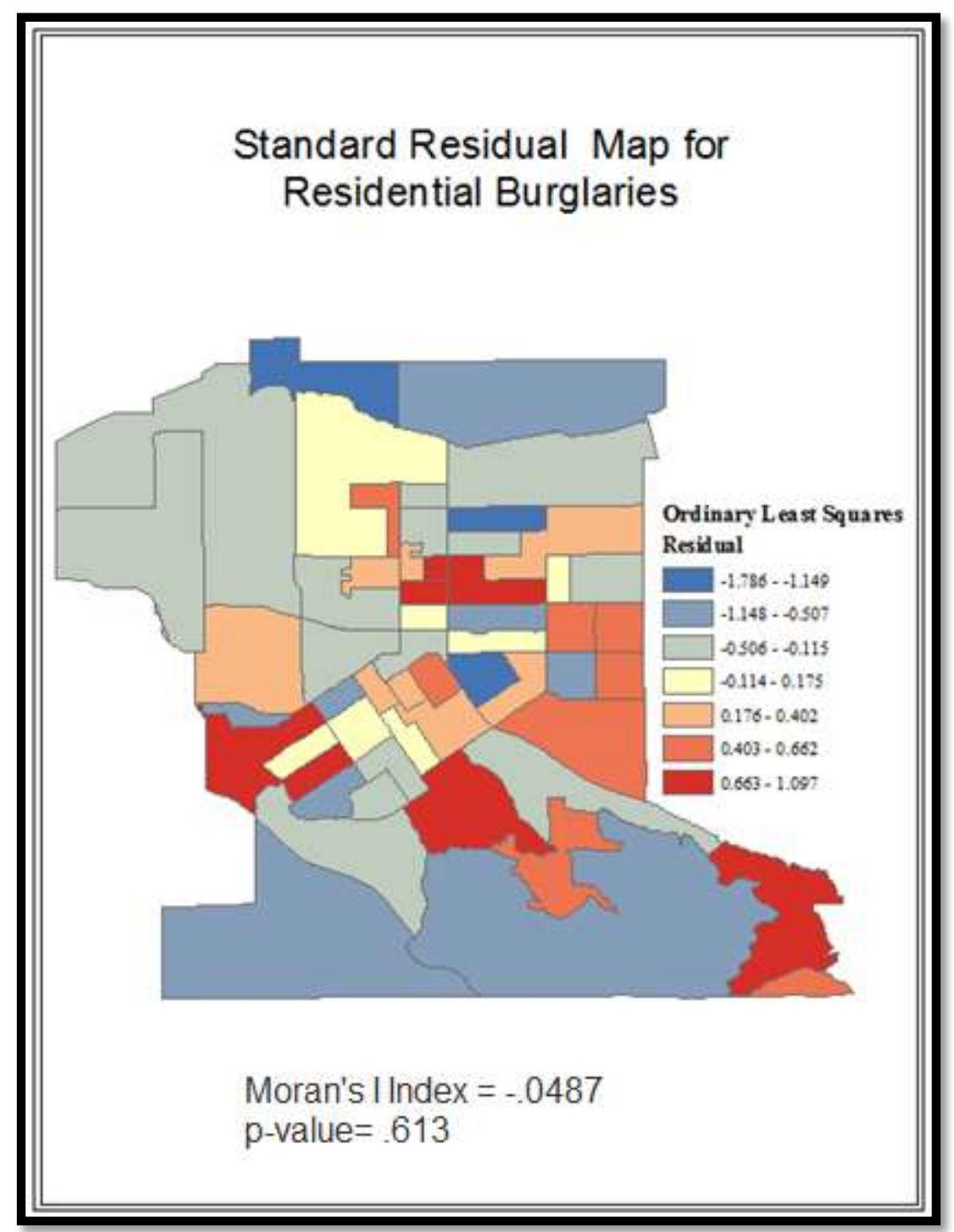

Figure 6-4: OLS Spatial Autocorrelation Results for Residential Burglaries

To improve the model, GWR was applied. The results of this model are shown in Table 8 . 
Table 8. GWR Results for Residential Burglaries

\section{Independent Variables}

Total Household units

Median House Value

Population Density

Percent Higher Education

$\mathrm{R}^{2}=.482$

Adjusted $\mathrm{R}^{2}=.394$

$\mathrm{AICc}=121.726$

The first step was to analyze and compare the OLS and the GWR model results. The OLS Adjusted R-squared was 0.352 and the GWR was 0.394 , which suggests some improvement in the model performance. The AICc for the OLS was 123.176 and for the GWR it was 121.726, a difference of about 1.45, which is evidence of some improvement in the fit of the model to the data. Once again, the residual pattern was also examined for the GWR results. Figure 6-5 shows that the Moran's I value is smaller than the previous value, indicating the chance of residuals being random is higher. 


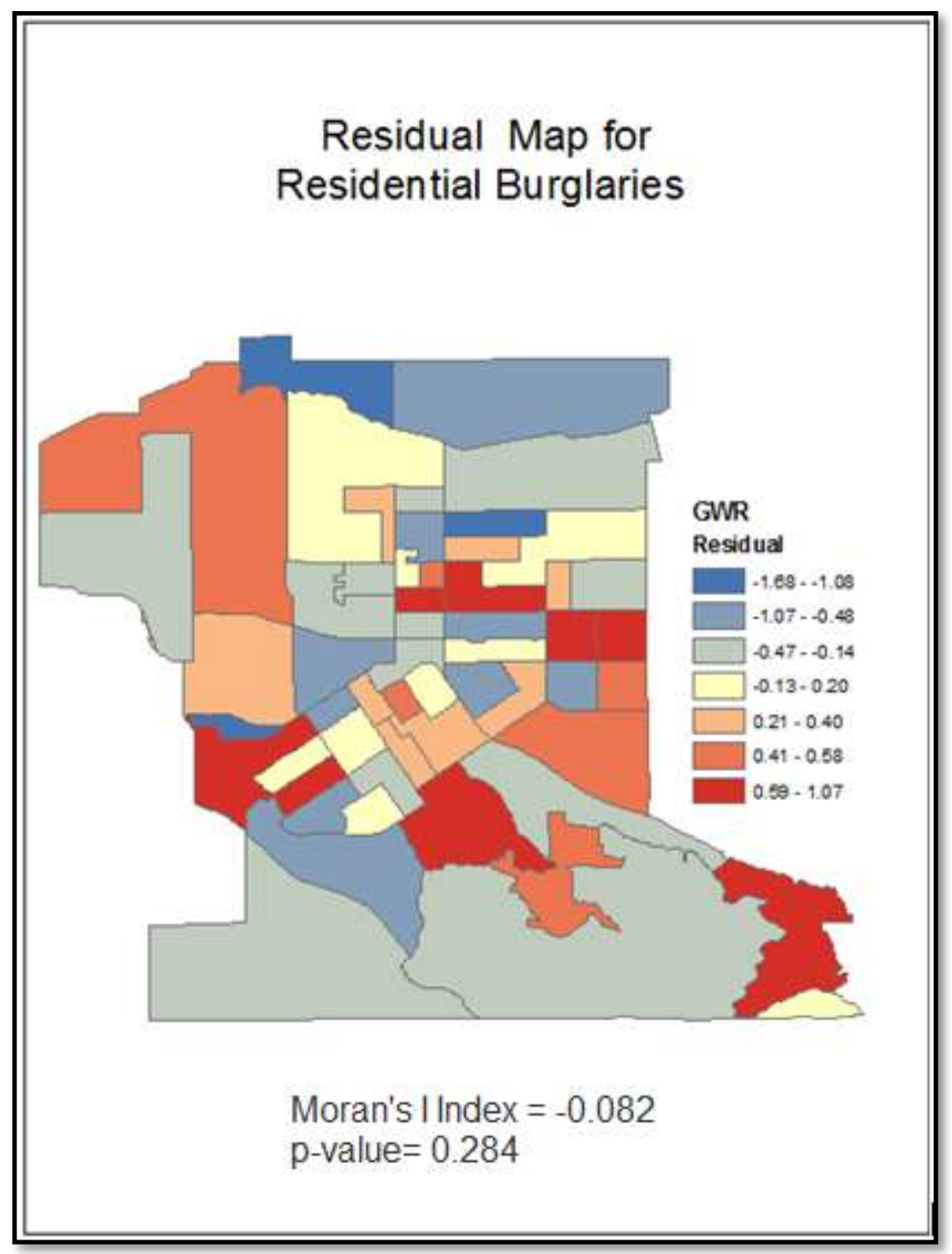

Figure 6-5: GWR Spatial Autocorrelation for Residential Burglaries

More importantly, GWR can reveal the regional variations of the relationship. For example, Figure 6-6 shows how the impact of education on residential burglaries varies in space. 


\section{Coefficient Map for Residential Burglary}

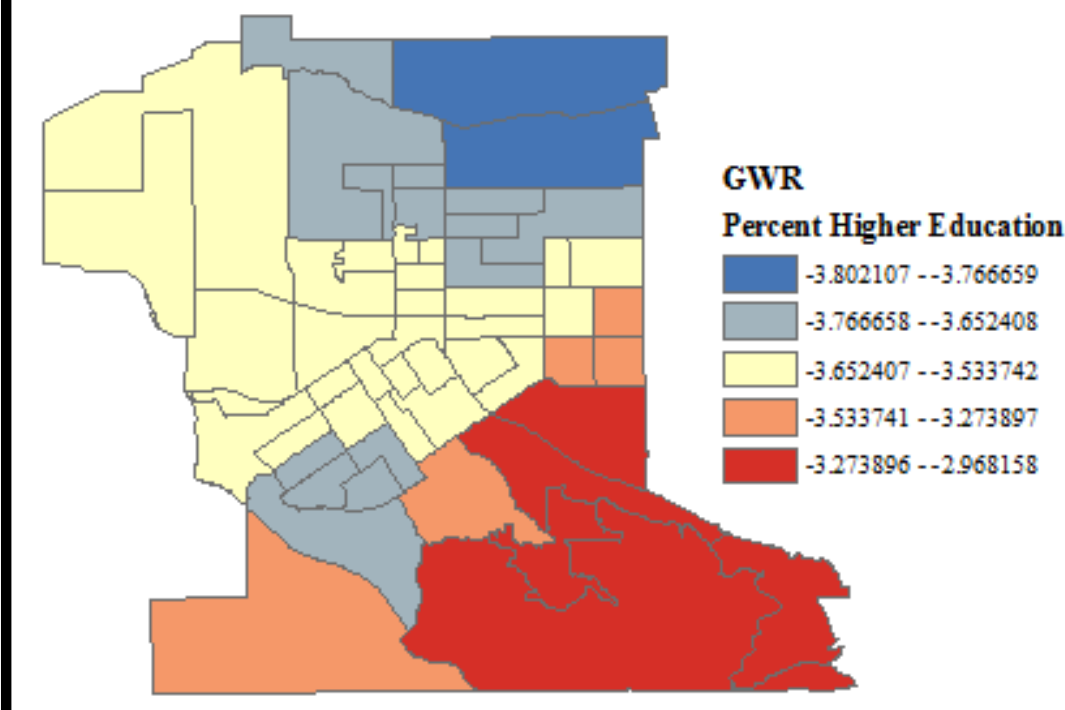

\section{Figure 6-6: Coefficient map for Percent Higher Education}

The percent of higher education has a strong influence in the southeast neighborhood. Because of this, there should be a lower concentration of residential burglaries in this area due to its negative relationship with the crime. The rest of the coefficient maps for residential burglaries can be found in Appendix A.

\subsubsection{Disturbances}

To help understand the descriptive information about the crime distribution, Figure 6-7 provides a choropleth map of disturbances in 2009. 


\section{Disturbances Number of Crimes per Block group}

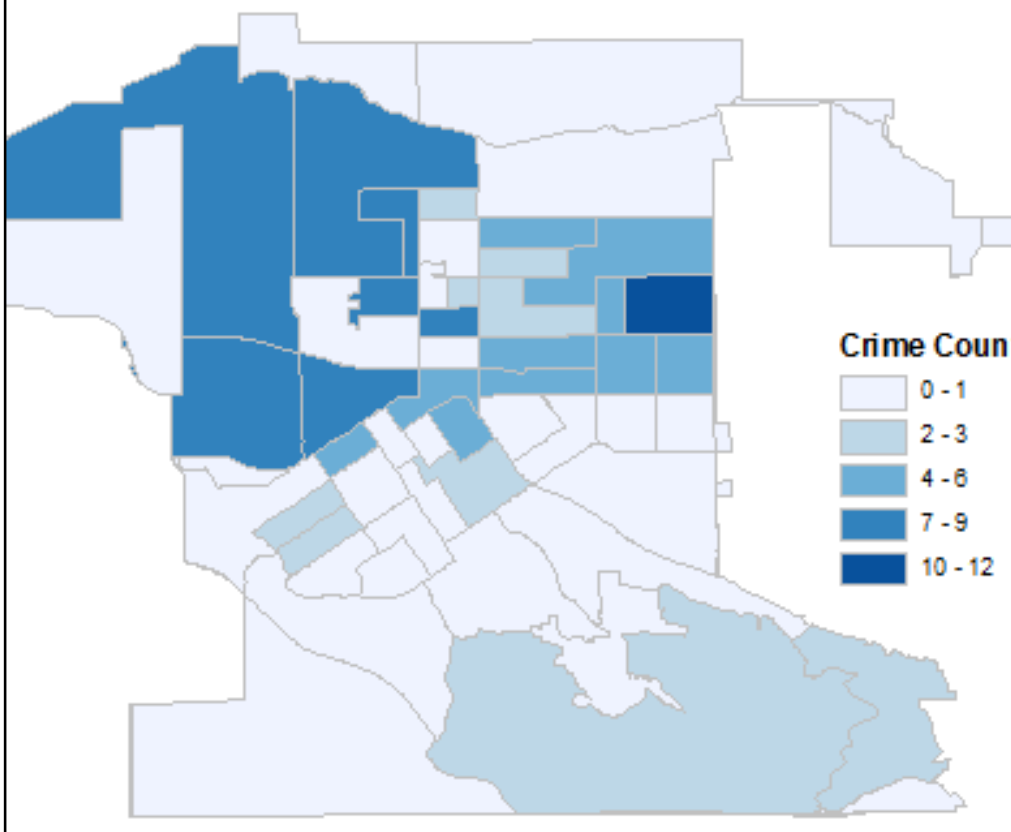

Figure 6-7: Choropleth Map of Disturbances in 2009

The map in figure 6-7 shows the most disturbances are occurring in the northern half of the city, which may be due to the bars and restaurants that are near this area. These types of geographic factors are something that could be investigated in future work. According to the regression, there are six significant variables: family households, unemployment rate, percent youth, percent married, percent divorced and percent nonfamily households. Originally, family households were expected to relate positively to disturbances because more family households mean more people that could cause disruptions. In addition, unemployment rate was expected to positively relate to disturbances because the unemployed are possibly staying at home more, and do not have a strict schedule. Percent youth originally was expected to have a positive influence on disturbances, because youth have the tendency to stay out late and possibly get into trouble. Originally, percent married was expected to have a negative influence on disturbances, because they are generally older and more settled down. Also, percent divorced were expected to positively relate to disturbances, because they are not settled. Finally, the percent of non-family households were expected to have a positive influence on disturbance, since there are more people that could cause disturbances with in the 
household. Table 9 summarizes the significant variables that were found after running the ordinary least squares tool.

Table 9. Model 2: Linear Regression Results on Disturbances in 2000

\begin{tabular}{|lllll|}
\hline Independent Variables & Coefficient & $\begin{array}{l}\text { Standard } \\
\text { Error }\end{array}$ & Relationship & $\begin{array}{c}\text { Significant } \\
\text { Level }\end{array}$ \\
\hline Family households & .008 & .006 & + & .034 \\
Unemployment Rate & .087 & .054 & + & .011 \\
Percent Youth & 12.154 & 4.936 & + & .001 \\
Percent Married & -5.815 & 2.414 & - & .036 \\
Percent Divorced & 6.731 & 5.342 & + & .034 \\
Percent of Non Family & 30.020 & 16.108 & + & .000 \\
& & & & \\
$\mathrm{R}^{2}=.532$ & & & & \\
Adjusted R $\mathrm{R}^{2}=.413$ & & & & \\
AICc $=172.068$ & & & & \\
F=4.458 & & & & \\
Significant level $=0.05$ & & & & \\
& & & & \\
\end{tabular}

As shown in Table 9, the coefficient of family households was positive, which meets the hypothesis. Controlling for other factors, one family household increase in the neighborhood results in a $1 \%$ increase in the crime. The coefficient for the unemployment rate is positive, which meets the hypothesis. The coefficient for percent youth is positive, which meets the hypothesis. The coefficient for the percent married was negative, which also meets the hypothesis. Controlling for other factors, one percent married increase in the neighborhood results in the crime decrease by $0.2 \%$. The coefficient for percent divorced was positive, which also met the hypothesis. Finally, the coefficient of percent non-family households was positive, which meets the hypothesis. Further, the model fitness is also summarized in Table 9. The model diagnostics were examined first.

The R-squared was 0.532 and the adjusted R-squared was 0.413 . The fitted model value was 0.413 , which indicated that it accounts for about $41 \%$ of the variation in the dependent variable; this shows that some variables have been omitted from the model because the model is failing to account for $59 \%$ of the variation in the crime of disturbances. The Akaike Information Criterion (AICc) in this model was 172.068. The residual pattern was also examined. The results of global Moran's I shows that the residuals were random, which means that there is no autocorrelation present (Figure 6-8) 


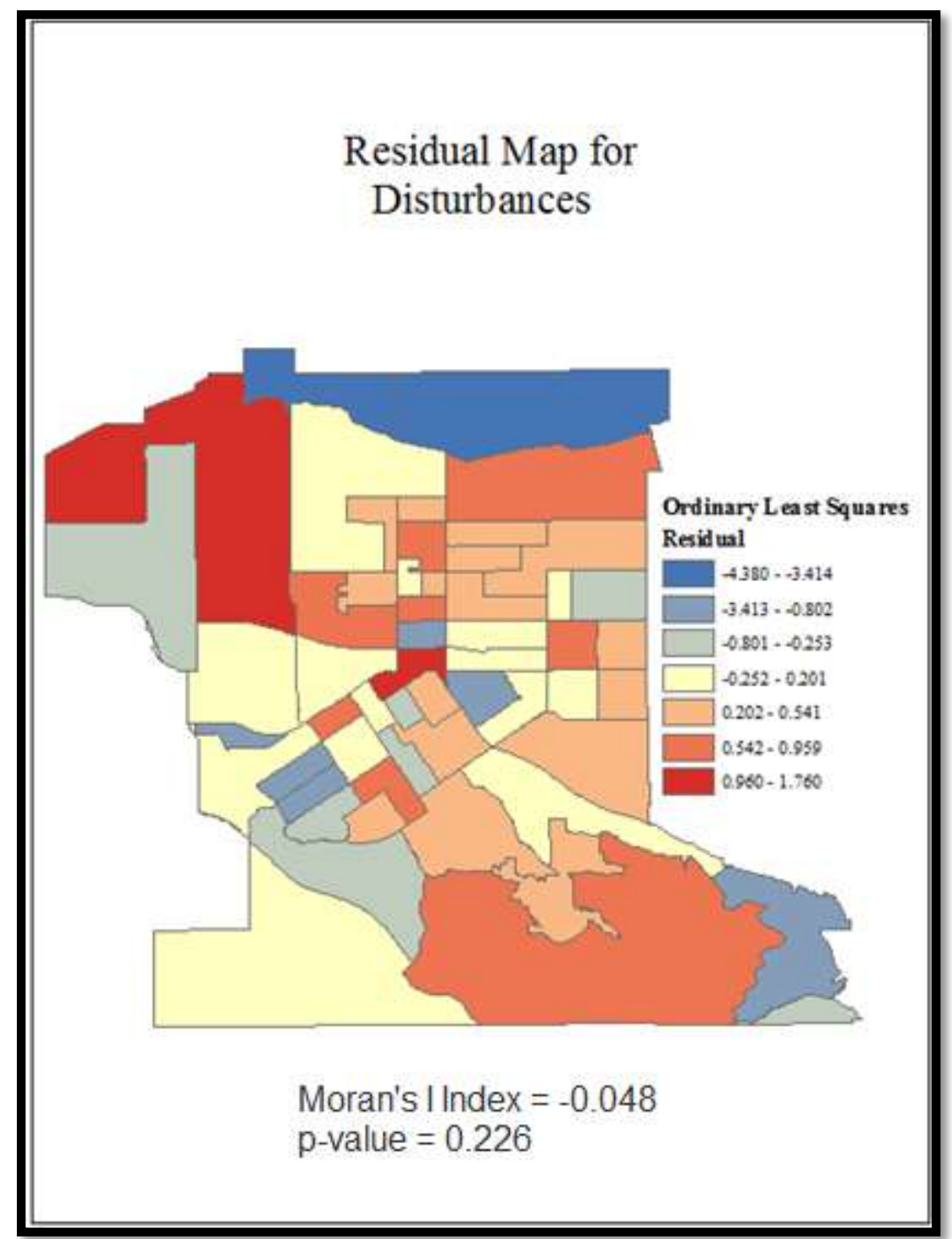

Figure 6-8: OLS Spatial Autocorrelation Results for Disturbances

To improve the model, GWR was applied. The results of this model can be found in Table 10. 
Table 10. GWR Results for Disturbances

\begin{tabular}{|l|}
\hline Independent Variables \\
\hline Family households \\
Unemployment Rate \\
Percent Youth \\
Percent Married \\
Percent Divorced \\
Percent of Non Family \\
$\mathrm{R}^{2}=.556$ \\
Adjusted $\mathrm{R}^{2}=.455$ \\
AICc $=170.920$ \\
\end{tabular}

The first step was to compare the OLS and the GWR model results. The OLS Adjusted R-squared was 0.413 and the GWR was 0.455 , which suggests that there was improvement in the model performance. The AICc for the OLS was 172.087, and the GWR was 170.920, a difference of about 2, which is evidence of some improvement in the fit of the model to the data. Once again, the residual pattern was also examined for the GWR results. Figure 6-9 shows that the Moran's I value is smaller than the previous value, indicating the chance of residuals being random is higher. 


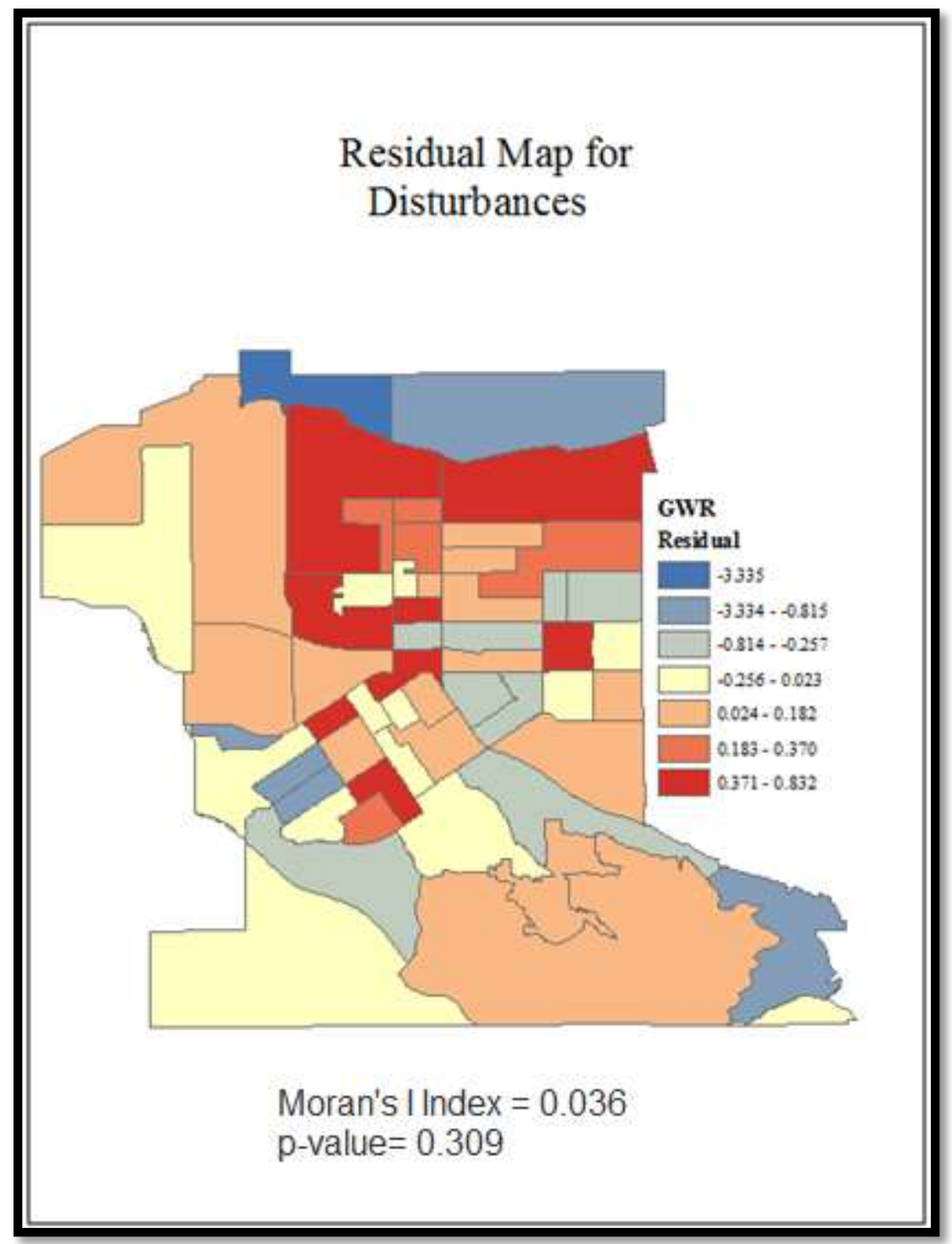

Figure 6-9: GWR Spatial Autocorrelation for Disturbances

More importantly, GWR can reveal the regional variations of the relationship. For example, Figure 6-10 shows how the impact of youth on disturbances varies in space. 


\section{Coefficient Map for Disturbances}

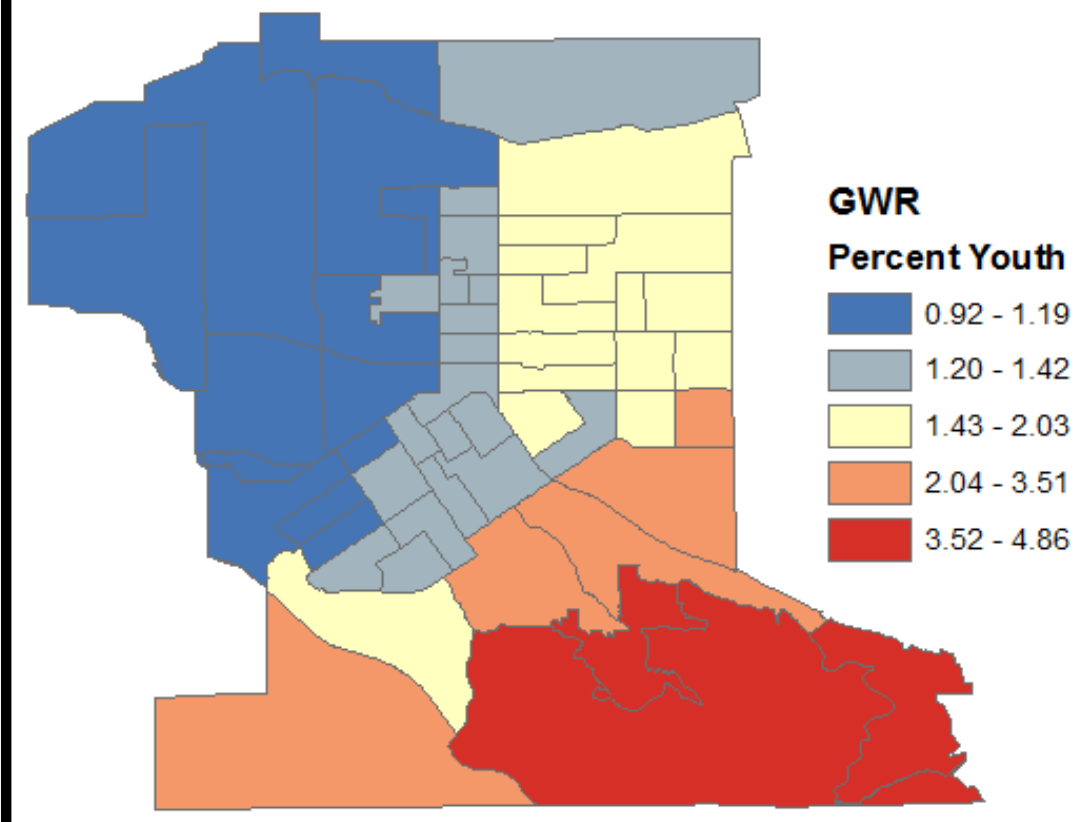

\section{Figure 6-10: Coefficient map for Disturbances}

The percent of youth has a strong influence in the southeast neighborhood. Because of this, there should be a higher concentration of disturbances in this area due to its positive relationship with the crime. The rest of the coefficient maps for disturbances can be found in Appendix A.

\subsubsection{Assaults}

To help understand the descriptive information about the crime distribution, Figure 6-11 provides a choropleth map of assaults in 2009. 


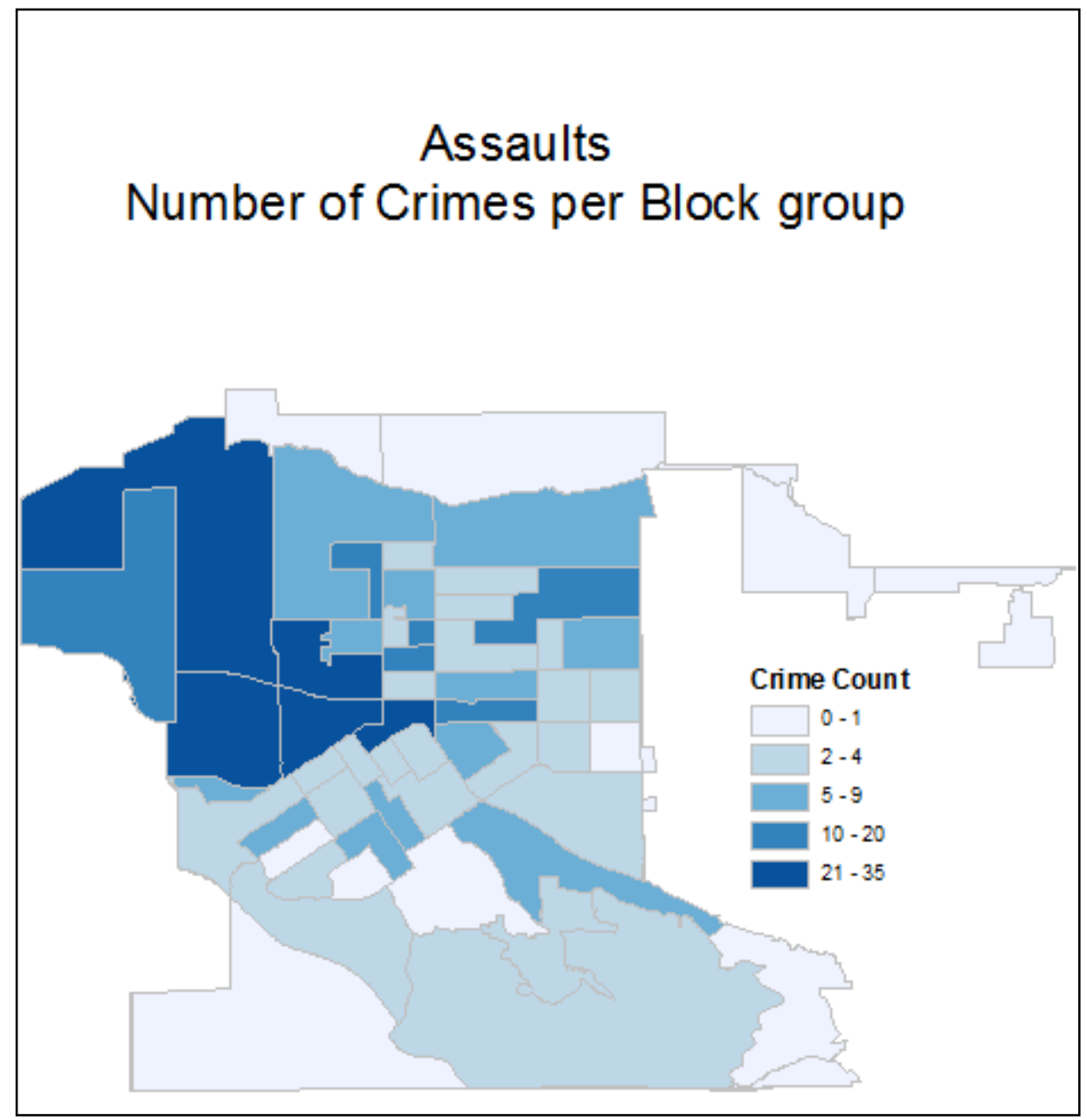

Figure 6-11: Choropleth Map of Assaults

The map in Figure 6-11 shows that most assaults are occurring in the northwest and central part of the city. This may be due to the large shopping centers, bars, and restaurants that are found in this area, which are geographical factors that could be used as variables in future work.

According to the regression, two variables are significant: total population and higher education. Originally, total population was expected to positively relate to assaults, because this variable accounts for the majority of people in Redlands who could be causing assaults. Originally, the percent of people with a higher education were expected to relate negatively to assaults because they possible know the consequences that they would have to face. Table 11 summarizes the significant variables that were found after running the ordinary least squares tool. 
Table 11. Model 3: Linear Regression Results on Assaults in 2000

\begin{tabular}{|lllll|}
\hline Independent Variables & Coefficient & $\begin{array}{l}\text { Standard } \\
\text { Error }\end{array}$ & Relationship & $\begin{array}{l}\text { Significant } \\
\text { Level }\end{array}$ \\
\hline Total Population & 0.000 & .000 & + & .030 \\
Higher Education & -1.536 & 0.843 & - & .039 \\
& & & & \\
$\mathrm{R}^{2}=.399$ & & & \\
Adjusted R $=.338$ & & & \\
AICc $=133.656$ & & & \\
F $=6.52$ & & & \\
Significant level $=0.05$ & & & \\
& & & \\
\end{tabular}

As shown in Table 11, the coefficient of total population is positive, which meets the hypothesis. The coefficient for percent of people with a higher education was negative, which meets the hypothesis. Further, the model fitness is also summarized in Table 11. The model diagnostics were examined first.

The R-squared was .399 and the adjusted R-squared was 0.338 . The fitted model value was 0.338 , indicating that it accounts for about $33 \%$ of the variation in the dependent variable. This shows that some variables have been omitted from the model because it is failing to account for $67 \%$ of the variation in the crime of disturbances. The AICc in this case was 133.656. The residual pattern was also examined. The results of global Moran's I show that the residuals are random, which means that there is no autocorrelation present (Figure 6-12). 


\section{Residual Maps for Assaults}

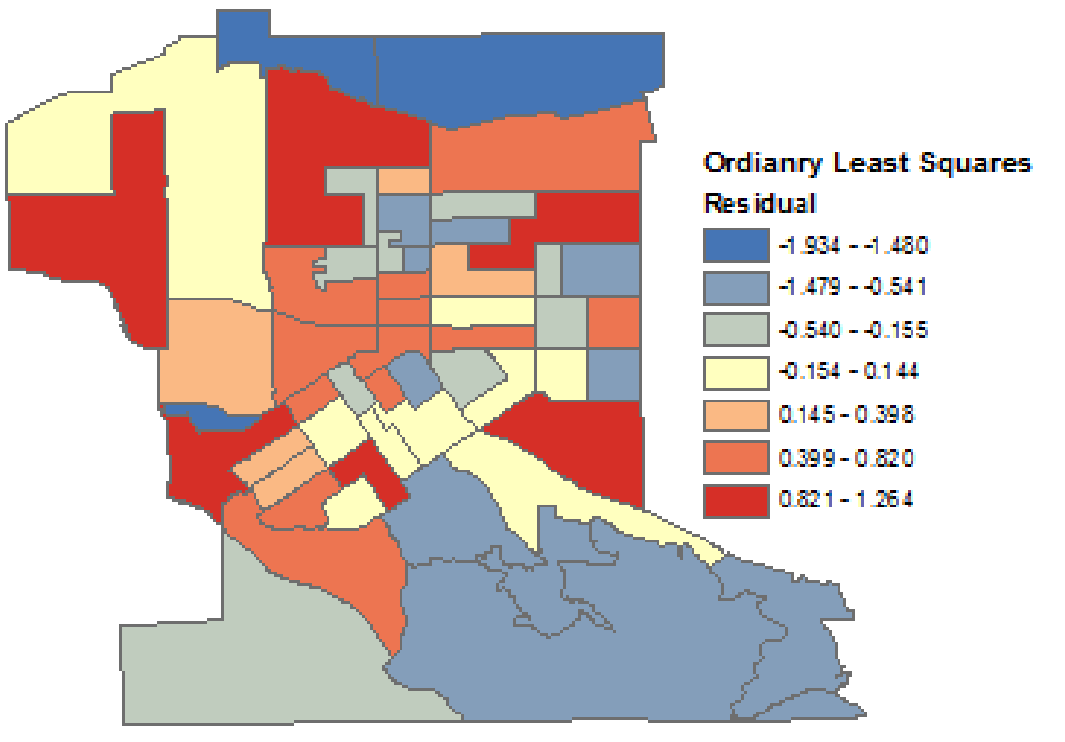

Moran's I Index $=-0.030$ $\mathrm{p}$-value $=0.845$

Figure 6-12: OLS Spatial Autocorrelation Results for Assaults

To improve the model, GWR was applied. The results of this model can be found in Table 12.

\section{Table 12. GWR Results}

\section{Independent Variables}

Total Population

Higher Education

$\mathrm{R}^{2}=.453$

Adjusted $\mathrm{R}^{2}=.349$

AICc $=131.347$ 
The first step was to compare the OLS and the GWR model results. The OLS Adjusted R-squared was 0.338 and the GWR was 0.349 , which suggests that there was some improvement in the model performance. The AICc for the OLS was 133.656 and for the GWR it was 131.347, a difference of about 2, which hardly improved the fit of the model to the data. Once again, the residual pattern was also examined for the GWR results. Figure 6-13 shows that the Moran's I value is smaller than the previous value, indicating the chance of residuals being random is higher.

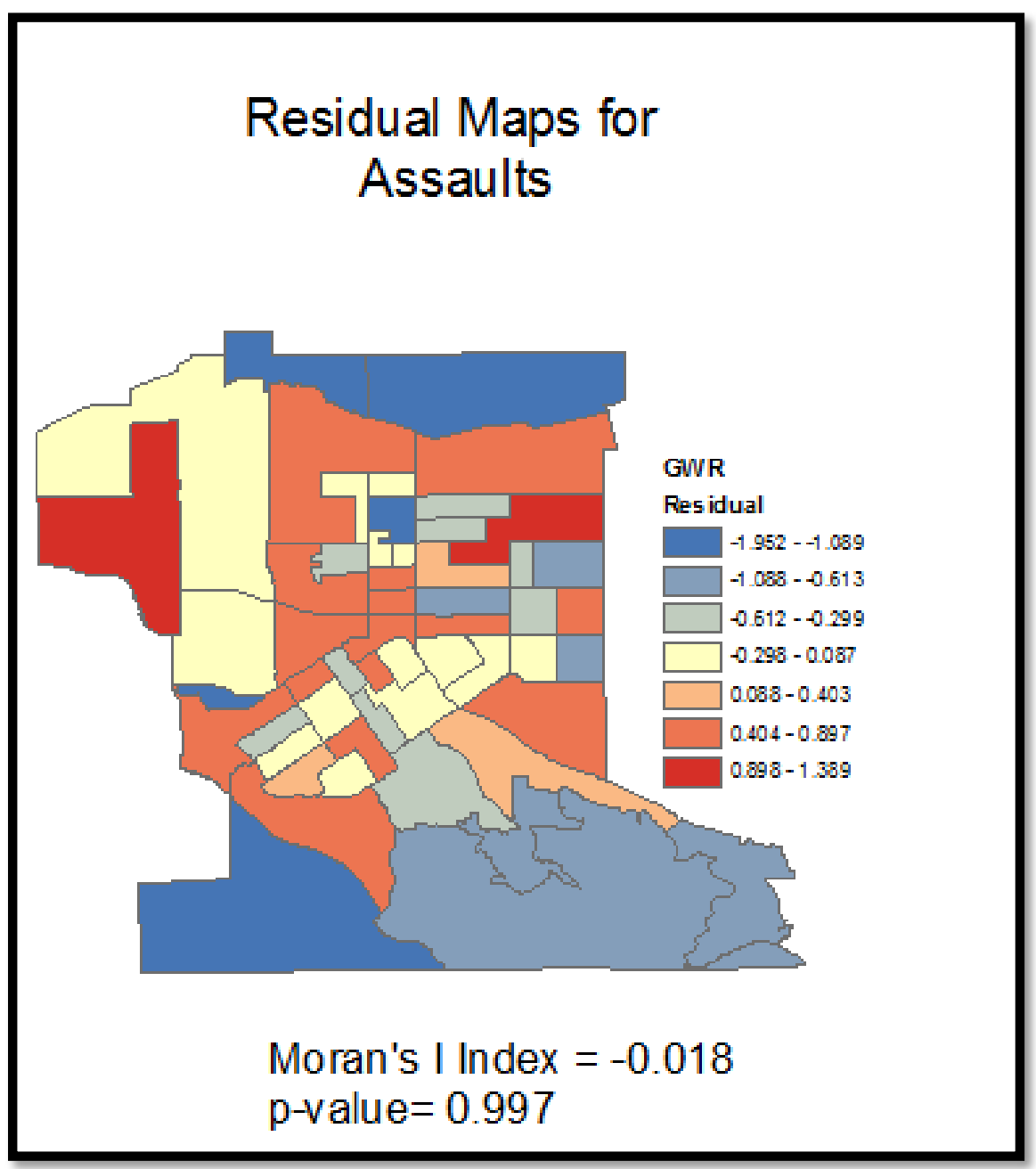

Figure 6-13: GWR Autocorrelation results for Assault

More importantly, GWR can reveal the regional variations of the relationship. For example, Figure 6-14 shows how the impact of percent of people with a higher education on assaults varies in space. 


\section{Coefficient Map for Assaults}

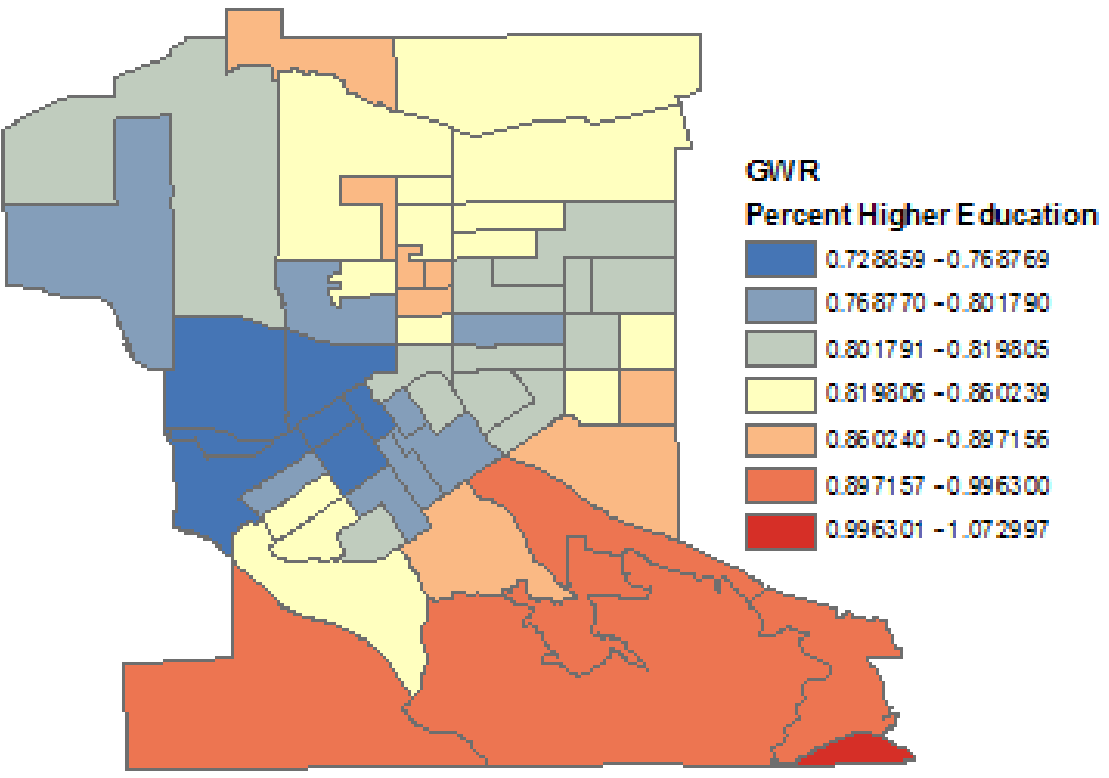

Figure 6-14: Coefficient Map for Assaults

The percent of people with higher education has a strong influence in the south, east west neighborhoods. Because of this distribution, there should be a lower concentration of assaults in this area due to its negative relationship with the crime. The other coefficient map for assaults can be found Appendix A.

\subsubsection{Alcohol/Drug-related crimes}

Figure 6-15 provides a choropleth map of alcohol/drug-related crimes in 2009. To help understand the descriptive information about the crime of alcohol/drug abuse. 


\section{Alcohol/drug Related Number of Crimes per Block group}

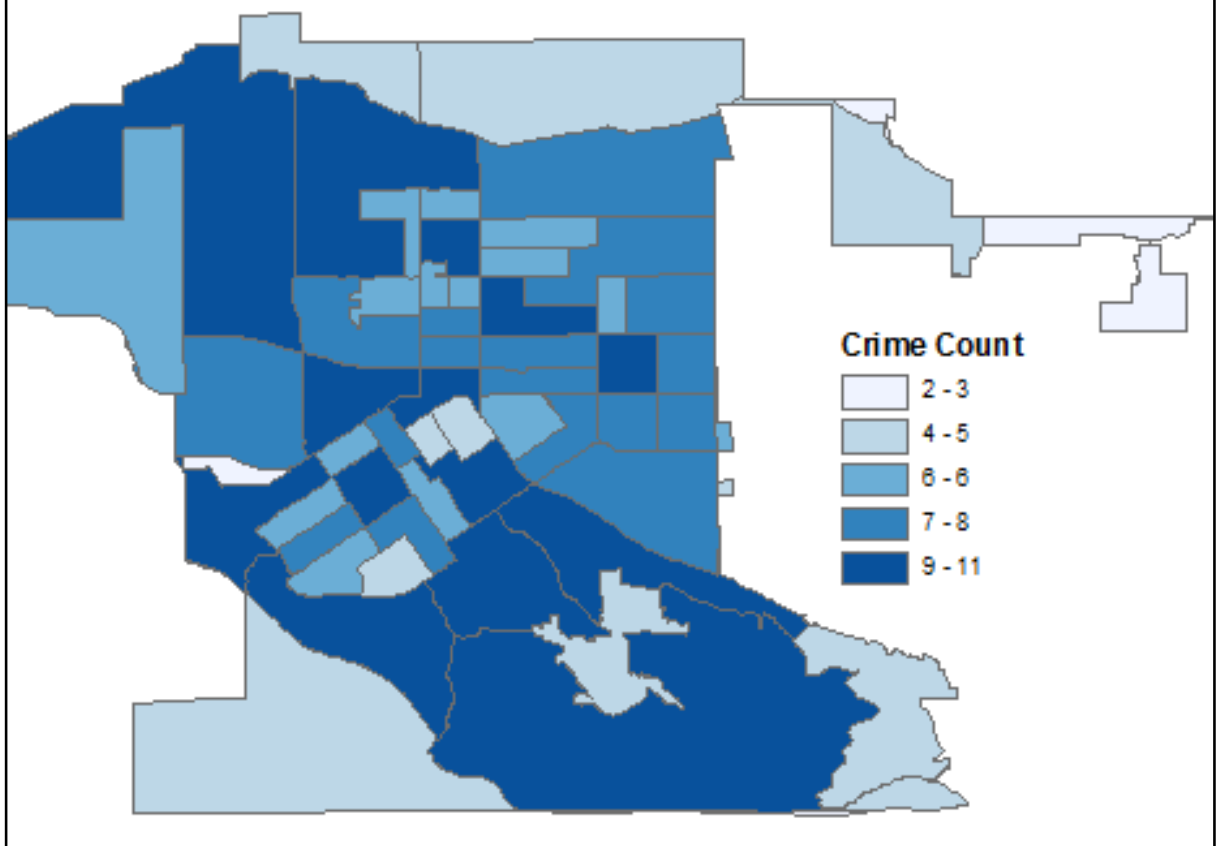

Figure 6-15: Alcohol/Drug Crime Count

Figure 6-15 shows that most alcohol/drug-related crimes are occurring in the northwest, central, and southeast areas of the city. This may be due to large shopping centers bars, restaurants, and houses that are found in these areas, which could be used as variables in future work. According to the regression, there are three significant variables: total population, percent married, and percent youth 18-25. Originally, the total population was expected to relate positively with alcohol/drug-related crimes, because it was assumed that most people have encountered both of these substances at one time or another. Originally, the percent married was expected to relate negatively with crime, because married people are assumed to be settled down, and older, and to have a stable household situation. Finally, the percent youth was expected to relate positively with the crime, because it is also assumed that percent youth are younger and cannot make informed decisions. Table 13 summarizes the significant variables that were found after running the ordinary least squares tool. 


\section{Table 13. Model 4 : Linear Regression Results on Alcohol/Drug-Related Crimes in 2000}

\begin{tabular}{|lllll|}
\hline Independent Variables & Coefficient & $\begin{array}{l}\text { Standard } \\
\text { Error }\end{array}$ & Relationship & $\begin{array}{l}\text { Significant } \\
\text { Level }\end{array}$ \\
\hline Total population & .000 & .000 & + & .000 \\
Percent married & -4.856 & 1.603 & - & .001 \\
Percent youth 18 to 25 & -2.972 & 1.878 & - & .036 \\
& & & & \\
$\mathrm{R}^{2}=.498$ & & & & \\
Adjusted R $\mathrm{R}^{2}=.459$ & & & & \\
AICc $=153.167$ & & & \\
F $=8.574$ & & & \\
Significant level $=0.05$ & & & & \\
\hline
\end{tabular}

As shown in Table 13, the coefficient of total population was positive, which meets the hypothesis. The coefficient for percent married was negative, which meets the hypothesis. Controlling for other factors, a one percent increase in the percent of married individuals in the neighborhood resulted in a $1.3 \%$ decrease in the crime. Finally, the coefficient for the percent youth 18 to 25 was negative, which does not meet the hypothesis. Controlling for other factors, a one percent youth 18-25 increase in the neighborhood resulted in a $5.1 \%$ decrease in crime. The model fitness is also summarized in Table 13. The model diagnostics were examined first.

The R-squared was 0.498 and the adjusted R-squared was 0.459 . The fitted model value was 0.459 , which indicated that it accounts for about $45 \%$ of the variation in the dependent variable. This shows that some variables have been omitted from the model because it is fails to account for $55 \%$ of the variation in the crime of disturbances. The $\mathrm{AICc}$ in this case is 153.167 . In addition, the residual pattern was also examined. The results of global Moran's I shows that the residuals are random, which means that there is no autocorrelation present (Figure 6-16). 


\section{Residual Map for Alcohol/Drug Crimes}

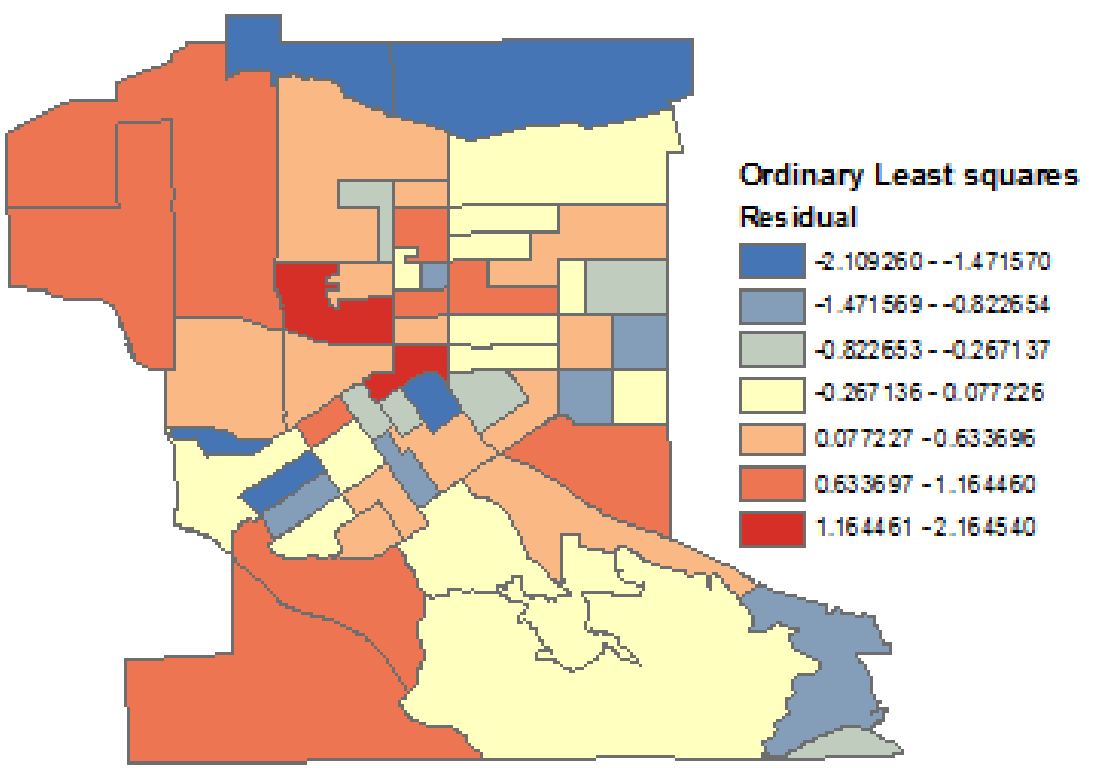

Moran's I Index $=0.031$

p-value $=.399$

\section{Figure 6-16: OLS Spatial Autocorrelation Results}

To improve the model, GWR was applied. The results of this model can be found in Table 14. 
Table 14. GWR Results

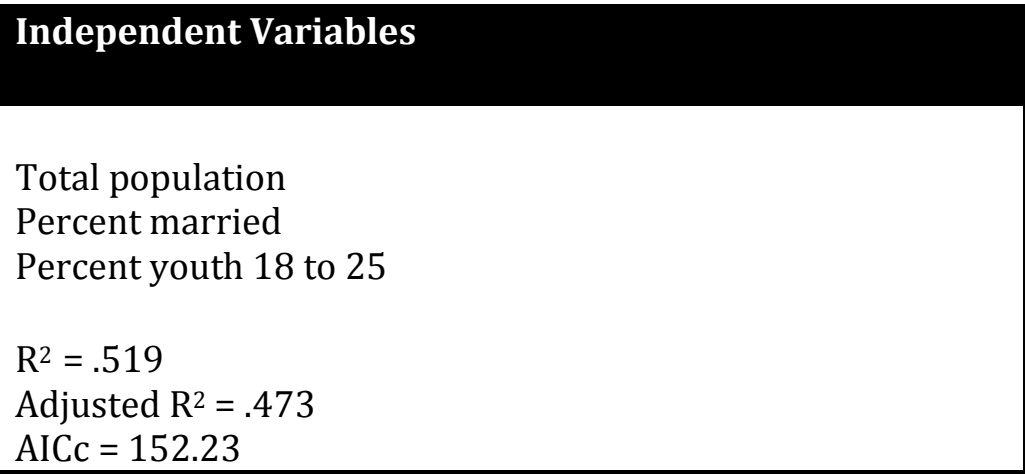

The first step was to compare the OLS and the GWR model results. The OLS Adjusted R-squared was 0.459 and the GWR was 0.473 , which suggested that there was some improvement in the model performance. The AICc for the OLS was 153.167 and for the GWR it was 152.23, a difference of about 1, which is evidence of improvement in the fit of the model to the data. Once again, the residual pattern was also examined for the GWR results. Figure 6-17 shows the Moran's I value is smaller than the previous value, indicating the chance of residuals being random is higher. 


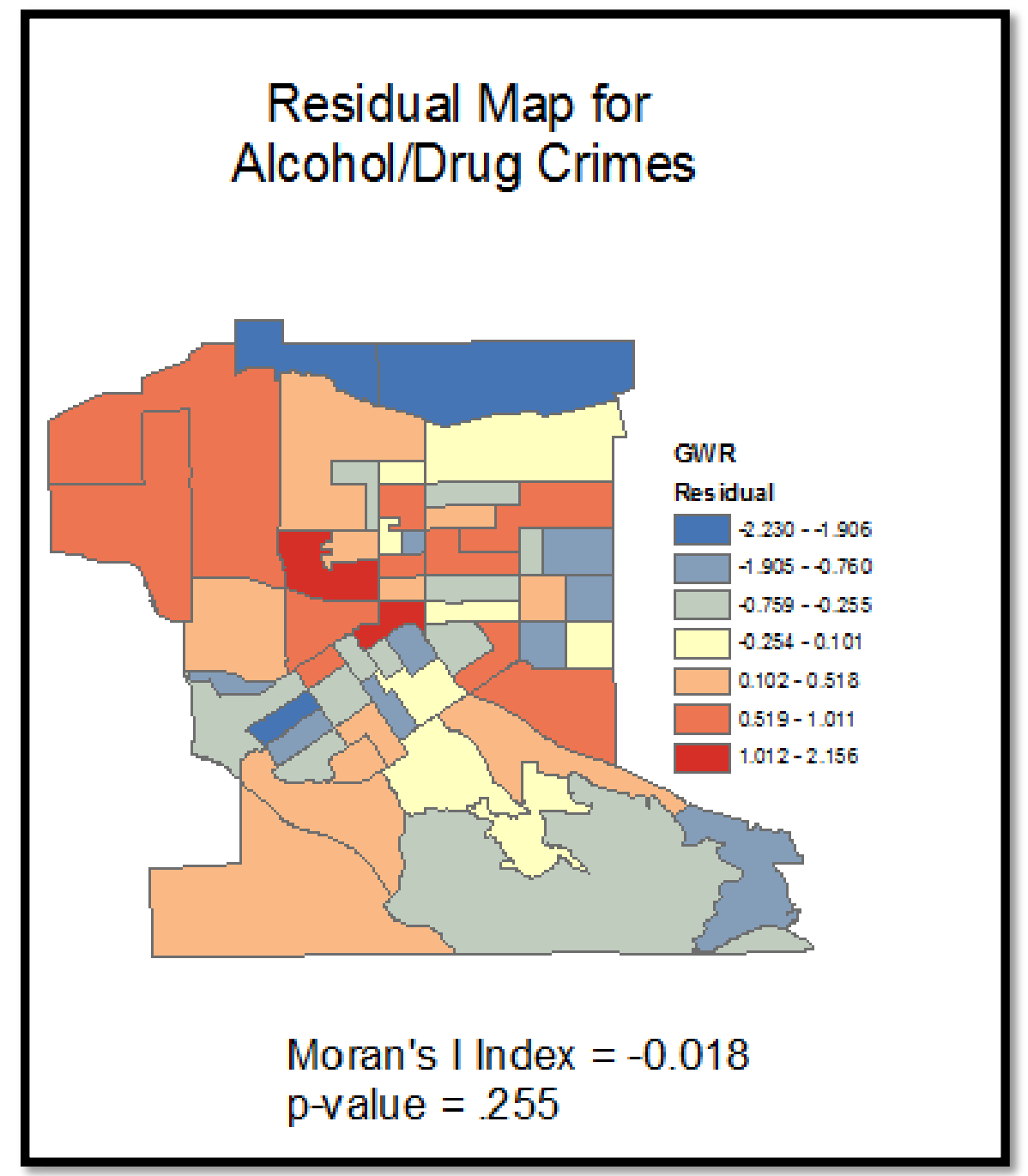

Figure 6-17: GWR Autocorrelation results for Alcohol and drug-related crimes

More importantly, GWR can reveal the regional variations of the relationship. For example, Figure 6-18 shows how the impact of youth 18-25 on alcohol/drug-related crimes varies in space. 


\section{Coefficient Map for Alcohol/Drug Crimes}

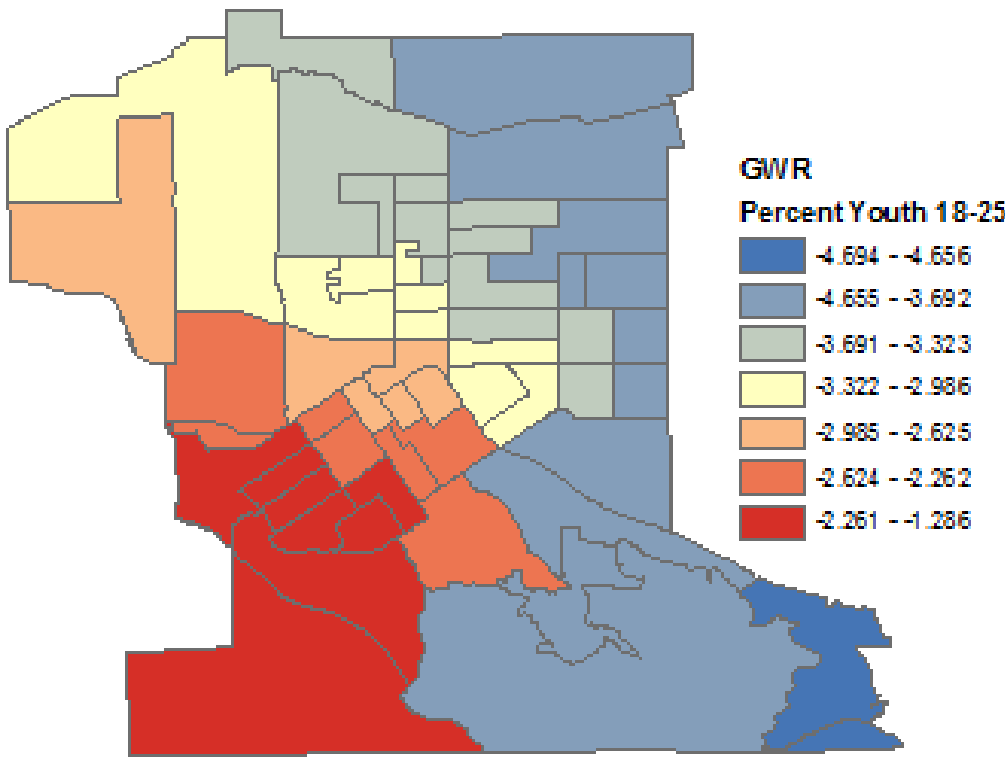

Figure 6-18: Coefficient Map for Alcohol/Drug-Related Crimes

The percent of youth 18-25 had a strong influence in the southwest neighborhood. Because of this, there should be a lower concentration of alcohol/drug-related crimes in this area due to its negative relationship with the crime. The rest of the coefficient maps can be found in Appendix A.

\subsubsection{Auto Thefts}

Figure 6-19 provides a choropleth map of auto thefts in 2009. 


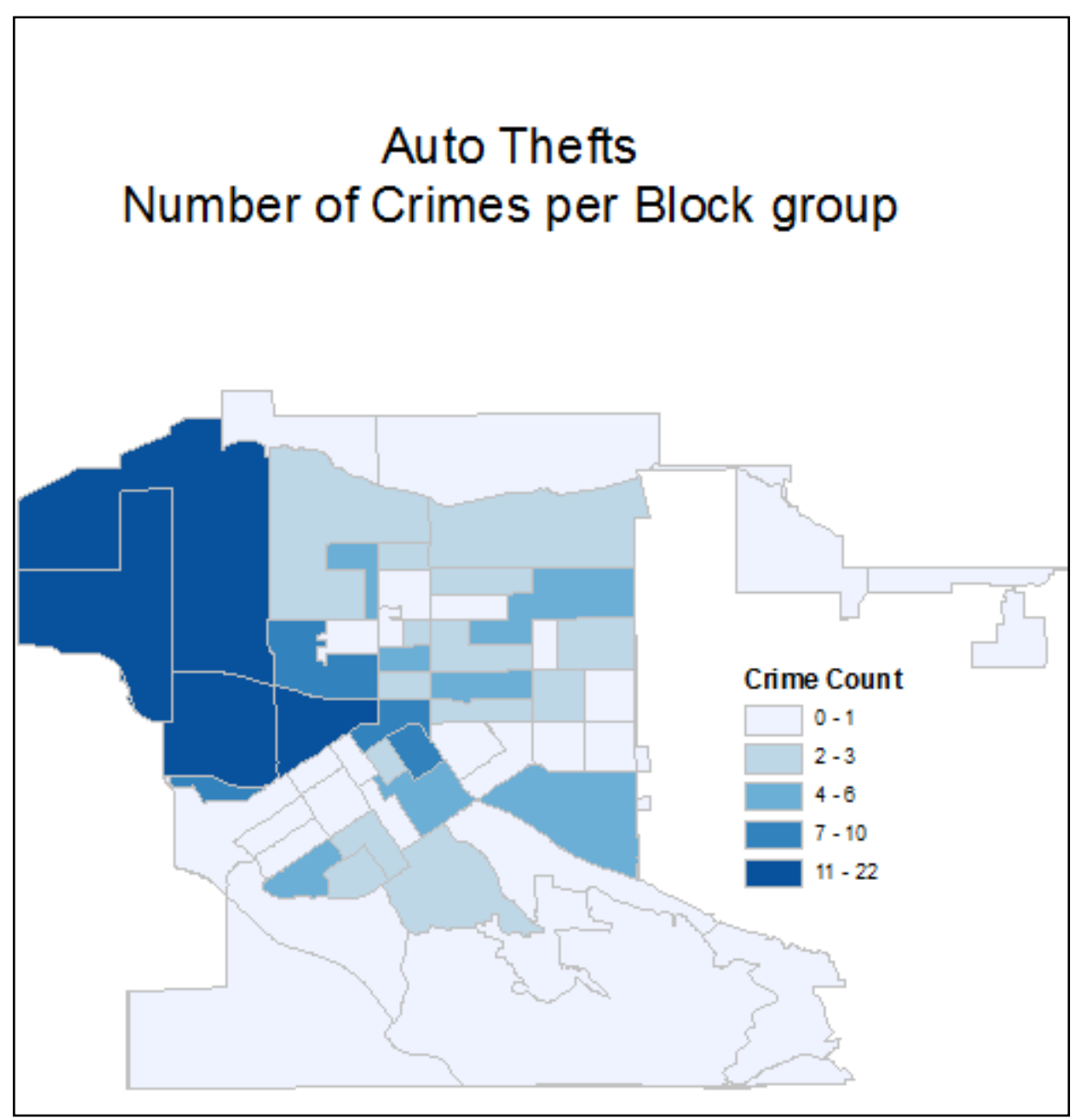

Figure 6-19: Choropleth Map of Auto Thefts in 2009

Figure 6-19 shows that most auto thefts occurred in the north and northeast part of the city, possibly due to the airport and shopping centers that there. These types of geographic variables are something that could be looked at in future work. According to the regression, there are three variables that are significant: total households, percent education, and percent with vehicles. Originally, total households were expected to relate positively to auto thefts, because more houses could mean more vehicles. Percent higher education was expected to relate negatively to disturbances because the percent higher education population may have the means and take more precautions when securing vehicles. Finally, the percent with vehicles was expected to relate positively to auto thefts, because places that have vehicles are natural targets for this type of crime. Table 15 summarizes the significant variables that were found after running the ordinary least squares tool. 
Table 15. Model 5: Linear Regression Results on Auto Thefts in 2000

\begin{tabular}{|llll|}
\hline Independent Variables & Coefficient & $\begin{array}{l}\text { Standard } \\
\text { Error }\end{array}$ & $\begin{array}{l}\text { Significant } \\
\text { Level }\end{array}$ \\
\hline Total households & 0.001 & 0.364 & .000 \\
Percent Higher Education & -3.052 & 0.000 & .000 \\
Percent with vehicles & 2.709 & 1.561 & .035 \\
& & & \\
$\mathrm{R}^{2}=.391$ & & & \\
Adjusted R $\mathrm{R}^{2}=.355$ & & & \\
AICc $=122.573$ & & \\
$\mathrm{~F}=10.942$ & & & \\
Significant level $=0.05$ & & & \\
\hline
\end{tabular}

As shown in Table 15, the coefficient of total households is positive, which meets the hypothesis. The coefficient for percent higher education is negative, which meets the hypothesis. Controlling all other factors, a one percent higher education increase in the neighborhood resulted in a $4.7 \%$ decrease in the crime. The coefficient for percent with vehicles is positive, which meets the hypothesis. Further, the model fitness is also summarized in Table 15.

The R-squared was 0.391 and the adjusted R-squared was 0.355 . The fitted model value was 0.355 , which indicated that it accounts for about $35 \%$ of the variation in the dependent variable; this shows that some variables have been omitted from the model because it is failing to account for $45 \%$ of the variation in the crime of disturbances. The AICc in this case is 122.573. In addition, the residual pattern was also examined. The results of global Moran's I shows that the residuals are random, which means that there is no autocorrelation present (Figure 6-20). 


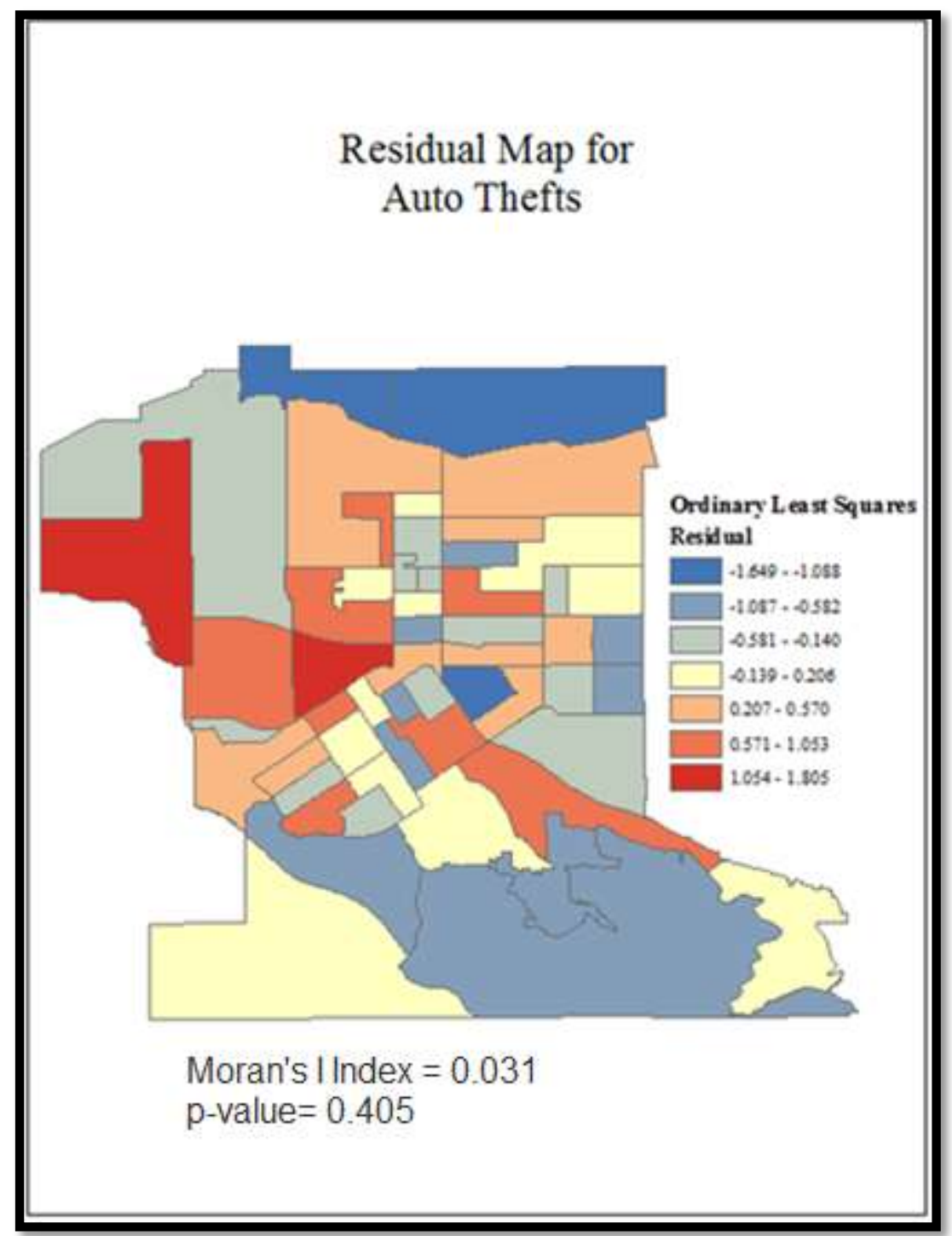

Figure 6-20: OLS Spatial Autocorrelation Results

To improve the model, GWR was applied. The results of this model can be found in Table 16. 


\section{Table 16. GWR results for Auto Thefts}

\section{Independent Variables}

Total households

Percent with vehicles

Percent higher education

$\mathrm{R}^{2}=.449$

Adjusted $\mathrm{R}^{2}=.375$

$\mathrm{AICc}=115.762$

The first step was to compare the OLS and the GWR model results. The OLS Adjusted R-squared was 0.335 and the GWR was 0.375 , which suggests that there was some improvement in the model performance. The AICc for the OLS was 122.573 and for the GWR it was 115.762, a difference of about 6 , which is evidence of some improvement in the fit of the model to the data. Once again, the residual pattern was also examined for the GWR results. Figure 6-21 shows the Moran's I value is smaller than the previous value, indicating the chance of residuals being random is higher. 


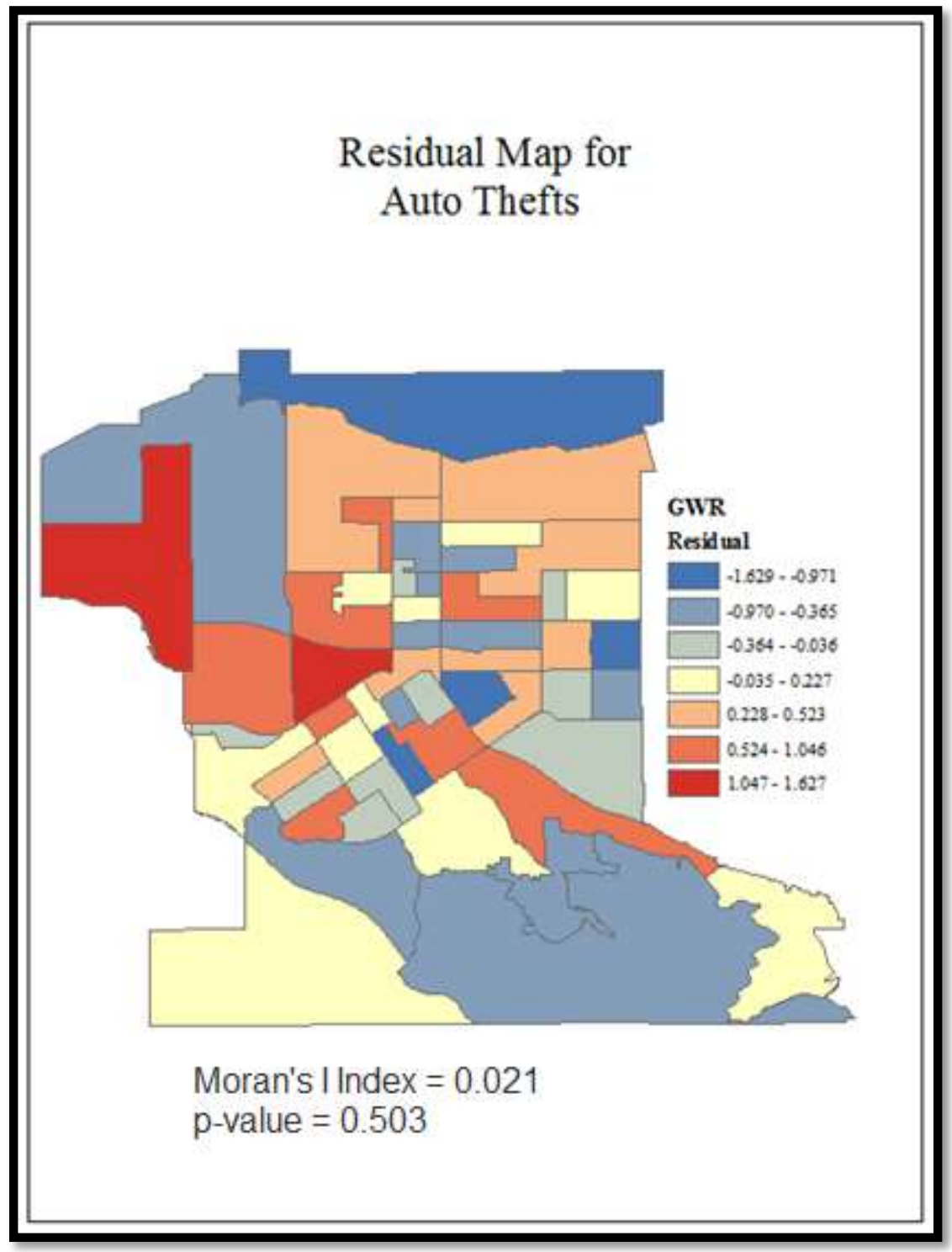

Figure 6-21: GWR Spatial Autocorrelation Results for Auto Thefts

More importantly, GWR can reveal the regional variations of the relationship. For example, Figure 6-22 shows how the impact of percent with vehicles on auto theft varies in space. 


\section{Coefficient Map for Auto Thefts}

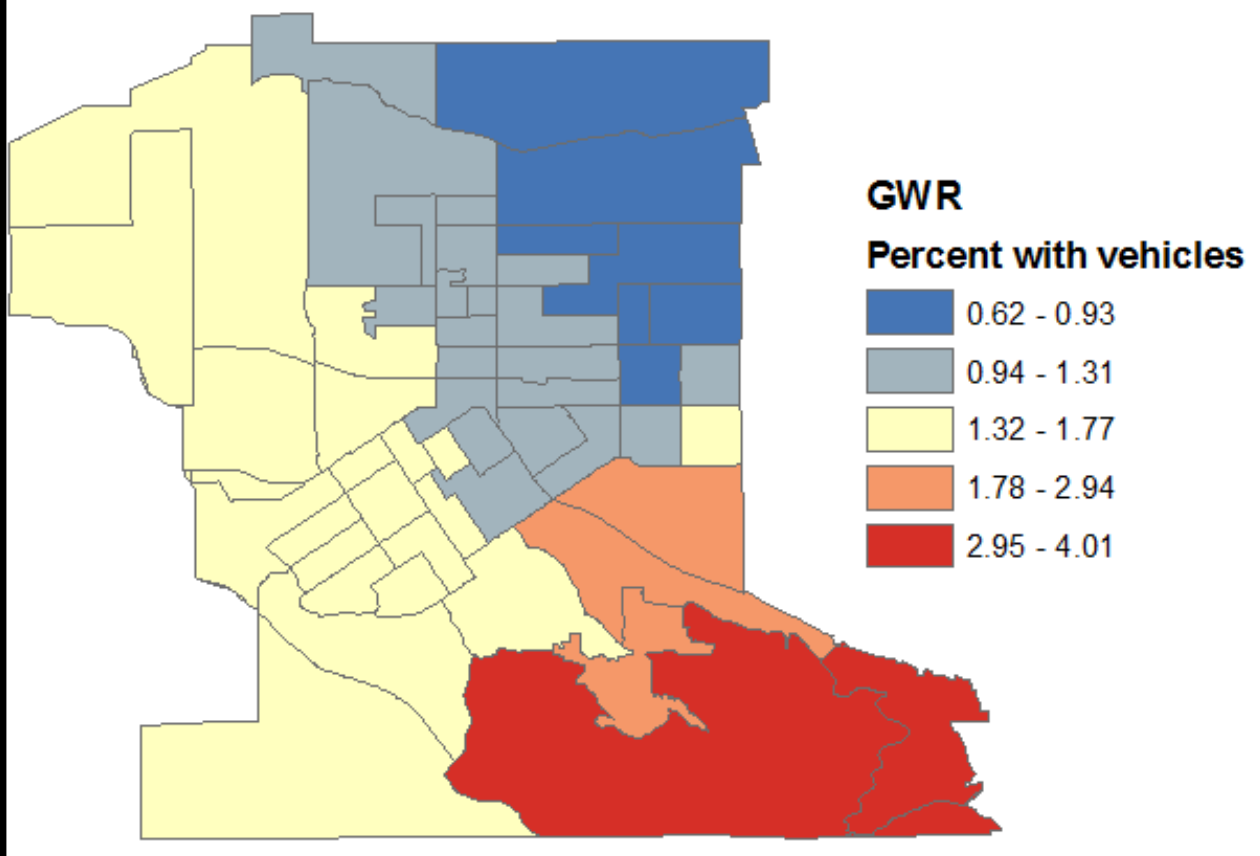

Figure 6-22: Coefficient Map for Auto Thefts

The percent of vehicles has a strong influence in the southeast neighborhood. Because of this, there should be a higher concentration of disturbances in this area due to its positive relationship with the crime. The rest of the coefficient maps for auto thefts can be found in Appendix A.

\subsection{Summary}

This chapter looked at the results of the crime kernel density model and the regression analysis tools. The densities and locations of the crime types were discussed, along with what years the different crimes had category-one densities. The ability to see where the crimes of interest were occurring most often could help the Redlands Police Department make informed decisions on what areas need more patrolling. The results of the ordinary least squared tool and the geographically weighted regression tool results were discussed in order to understand what variables influenced the different crime types. Finally, the 
autocorrelation tool was used in order to examine the residual pattern. The variables that were significant in more than one model were percent higher education, percent of people with an income of $\$ 10,000$ to $\$ 20,000$, the total number of households, and the percent of people that were married. Overall, the variables were able to explain about $40 \%$ of what influences the crime types. 


\section{Chapter 7 - Conclusions and Future Work}

The final chapter looks at what the project carried out and examines the analysis that was performed. This chapter will also be looking at future work.

\subsection{Conclusion}

The overall goal of this project was to help the City of Redlands determine where crimes are occurring and why these crimes are happening. The hope of solving these problems was to assist the City of Redlands law enforcement agency in making intuitive decisions on decreasing the crime in Redlands. The goals were achieved by completing the following objectives:

- Used Model Builder to produce the crime kernel density surfaces

- Classified and designed 20 years worth of maps for each crime type

- Animated the crime Density Maps

- Performed regression analysis using Ordinary Least squares and geographically weighted regression.

The Crime Kernel Density model created density surfaces, which showed where the highest concentrations of crimes were located. By classifying the different densities, it was possible to make an accurate comparison of crimes from year to year. The animation tool bar was used because there was such a large amount of data over such a long period of time. Most importantly, it helped show the change in crime over time. The regression analysis helped in understanding why the crimes of interest were occurring, while most of the explanatory variables influenced the different crimes of interest.

\subsection{Future Work}

Future work could add more variables to the framework of this project to improve its performance and analytical capabilities. The following sections discuss additional crime data added to the model, temporal analysis added to the model, a web application, and geographic factors for the regression analysis.

\subsubsection{Additional Crime Types}

Incorporating more crime types into the model would help in viewing more crimes that have occurred over the past 20 years. For instance, it would improve the model if more expressions were incorporated in the process. This was not incorporated into the model because it was outside of the project scope. However, the ability to produce multiple crime types and their densities at the same time will improve the efficiency of viewing multiple crime types.

\subsubsection{Temporal Analysis}

A temporal crime analysis based on an hourly distribution would highlight the crimes that are likely to take place at specific hours of the day. The analysis would be performed 
within model builder using a more precise date expression. Knowledge of the temporal distribution of the crime could enhance the officers' ability to patrol affected areas.

\subsubsection{Web Application}

The results of the crime kernel density model could be implemented into a web application. This would help the city and the public visualize locations of high crime in the Redlands area. Also, by creating a web application for this data, there could be the option of checking on three different crimes that allow someone to view and compare the crimes of interest. The user could specify a year and compare different years side by side. Ultimately, a web application would enable crime comparison over the years.

\subsubsection{Geographic Factors for Regression Analysis}

Most of the regression results suggested additional variables that were not present in the calculation. Identifying and incorporating the missing variables would improve the model fitness. Some of those variables are geographic factors that include shopping center, bars, restaurants, and industrial areas. The analysis would benefit from utilizing types of regressions other than linear. This could improve the regression results to further understand the factors that influence crime. 


\section{Works Cited}

The International Association of Crime Analysts. (2004). Exploring Crime Analysis: Reading on Essential Skills. North Charleston: BookSurge, LLC.

Anselin, L., Cohen, J., Cook, D., Gorr, W., \& Tita, G. (2000). Spatial Analysis of Crime. Criminal Justice, 4, 213-262.

Boba, R. (2005). Crime Anaylsis and Crime Mapping. London, United Kingdom: Sage Publishing Inc.

Brundson, C., Corcoran, J., \& Higgs, G. (2007). Visualizing space and time in crime patterns: A comparison of methods. Science Direct: Computers, Environment and Urban Systems, 31, 52-75.

Ceccato, V., Haining, R., \& Signoretta, P. (2002). Exploring offence statistics in Stockholm city using spatial analysis tools. Annals of the Association of American Geographers, 92 (1), 29-51.

Charlton, M., \& Fotheringham, A. S. (2009). ArcGIS 9.3 Geographically Weighted Regression Tool: Tutorial. Retrieved May 12, 2010, from http://www.ncg.nuim.ie/ncg/GWR/GWR_Tutorial

Eck, J. E. (2005, August). Mapping Crime, Understanding hot spots. Retrieved September 28, 2009, from Office of Justice Programs, National Institute of Justice: http://www.ncjrs.gov/pdffiles1/nij/209393.pdf

Grubesic, T. H., \& Mack, E. A. (2008). Spatio-temperal interaction of Urban crime. Journal of Quantitative Crimonology, 24 (3), 285-306.

Katz, C. M., Scheafer, D. R., \& Uchida, C. D. (2002, October ). Exploring the Gang Problem in Redlands, CA: An Evaluation of a Problem Solving Partnership. Retrieved October 18, 2009, from Jutice and Security Strategies: http://www.jssinc.org/publications/JSS-020-1.pdf

Levine, N. (2005). Crime Mapping and the CrimeStat Program. Geographical Analysis. The Ohio State University, 24, 41-56.

Morenoff, J. D., \& Sampson, R. J. (1997). Violent Crime and the Spatial Dynamics of Neighborhood Transiton: Chicago, 1970-1990. Social Forces, 76 (1), 31-64.

Olligschlaeger, A. (1997). Spatial Analysis of Crime Using GIS-Bases Data: Weighted Spatial Adaptive Filtering and Chaotic Cellular Forecasting with Applications to Street Level Drug Markets. Doctorial dissertation, Carnegie Mellon University.

Paulsen, D. J., \& Robinson, M. B. (2004). Crime Mapping and Spatiak Aspects of Crime (3rd ed.). New Jersey: Pearson Education, INC.

Ratcliffe, J. H. (2004). The Hotspot Matrix: A Framework for the Spatio-Temporal Targeting of Crime Reduction. Police Practice and Research, 12 (7), 05-23.

Ratcliffe, J. H., \& McCullagh, M. J. (1998). Aoristic crime analysis. International Journal of Geographic Information Science, 12 (7), 751-764.

Redlands Police Department. (2009, September 30). City of Redlands. Retrieved october 20, 2009, from Monthly Service Measures: http://www.ci.redlands.ca.us/police/PDFs/0809MSM_Cover.pdf

Sampson, R. J., \& Groves, B. W. (1989). Community Structure and Crime: Testing Social-Disorganization Theory. The American Journal of Sociology, 94 (4), 774802. 
Williamson, D., McLafferty, S., Goldsmith, V., Mollenkopf, J., \& McGuire, P. (1999, January). A Better Method to Smooth Crime Incident Data. Retrieved october 10, 2009, from ESRI ArcUser Magazine:

http://www.esri.com/news/arcuser/0199/crimedata.html 


\section{Appendix A. Coefficient Map Results}

\section{Residential Burglary Results:}

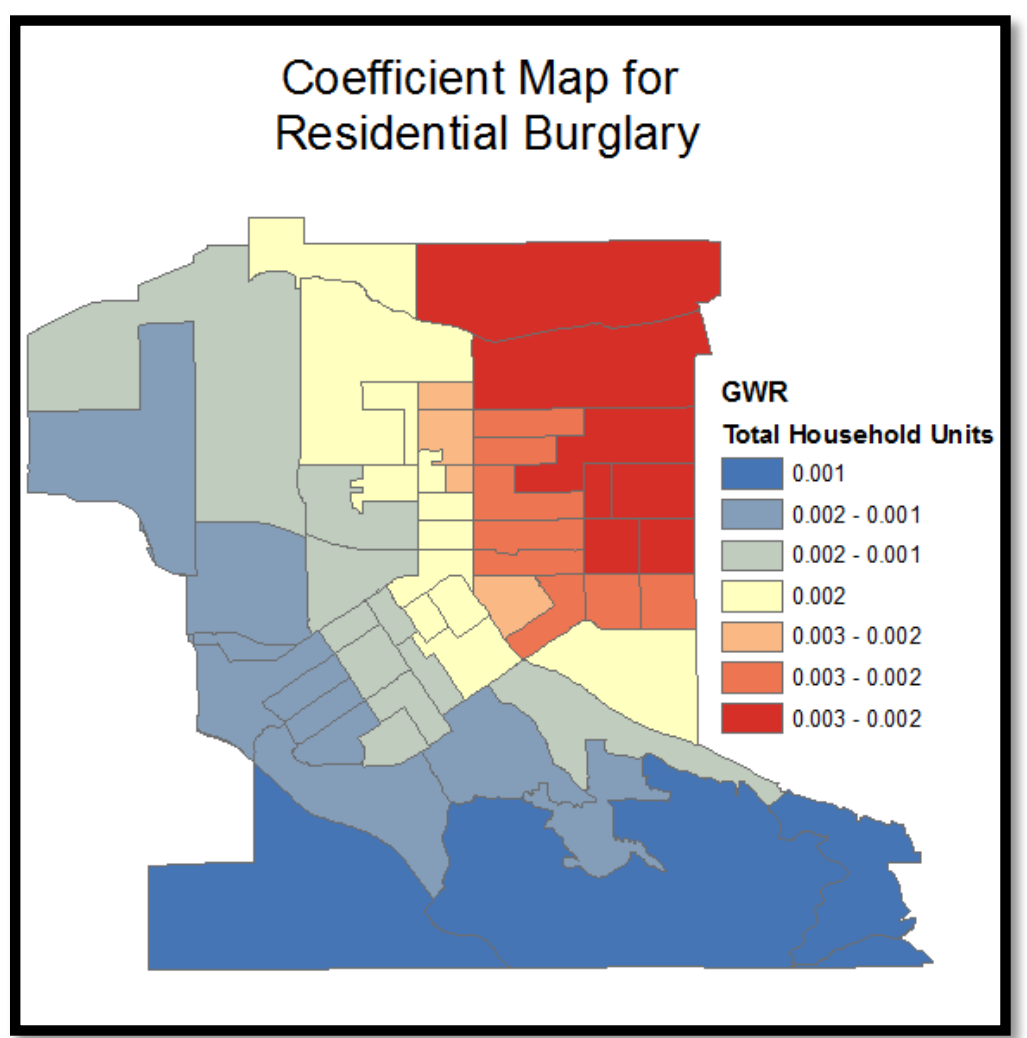



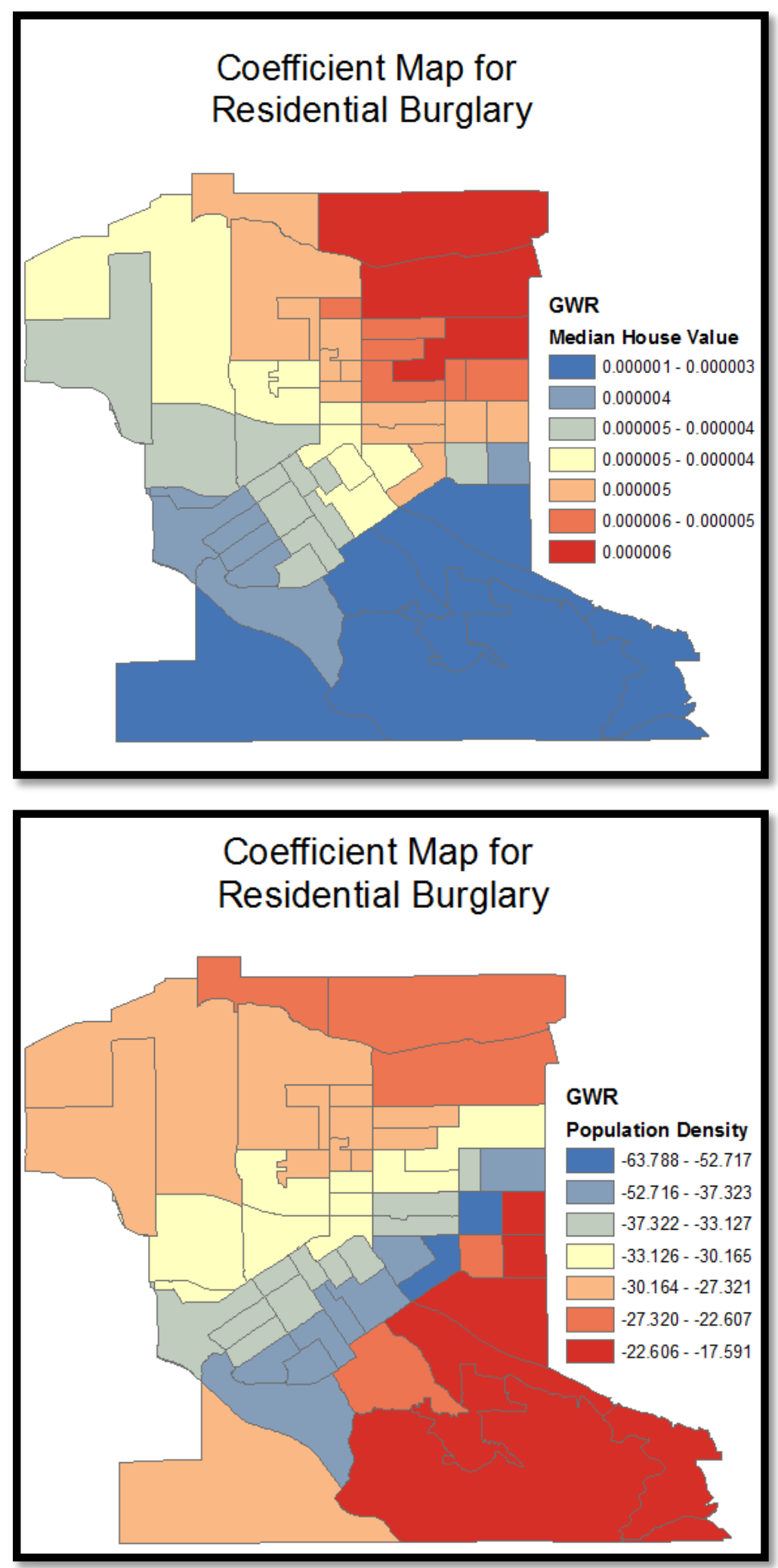


\section{Disturbances Results:}
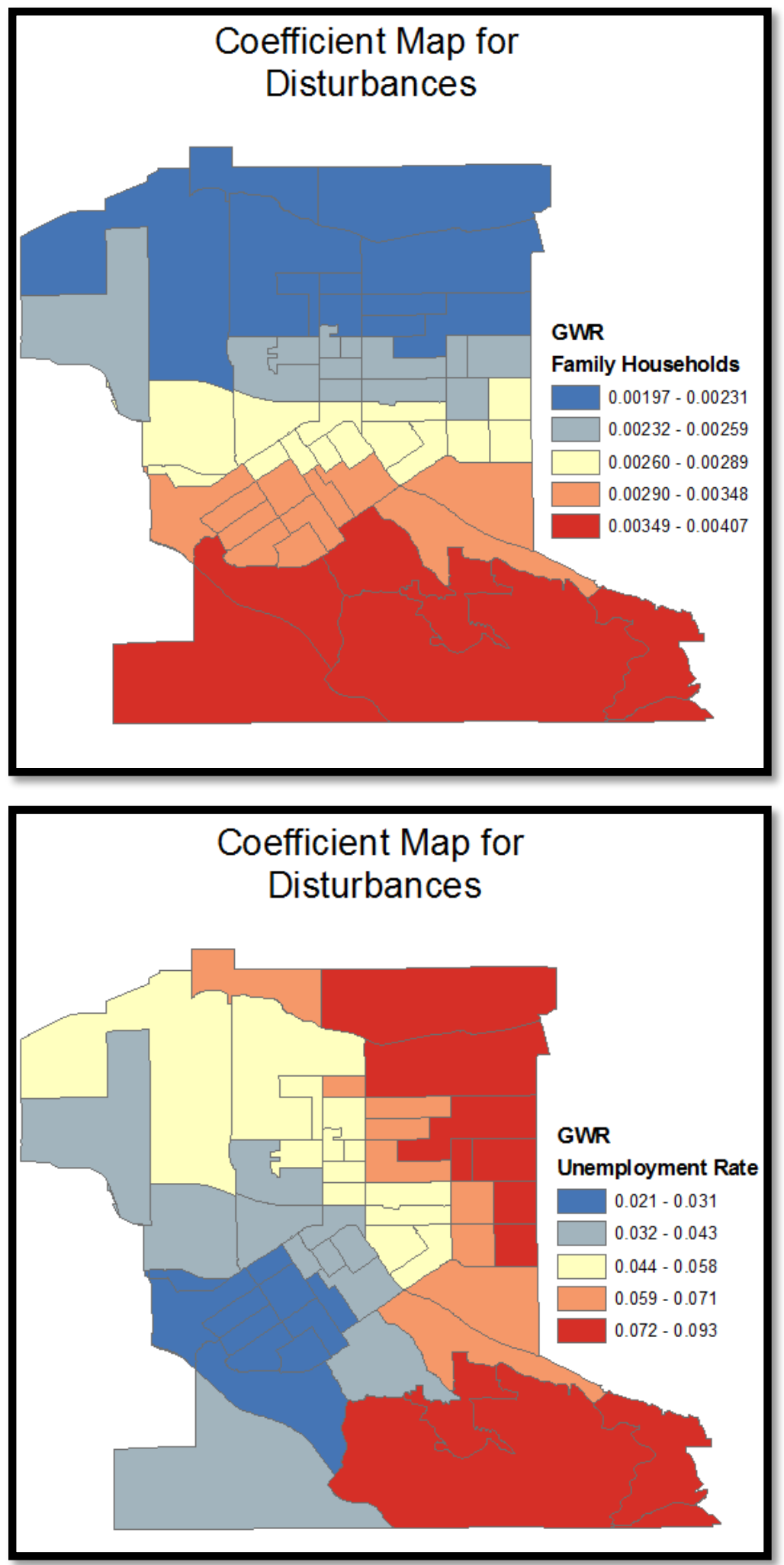

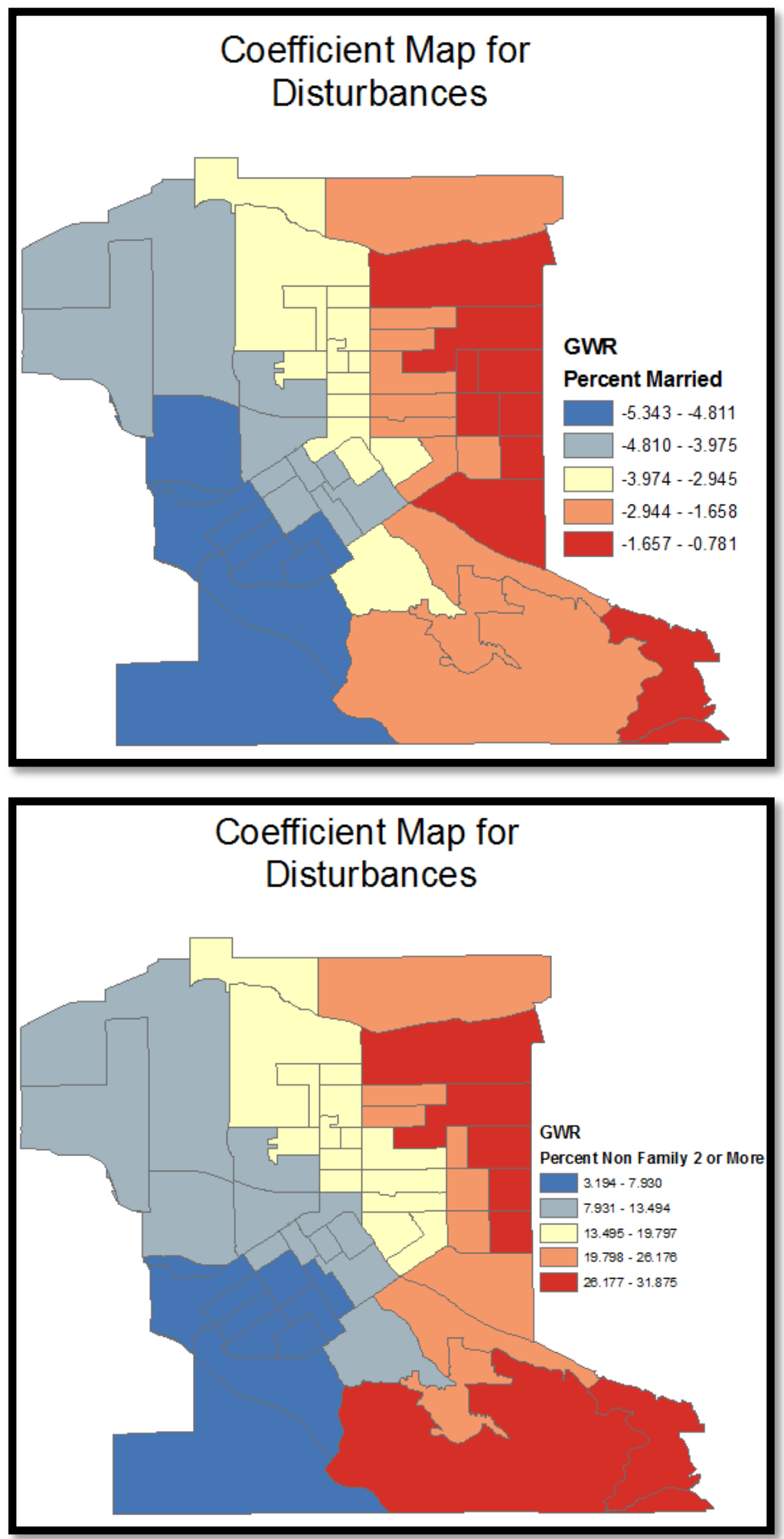


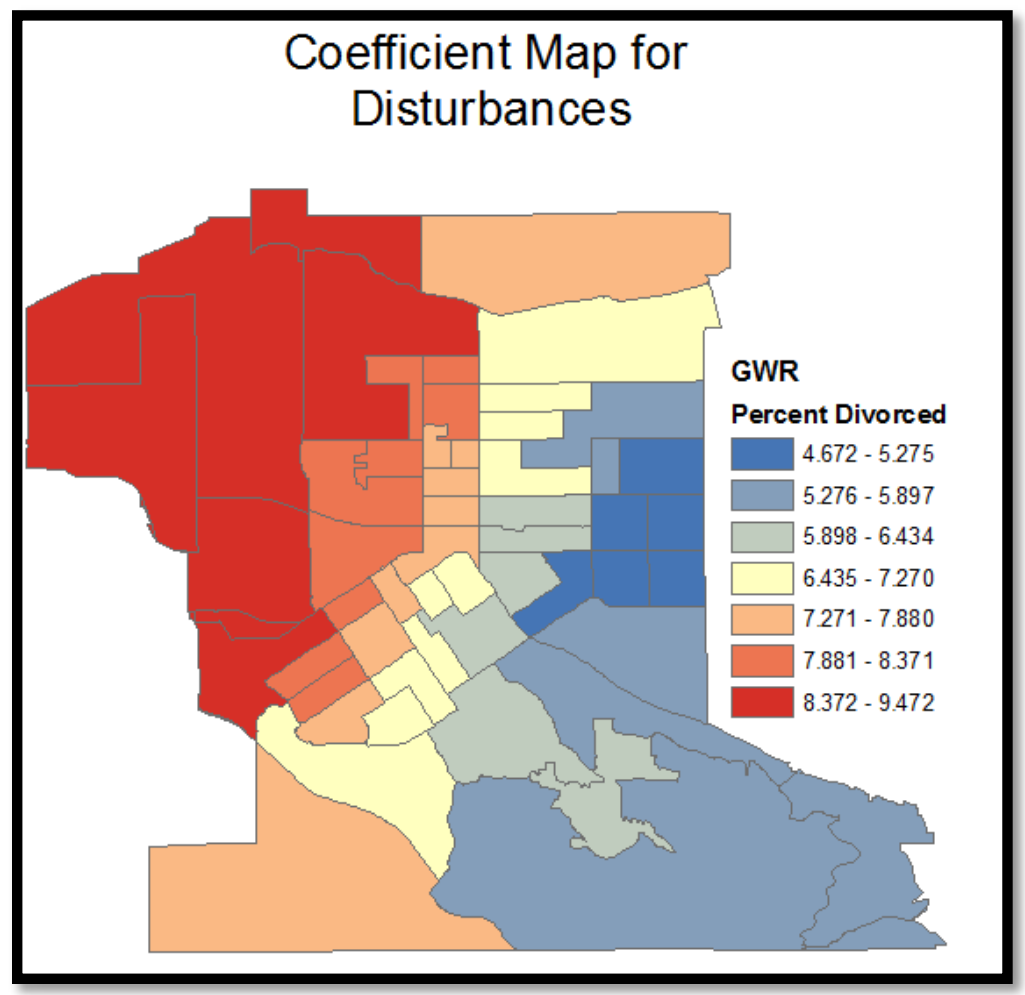

\section{Assaults Results:}

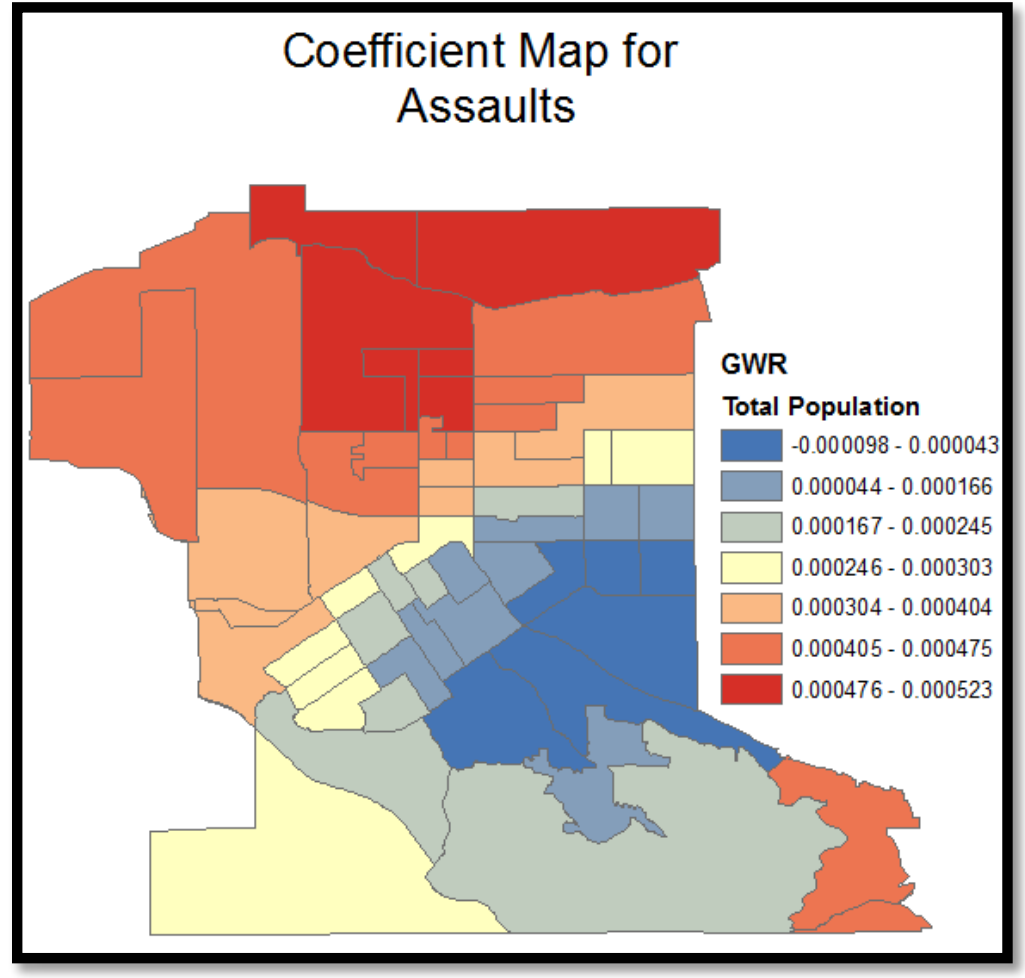




\section{Alcohol/Drug Related Results:}
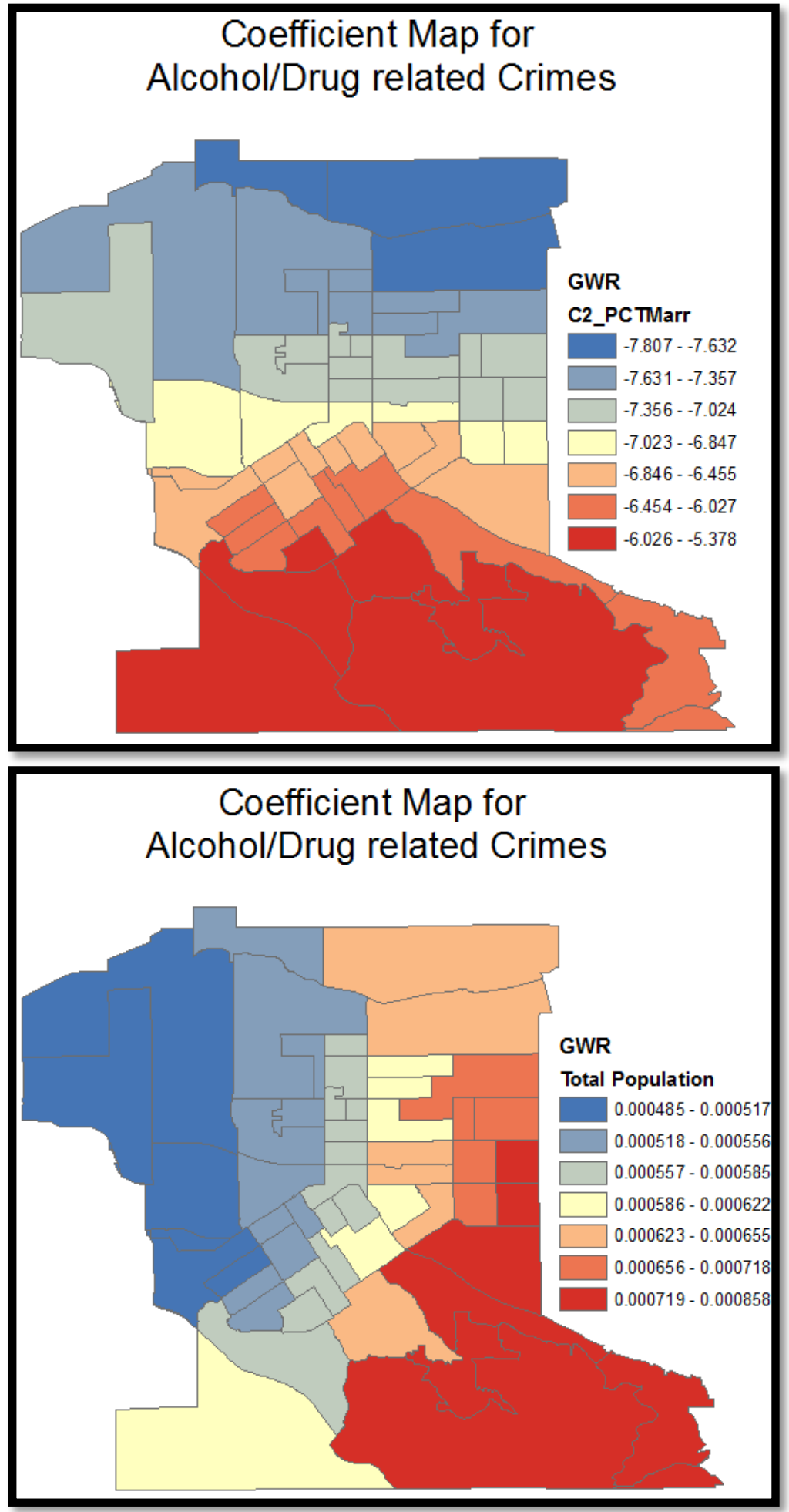


\section{Auto Theft Results:}
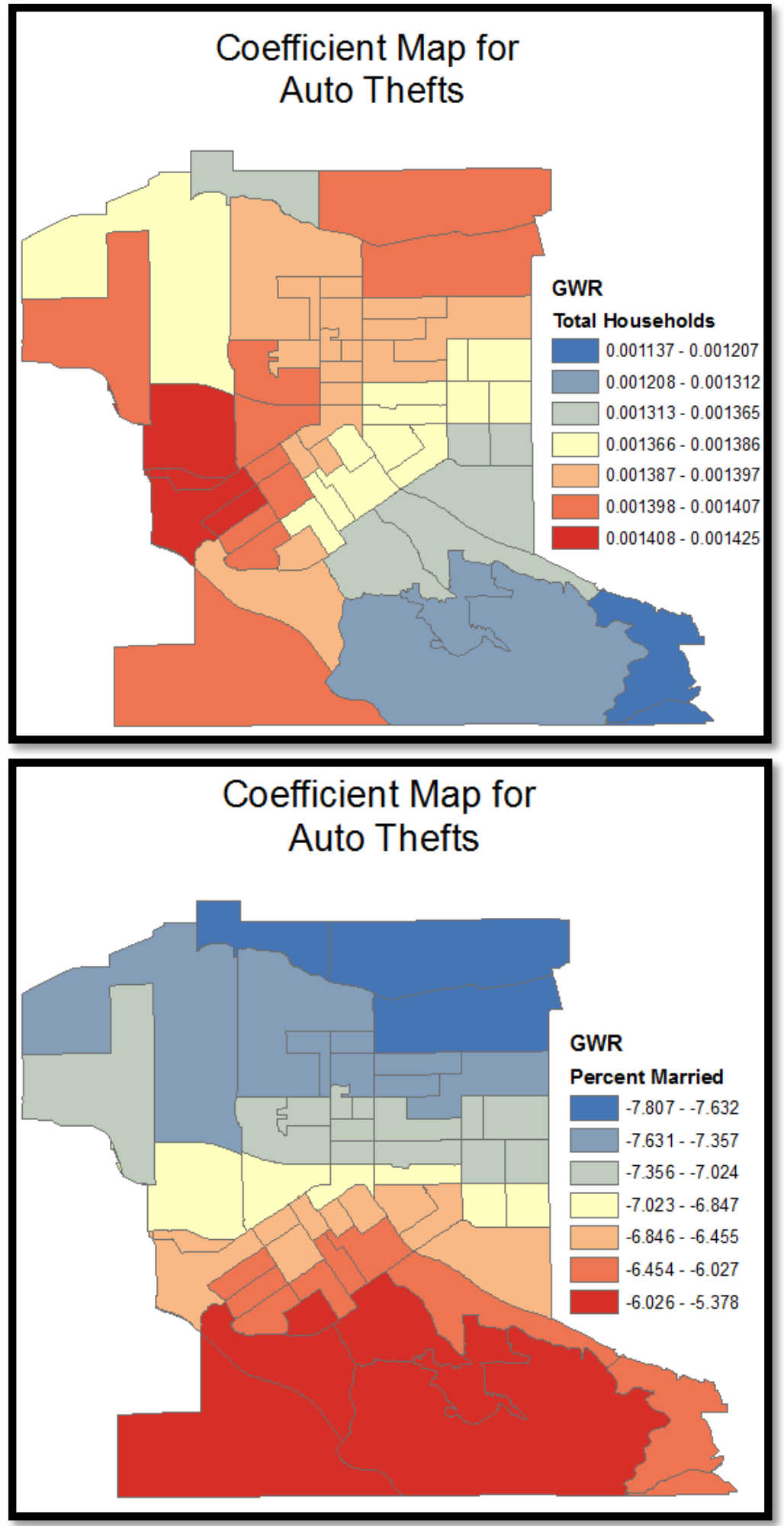
